OPEN ACCESS

Edited by:

Cristoforo Comi,

University of Eastern Piedmont, Italy

Reviewed by:

Gundars Goldsteins, University of Eastern Finland, Finland

Cláudia Pereira,

University of Coimbra, Portugal

*Correspondence:

Xin Chen

xinchentianjin@163.com

Specialty section:

This article was submitted to

Multiple Sclerosis

and Neuroimmunology,

a section of the journal

Frontiers in Immunology

Received: 13 October 2021 Accepted: 17 December 2021

Published: 10 January 2022

Citation:

Shi M, Chai Y, Zhang J and Chen $X$ (2022) Endoplasmic

Reticulum Stress-Associated Neuronal Death and Innate Immune Response in Neurological Diseases.

Front. Immunol. 12:794580. doi: 10.3389/fimmu.2021.794580

\section{Endoplasmic Reticulum Stress- Associated Neuronal Death and Innate Immune Response in Neurological Diseases}

\author{
Mingming Shi ${ }^{1,2,3}$, Yan Chai ${ }^{2,3}$, Jianning Zhang ${ }^{1,2,3}$ and Xin Chen ${ }^{1,2,3 *}$ \\ ${ }^{1}$ Department of Neurosurgery, Tianjin Medical University General Hospital, Tianjin, China, 2 Tianjin Neurological Institute, Key \\ Laboratory of Post-trauma Neuro-Repair and Regeneration in Central Nervous System, Ministry of Education, Tianiin, China, \\ ${ }^{3}$ Department of Neurosurgery, Tianjin Key Laboratory of Injuries, Variations and Regeneration of Nervous System, Tianjin, China
}

Neuronal death and inflammatory response are two common pathological hallmarks of acute central nervous system injury and chronic degenerative disorders, both of which are closely related to cognitive and motor dysfunction associated with various neurological diseases. Neurological diseases are highly heterogeneous; however, they share a common pathogenesis, that is, the aberrant accumulation of misfolded/unfolded proteins within the endoplasmic reticulum (ER). Fortunately, the cell has intrinsic quality control mechanisms to maintain the proteostasis network, such as chaperone-mediated folding and ER-associated degradation. However, when these control mechanisms fail, misfolded/unfolded proteins accumulate in the ER lumen and contribute to ER stress. ER stress has been implicated in nearly all neurological diseases. ER stress initiates the unfolded protein response to restore proteostasis, and if the damage is irreversible, it elicits intracellular cascades of death and inflammation. With the growing appreciation of a functional association between ER stress and neurological diseases and with the improved understanding of the multiple underlying molecular mechanisms, pharmacological and genetic targeting of ER stress are beginning to emerge as therapeutic approaches for neurological diseases.

Keywords: neuronal death, inflammatory response, neurological diseases, endoplasmic reticulum stress, proteostasis, unfolded protein response

\section{INTRODUCTION}

The endoplasmic reticulum (ER) is the largest tubular-reticular organelle. It plays essential roles in multiple cellular processes, including calcium homeostasis, lipid synthesis, and the synthesis, folding, maturation, and trafficking of more than one-third of the cellular proteome $(1,2)$. Multiple disturbances can cause ER proteins to fail to fold into the correct form. Fortunately, the cell has intrinsic quality control mechanisms that discard misfolded/unfolded proteins, such as chaperone-mediated folding (3) and ER-associated degradation (ERAD) (4). However, when these control mechanisms fail, misfolded/unfolded proteins accumulate in the ER lumen. 
One consequence of the abnormal accumulation of misfolded/ unfolded proteins inside the ER lumen is the generation of ER stress, which subsequently triggers a rapid and coordinated biochemical response that is linked to the maintenance of cellular proteostasis; this adaptive process is known as the unfolded protein response (UPR) $(5,6)$. The UPR is a sophisticated mechanism that can be divided into three types of effector functions: adaption, alarm, and death (7). The initial intent of the UPR when activated by ER stress is restoration of homeostasis and normal ER function. However, when this adaptive mechanism is overwhelmed, such as when ER stress is intense or prolonged, intracellular cascades of death and inflammation are induced $(8,9)$. Aberrant aggregation of misfolded proteins and concomitant induction of ER stress have been reported to be associated with neuronal death and the inflammatory response in many neurological diseases and implicated in disorders ranging from acute central nervous system (CNS) injuries to neurodegenerative diseases $(10,11)$. Emerging evidence demonstrates that ER stress plays an essential role in the pathophysiology of neurological diseases; however, the specific mechanisms by which ER stress determines neuronal fate and inflammatory response are not yet understood. In this review, we discuss recent advances in the understanding of the functional links between ER stress and neuronal death and the innate immune responses in the CNS, highlighting their critical roles in the pathogenesis of various neurological diseases and emerging therapeutic opportunities for drug discovery.

\section{UNFOLDED PROTEIN RESPONSE SIGNAL TRANSDUCTION MECHANISMS}

In metazoans, three trans-ER membrane proteins sense the aberrant accumulation of misfolded/unfolded proteins and provoke a series of signal transduction pathways to modulate transcriptional and translational programs that combat ER stress (Figure 1). The three trans-ER membrane stress sensors that exhibit this coordinated action are inositol-requiring enzyme $1 \alpha$ (IRE1 $\alpha$ ), protein kinase RNA-like ER kinase (PERK), and activating transcription factor 6 (ATF6) (12). Under homeostatic conditions, the luminal domains of these ER stress sensors are maintained in an inactive state through their interactions with the ER-resident protein chaperone glucoseregulated protein 78 (GRP78; also known as BiP) (13). However, GRP78 has a higher affinity for misfolded proteins than for ER stress sensors; therefore, the excessive accumulation of misfolded/unfolded proteins leads to recruitment of GRP78 away from all three ER stress sensors, permitting the activation of downstream signaling pathways (13). Additionally, misfolded/ unfolded proteins can directly bind to PERK and IRE1 $\alpha$, leading to activation of the UPR via a ligand-receptor-type interaction (14-16).

IRE1 $\alpha$ has been widely reported to be involved in cell death and inflammation in various neurological diseases (6). IRE1 $\alpha$ is the most evolutionarily conserved ER stress transducer and contains both kinase and endoribonuclease (RNase) domains.
Upon release from GRP78, IRE1 $\alpha$ undergoes dimerization in the ER membrane and autophosphorylation, which elicits RNase activity for splicing the mRNA of X-box-binding protein 1 (XBP1) (17). Spliced XBP1 (XBP1s) enters the nucleus and subsequently induces the transcription of various genes involved in protein folding, quality control mechanisms, and ERAD. Additionally, the RNase activity of IRE $1 \alpha$ can degrade a subset of mRNAs and microRNAs through a process known as regulated IRE1 $\alpha$-dependent decay (RIDD), which modulates various biological processes including stress mitigation, inflammation, and apoptosis $(18,19)$. Activation of IRE1 $\alpha$ kinase results in recruitment of the adaptor protein TNF receptor-associated factor 2 (TRAF2), which mediates signaling crosstalk with other stress pathways, including the mitogenactivated protein (MAP) kinase (MAPK) pathway and the nuclear factor kappa-light-chain-enhancer of activated B cells $(\mathrm{NF}-\mathrm{\kappa B})$ pathway (20). Collectively, IRE1 $\alpha$ plays a dual role in the response to ER stress, primarily through XBP1s-mediated adaptative proteostasis, the MAP kinase pathway, RIDD, and NF- $\kappa \mathrm{B}$ pathway-mediated apoptosis and inflammation.

Additionally, the PERK-mediated arm of the UPR has been reported to play an important role in various neurological diseases (21). Similar to IRE1 $\alpha$, PERK undergoes dimerization and autophosphorylation to activate its kinase activity following release from GRP78. Additionally, aberrant lipid metabolism of the ER membrane can directly activate PERK, demonstrating that lipid metabolism is a direct trigger of the $\operatorname{UPR}(22,23)$. PERK phosphorylates the downstream eukaryotic translation initiator $2 \alpha(\mathrm{eIF} 2 \alpha)$, which reduces protein synthesis and consequently prevents the loading of nascent proteins into the ER lumen (5). Additionally, eIF2 $\alpha$ can be phosphorylated in mammals independent of ER stress by three additional kinases, including protein kinase R (PKR), heme-regulated eIF2 $\alpha$ kinase (HRI), and general control nonderepressible 2 kinase (GCN2). Phosphorylated eIF2 $\alpha$ (p-eIF2 $\alpha$ ) tightly interacts with the guanine-nucleotide exchange factor (GEF) eIF2B. This process rapidly prevents the formation of the complex needed to load the $43 \mathrm{~S}$ ribosome with methionine, thereby inhibiting the initiation of translation (24). However, several mRNAs can overcome this suppression, and they are selectively translated following an increase in p-eIF2 $\alpha$, including activating transcription factor 4 (ATF4). ATF4 plays essential roles in modulating the expression of genes involved in redox control, amino acid metabolism, autophagy, and protein synthesis and folding (25).

In addition, ATF4 promotes PPP1R15A expression, which subsequently induces the expression of DNA damage-inducible 34 (GADD34), a regulatory subunit of protein phosphatase 1 (PP1); this results in dephosphorylation of eIF2 $\alpha$, leading to restoration of mRNA translation (26). When ER stress is intense or persistent, ATF4 additionally promotes pro-apoptotic factors, such as $\mathrm{C} / \mathrm{EBP}$ homologous protein (CHOP), and enhances oxidative stress, leading to cell death (27). PERK activation generally restores ER proteostasis; however, if the adaptive mechanism is overwhelmed, it triggers cell death cascades.

ATF6 is an ER-membrane-bound transcription factor that is a member of the basic leucine zipper protein (bZIP) 


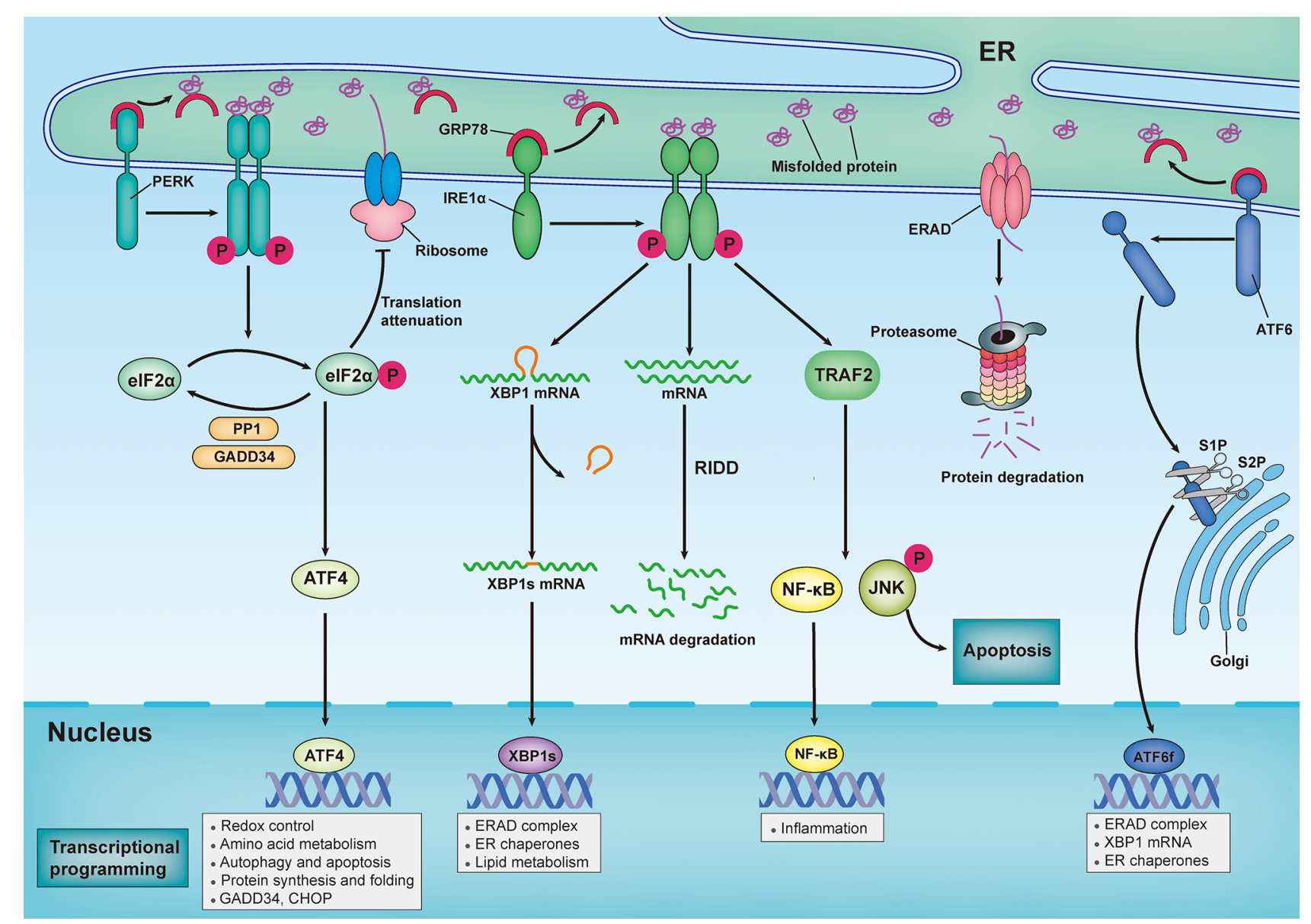

FIGURE 1 | Sensing and responding to endoplasmic reticulum stress: canonical roles of unfolded protein response. In response to an increasingly accumulation of misfolded proteins in endoplasmic reticulum (ER) lumen, three sensors that located in ER membrane - inositol-requiring enzyme 1 $\alpha$ (IRE1 $\alpha$ ), protein kinase RNA-like ER kinase (PERK) and activating transcription factor 6 (ATF6) - provoke unfolded protein response (UPR). Under homeostatic conditions, ER-resident protein chaperone glucose regulated protein 78 (GRP78) interacts with these ER stress sensors to restrain their activation. However, the excessive accumulation of misfolded proteins recruit GRP78 away from all three ER stress sensors, leading to activation of downstream signal transduction pathways. Upon ER stress, PERK undergoes its dimerization and autophosphorylation to phosphorylate eukaryotic translation initiator $2 \alpha(\mathrm{elF} 2 \alpha)$, which then selectively increases translation of activating transcription factor 4 (ATF4). ATF4 modulates the expression of genes involved in redox control, amino acid metabolism, autophagy, apoptosis, and protein synthesis and folding. Additionally, Phosphorylated elF2 $\alpha$ ( $\mathrm{p}$-elF2 $\alpha$ ) prevents ribosome assembly, which results in a translational block. Once ER stress is resolved, $p$-elF2 $\alpha$ is dephosphorylated by the GADD34-protein phosphatase 1 (PP10) complex to restore protein translation. In response to ER stress, IRE1 $\alpha$ oligomerizes and promote autophosphorylation, eliciting RNase activity to splice the mRNA of $x$-box-binding protein 1 (XBP1). Spliced XBP1(XBP1s) mRNA codes for the functionally active proteins of XBP1s, which translocated into nuclear and subsequently induces the transcription of various genes that are involved in protein folding, lipid metabolism and ER-assisted protein degradation (ERAD). In addition, the RNase activity of IRE1 $\alpha$ can also degrades a subset of mRNAs in a process termed regulated IRE1 $\alpha$-dependent decay (RIDD). By interacting with adaptor protein TNF receptor-associated factor 2 (TRAF2), IRE1 $\alpha$ can also activate C-Jun Nterminal kinase (JNK) and nuclear factor $\mathrm{\kappa B}(\mathrm{NF}-\mathrm{KB})$ pathways, thereby modulating inflammation and apoptosis. Upon ER stress, ATF6 is transported to Golgi, where it is cleaved by Site-1 protease (S1P) and Site-2 protease (S2P), releasing its active cytosolic fragment (ATF6f) that functions as a transcription factor. ATF6f induces genes required for ERAD and modulates the XBP1 mRNA levels and ER chaperone expression.

transcription factor family, which is expressed in the ER and which senses various stress stimuli in different cell types (20). Upon ER stress, ATF6 is transferred to the Golgi apparatus, where it is cleaved by site- 1 protease (S1P) and site-2 protease (S2P), leading to the release of its active cytosolic fragment (ATF6f) (28). ATF6f is then transported into the nuclear compartment, where it functions as a transcription factor and facilitates the transcription of various genes involved in protein folding, including ER protein chaperones; modulation of XBP1 mRNA levels; and $\operatorname{ERAD}(29,30)$.
Overall, once activated, IRE1 $\alpha$, PERK, and ATF6 constitute sophisticated and coordinated mechanisms that are involved in easing the aberrant accumulation of misfolded or unfolded proteins within the ER lumen by upregulating the expression of ER chaperones that attenuate protein translation, inhibiting protein entry into the ER, and promoting the retrograde export of misfolded/unfolded proteins from the ER to the cytosol for proteasome-mediated degradation. However, if these adaptive mechanisms are overwhelmed, persistent UPR activation leads to cell death and inflammation. 


\section{ROLE OF ENDOPLASMIC RETICULUM STRESS IN NEURONAL DEATH}

Although limited neuronal death is a highly regulated and essential homeostatic mechanism for the maintenance of CNS functional development (31), pathological neuronal loss in mature CNS leads to irreversible functional decline of motor and cognitive function, ranging from acute CNS injuries, such as traumatic brain injury (TBI) and ischemic stroke, to chronic neurodegenerative diseases, such as Alzheimer's disease (AD) and Parkinson's disease (PD) (32). There are at least a dozen mechanisms for neuronal death resulting from various neurological diseases (32). Numerous modulatory mechanisms are involved in determining cell death, and ER stress and the UPR play essential roles in regulating mechanisms of programmed neuronal death, such as apoptosis, necroptosis, pyroptosis, ferroptosis and autophagy (33-35).

\section{Endoplasmic Reticulum Stress and Neuronal Apoptosis}

If the adaptive mechanism fails to restore ER proteostasis, the UPR continues to activate and triggers three ER transducers and a series of downstream signaling pathways, leading to neuronal apoptosis. During the UPR, IRE1 $\alpha$-induced RIDD increases cell apoptosis by degrading mRNAs encoding growth-promoting proteins (18). Additionally, the IRE1 $\alpha /$ TRAF2/c-Jun Nterminal kinase (JNK) pathway has been broadly reported to play an important role in regulating neuronal apoptosis in response to ER stress $(36,37)$. The phosphorylation of JNK potentiates BAX-dependent apoptosis by up-regulating the proapoptotic BCL-2 family member BIM and down-regulating the anti-apoptotic protein BCL-2 $(38,39)$. IRE1 $\alpha$ is also reported to directly interact with two pro-apoptotic proteins, BCL-2 associated $\mathrm{X}$ protein (BAX) and BCL-2 antagonist/killer (BAK), to modulate IRE1 $\alpha$-mediated cell apoptosis (40). Finally, IRE1 $\alpha$-mediated phosphorylation has been reported to recruit caspase 12 (CASP 12), which is involved in regulating neuronal ER-specific apoptosis and cytotoxicity $(41,42)$. Persistent ER stress-induced PERK activation and concomitant downstream eIF2 $\alpha / \mathrm{ATF} 4 / \mathrm{CHOP}$ activation play vital roles in promoting neuronal apoptotic death (43-45). CHOP, a transcription factor downstream of the PERK/ATF4 pathway, is thought to be essential to ER stress-induced apoptosis, as its depletion or inhibition attenuates tissue insults in response to ER stress (46-49). Downregulation of CHOP using siRNA significantly reduced neuronal apoptosis in a mouse model of intracerebral hemorrhage (ICH) (50). Importantly, CHOP is also reported to be a common downstream component at the convergence of the IRE1 $\alpha$, PERK, and ATF6 pathways (51). Moreover, CHOP has been demonstrated to bind to an element in the promoter of the gene encoding various pro-apoptotic members of the BCL-2 family (21). CHOP may also exacerbate ER stress-induced apoptosis by promoting the expression of GADD34, Tribbles-related protein 3 (TRB3), and endoplasmic reticulum oxidoreductin $1 \alpha(\mathrm{ERO} 1 \alpha)(52)$. Further, ATF6 is highly expressed in neurons and is well described to regulate neuronal apoptosis, primarily by upregulating the expression of CHOP $(50,53,54)$.

\section{Endoplasmic Reticulum Stress and Neuronal Necroptosis}

Different from apoptosis, necroptosis is a form of regulated necrotic cell death that occurs in a caspase-independent manner and is mediated by receptor-interacting protein kinase 1 (RIPK1), RIPK3, and mixed lineage kinase domain-like protein (MLKL). Recently, necroptosis has been shown to play an essential role in neuronal programmed death in various acute CNS injuries and neurodegenerative diseases, and occurs following disruption of the plasma membrane and cell lysis (55). In addition to the activation of various death receptors, intrinsic ER stress has been recently demonstrated to be an essential contributor to necroptosis. In both in vitro and in vivo models of cardiac ischemia-reperfusion, it was elucidated that RIPK3-induced necroptosis was primarily mediated by ER stress via the calcium overload/xanthine oxidase/reactive oxygen species/mitochondrial permeability transition pore opening pathway (56). Additionally, it was demonstrated that necroptosis induced by PFWRIRIRR-NH2 (PFR) was regulated by ER stress via cytoplasmic calcium overload/the mitochondrial reactive oxygen species axis (57). It has been demonstrated that necroptosis-induced by various ER stressors in fibroblasts is primarily mediated by tumor necrosis factor receptor 1 (TNFR1). Moreover, repression of RIPK1, RIPK3, or MLKL in these cells resulted in switching the form of ER stress-induced cell death from necroptosis to apoptosis (58). Additionally, one confounding study found that an inhibitor of PERK, GSK2606414, prevented necroptosis by blocking RIPK1 (59). Inhibiting ER stress by Tauroursodeoxycholic acid (TUDCA) prevents Necrostatin-1-induced necroptosis in NP cells (60). Additionally, another inhibitor of ER stress, 4-phenylbutyrate (4-PBA), has been shown to attenuate necroptosis of microglia (61). Consistently, an in vitro study investigating the effects of ER stress on neurotoxicity found that ER stress inhibitor 4-PBA and tangeretin significantly reduced JNK-medicated neuronal necroptosis (62). Furthermore, in a rat model of global cerebral ischemia, administration of the ER stress inhibitor salubrinal after cerebral ischemia significantly decreased the expression of necroptotic markers and reduced selective neuronal necroptosis (63).

\section{Endoplasmic Reticulum Stress and Neuronal Pyroptosis}

Unlike apoptosis and necroptosis, pyroptosis is characterized by inflammasome-triggered, caspase 1- or caspase 11-mediated, and gasdermin-executed formation of plasma membrane pores and plasma membrane rupture. It is a rapid, inflammatory form of lytic programmed cell death (64). There is a growing appreciation for pyroptosis as a pivotal factor in neuronal death and neuroinflammation in neurological diseases (65). Recent studies have shown that ER stress is widely involved in multiple steps of pyroptosis induction (66). Recently, in a mouse model of acute hemorrhage stroke, ER stress was found to modulate neuronal 
pyroptosis by regulating the expression of IL-13 (67). IRE1 $\alpha$ has been shown to play a pivotal role in NLRP3 inflammasome assembly, caspase- 1 activation, and pro-IL-1 $\beta$ processing in monocytes and human peripheral blood mononuclear cells (PBMCs) (68). IRE1 $\alpha$ activation was reported to induce NLRP3 inflammasome-mediated pyroptosis by increasing the expression of thioredoxin-interacting protein (TXNIP) $(69,70)$. TXNIP, an endogenous negative modulator of the antioxidant protein thioredoxins (TXNs), was recently reported to be closely associated with NLRP3 inflammasome activation (71). Consistent with this observation, in the cerebral venous sinus thrombosis (CVST) model, p-PERK and p-IRE1 $\alpha$ were found to be expressed primarily in neurons; they contributed to neuronal pyroptosis by regulating TXNIP-NLRP3 inflammasome activation (72). In addition, recent research demonstrated that IRE1 $\alpha$ could modulate NLRP1 inflammasome-mediated neuronal pyroptosis by regulating the expression of miR-125-b-2-3p (73). PERK inhibition has been reported to inhibit NLRP3 inflammasome activation by regulating the mitochondriaassociated endoplasmic reticulum membrane (MAM)-induced calcium release (74). Further research showed that silencing PERK reduced the expression of TXNIP and NLRP3 in the tunicamycin-treated hepatocyte-derived AML 12 cell line (75). A recent study aimed at revealing the relationship between pyroptosis and ER stress found that the PERK inhibitor GSK2656157 inhibited GSDEME-mediated neuronal pyroptosis in neuronal cells exposed to methamphetamine (76). Cleaved ATF6 has been shown to be involved in NLRP3 inflammasome activation and pyroptosis in monocytes (77). Similarly, ATF6 has been reported to be associated with neuronal pyroptosis, where downregulation of ATF6 could reverse GSDEME-mediated pyroptosis in neuronal cells (76). Collectively, these studies imply that ER stress is involved in inflammasome-mediated neuronal pyroptosis.

\section{Endoplasmic Reticulum Stress and Neuronal Ferroptosis}

Ferroptosis is an iron-dependent, non-apoptotic form of programmed cell death characterized by loss of activity of the lipid repair enzyme glutathione peroxidase 4 (GPX4) and concomitant accumulation of lipid reactive oxygen species (78). Although well described in cancer cells, ferroptosis has been reported to play pivotal roles in neurons in various neurological diseases (79). Recently, several studies have indicated a close correlation between ferroptosis and ER stress. First, inhibition of system $\mathrm{Xc}^{-}$(a cell-surface cystine-glutamate antiporter) with several ferroptotic agents was shown to result in both eIF2 $\alpha /$ ATF 4 pathway activation and ferroptotic cell death $(80,81)$. Similarly, microassay studies showed that the ferroptosis activator glutathione S-transferase inhibitor artesunate (ART) increased the expression of ATF4-dependent genes such as CHOP and ASNS (82). Another recent study revealed that the PERK downstream protein ATF4 significantly increased the expression of system $\mathrm{Xc}^{-}$and promoted tumor angiogenesis, which can be attenuated by pharmacological or genetic system $\mathrm{Xc}^{-}$inhibition or ferroptotic agents such as sorafenib and erastin (83). Additionally, in both in vivo and in vitro models of glioma, the mechanism by which dihydroartemisinin exerts anticancer effects on glioma cells was found to be dependent on promoting ferroptosis via the PERK-ATF4-heat shock protein family A member 5 (HSPA5)GPX4 pathway (84). Recently, emerging evidence revealed that nuclear factor erythroid 2-related factor 2 (NRF2) plays a key role in linking ferroptosis and ER stress. NRF2, a key orchestrator of the cellular antioxidant response, is directly regulated by PERK $(85,86)$. Growing evidence suggests that NRF2, as a transcription factor, plays a pivotal role in inducing the transcription of multiple genes involved in lipid peroxidation and regulators of ferroptosis, such as GPX4 and system $\mathrm{Xc}^{-}$(87, 88 ). Finally, ROS, which play pivotal roles in lipid peroxidationinduced ferroptotic death, are also regulated by ER stress (89, 90). Overall, there was a close crosstalk between ER stress and ferroptosis. However, the precise molecular mechanism of the crosstalk between the three ER stress responses and neuronal ferroptosis signaling remains elusive, and further investigation is required to identify it.

\section{Endoplasmic Reticulum Stress and Neuronal Autophagy}

Autophagy is the major intracellular degradation system by which cytoplasmic material is engulfed by autophagosomes and degraded upon autophagosome fusion with lysosomes (91). Adaptive autophagy in response to initial ER stress is usually considered a protective mechanism; however, the devastating ER stress can shift protective autophagy to compromised autophagy, leading to autophagic cell death (92). Dysfunction of autophagy flux determines neuronal death, which is involved in many neurological diseases in which ER stress plays an important regulatory role (33). In a mouse model of $\mathrm{PD}$, it was first demonstrated that autophagy induced by mild ER stress inhibited neuronal death (93). Additionally, it was demonstrated in both in vitro and in vivo experimental models of diabetes that activation of the ER-stress-induced JNK signaling pathway may contribute to the induction of autophagy, which confers neuroprotection to ER-stress-associated neuronal damage (94). Furthermore, Japanese encephalitis virus (JEV)-induced autophagy has been shown to delay virus-induced neuronal death by activating ER stress and its downstream pathways (95). In another study, rapamycin-induced neuronal autophagy protected neurons from apoptotic death (96). However, excessive ER stress may lead to neuronal autophagic death. A recent study investigating the effects of pre-ischemia melatonin treatment on neuronal injury showed that the inhibition of ER stress-dependent autophagy significantly attenuated neuronal injury (97). Neuronal death promoted by fluoride-induced neurotoxicity has been demonstrated to primarily result from excessive ER stress-associated autophagic flux dysfunction (98). Additionally, in the Drosophila model of PD, IRE1 $\alpha$ overexpression led to parkinsonian neurodegeneration through autophagy-dependent dopaminergic neuron loss (99). Similarly, hypercholesterolemia has been shown to activate the IRE1 $\alpha /$ JNK signaling pathway in heart tissue, leading to autophagic cell death (100). Heme, which is 
released from hemorrhagic blood following intracerebral hemorrhage $(\mathrm{ICH})$, was reported to increase autophagydependent neuronal death via ER stress (101). In glioblastoma cells, doxorubicin was reported to elicit persistent ER stress, thereby leading to autophagic and apoptotic cell death (102). A recent study revealed that knockout of ATF4 significantly inhibited compound loperamide-induced autophagic cell death in glioblastoma cells (103). Further investigation in this study showed that ATF4 is required for loperamide-induced reticulophagy (103), whereby autophagy degrades the ER itself, amplifying ER stress and cell death (104). Collectively, these observations indicate that ER stress-induced autophagy plays a dual role in determining neuronal fate; autophagy induced by mild ER stress plays a pro-adaptive role, while excessive or persistent ER stress conditions directly evoke a shift of autophagy toward its pro-death role, thereby leading to neuronal autophagic death.

\section{THE ROLE OF ENDOPLASMIC RETICULUM STRESS IN INNATE IMMUNE RESPONSE IN THE CENTRAL NERVOUS SYSTEM}

Emerging evidence indicates that neuroinflammation is a pathology common to various neurological disorders, including CNS injury and neurodegenerative diseases (105). Neuroinflammation is a complex immune response characterized by the activation of resident CNS glial cells (microglia and astrocytes), peripherally derived immune cells, and production of inflammatory cytokines and chemokines (106). As a key component of the CNS innate immunity, microglia- and astrocyte-mediated innate immune responses initially exert essential and functional roles in cellular debris clearance and neural tissue repair. However, under chronic pathological conditions, the innate immune response in the CNS gradually becomes an important contributor to the aggravation of blood-brain barrier (BBB) disruption, tissue damage, and neuronal death (107). ER stress not only regulates inflammatory responses in peripheral tissues but also plays a role in innate immune responses associated with neurological disorders (108).

\section{Endoplasmic Reticulum Stress and Inflammatory Pathways}

ER stress has been implicated as playing a role in various inflammatory diseases by directly regulating the inflammatory pathways. Emerging findings reveal that there is a reciprocal regulation between ER stress and inflammatory responses (Figure 2). Previous studies have demonstrated that XBP1s, as a transcription factor, is implicated in pro-inflammatory gene expression $(109,110)$. ATF4 has been shown to directly interact with the IL-6 promoter to elicit a pro-inflammatory response (111). Additionally, in astrocytes, PERK directly interacts with Janus kinase 1 (JAK1) and promotes signal transducer and activator of transcription 3 (STAT3) phosphorylation in response to ER stress, thereby leading to inflammatory gene expression (112). Recently, the transcription factor ATF6 has been reported to increase the expression of various pro- inflammatory cytokines in response to persistent ER stress (113). Importantly, the NF- $\mathrm{KB}$ and mitogen-activated protein kinase (MAPK) family proteins JNK and p38 are the primary inflammatory signaling molecular players, which are directly initiated by ER stress (114). In turn, pro-inflammatory stimuli, such as ROS, Toll-like receptor (TLR) ligands, and cytokines, can aggravate ER stress and amplify inflammatory responses via a positive feedback loop (115).

$\mathrm{NF}-\kappa \mathrm{B}$, a master transcription factor of pro-inflammatory pathways, plays a pivotal role in inflammation and immunity (116). During ER stress, the interaction of IRE1 $\alpha$ and TRAF2 can lead to the recruitment of IKB kinase (IKK), as well as the phosphorylation and subsequent degradation of IKB (117). Subsequently, free $\mathrm{NF}-\kappa \mathrm{B}$ is transported into the nucleus, where it binds to $\mathrm{\kappa B}$ sites in gene promoters and drives the expression of pro-inflammatory cytokines. Additionally, the IRE1 $\alpha-$ TRAF2 complex can activate NF- $\kappa B$ by triggering the nucleotide-binding oligomerization domains 1 and 2 (NOD1/2)receptor-interacting serine/threonine-protein kinase 2 (RIPK2) pathway $(118,119)$. Emerging evidence has suggested that the IRE1 $\alpha / \mathrm{XBP} 1 \mathrm{~s}$ pathway is also responsible for the activation of NF- $\kappa B$ (120-123). During the UPR, IRE1 $\alpha$-induced RIDD participates in promoting the production of retinoic acidinducible gene 1 (RIG-1), which is responsible for activating NF- $\kappa B$ (124). Additionally, PERK and ATF6 have been reported to promote NF- $\mathrm{BB}$ activation; however, the mechanisms are different from those employed by IRE1 $\alpha$. In response to ER stress, activation of the PERK/eIF $2 \alpha$ signaling pathway can result in decreased translation of both I $\kappa \mathrm{B}$ and NF- $\kappa \mathrm{B}$. However, this results in an increase in NF- $\kappa \mathrm{B}$ levels compared to I $\kappa \mathrm{B}$ levels, because $I \kappa B$ has a shorter half-life than NF- $\kappa B$, thereby promoting NF- $\kappa \mathrm{B}$-mediated inflammatory responses (125, 126). Moreover, the ATF6-mediated arm of the UPR has been demonstrated to activate $\mathrm{NF}-\kappa \mathrm{B}$ by inducing the phosphorylation of AKT $(127,128)$.

The MAPK family consists of stress-inducible kinases, including JNK, p38, MAPK, and extracellular signal-regulated kinase (ERK). These enzymes are serine-threonine protein kinases that mediate various biological processes, such as proliferation, apoptosis, and inflammation (129). In addition to the activation of NF- $\kappa \mathrm{B}$, the IRE1 $\alpha$-TRAF2 complex can recruit apoptosis signal-regulating kinase 1 (ASK1) and subsequently activate JNK, resulting in the expression of pro-inflammatory genes by stimulating the bZIP transcription factor activator protein 1(AP-1) (130, 131). Additionally, hyperactivation of IRE $1 \alpha$ in response to inefficient XBP1 signaling can elicit inflammatory responses by activating JNK (132). In retinal Müller cells, hyperglycemia- and hypoxia-induced ER stress promotes activation of ATF4, which upregulates inflammatory genes by activation of hypoxia-inducible factor (HIF) and JNK, resulting in the retinal expression of inflammatory cytokine tumor necrosis factor (TNF- $\alpha$ ) and VEGF (133). Furthermore, in an in vitro experimental model of ventilator-induced lung injury, inhibition of ER stress effectively prevented the inflammatory response by regulating $\mathrm{NF}-\kappa \mathrm{B}$ and the MAPK family (JNK, ERK, and p38) signaling pathways (134). 


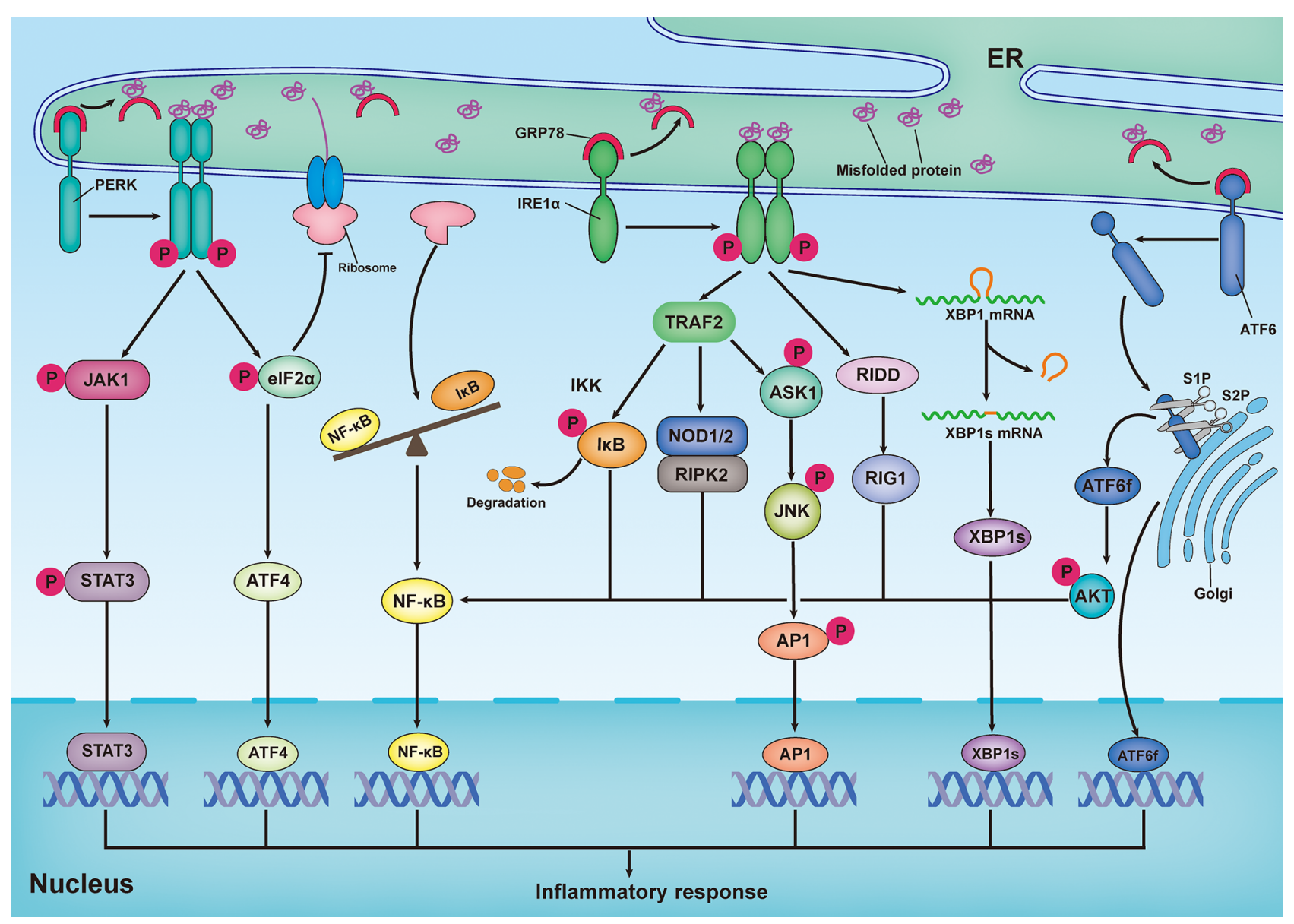

FIGURE 2 | Inflammatory response induced by the unfolded protein response. Upon ER stress, PERK undergoes its dimerization and autophosphorylation to phosphorylate eukaryotic translation initiator $2 \alpha(\mathrm{elF} 2 \alpha)$ and Janus kinase 1 (JAK1), which respectively promote activating transcription factor 4 (ATF4) expression and signal transducer and activator of transcription 3 (STAT3) phosphorylation, thereby leading to inflammatory gene expression. In addition, translation attenuation by

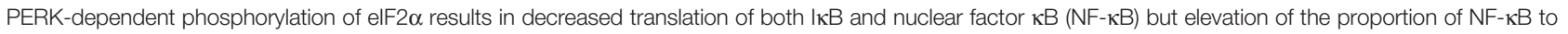

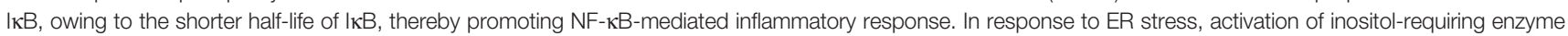
$1 \alpha(\operatorname{IRE} 1 \alpha)$ increase the expression of functionally active proteins of XBP1s, leading to inflammatory gene expression. During ER stress, interaction of IRE1 $\alpha$ and TRAF2 can promote NF-kB-mediated inflammatory response by triggering IKB kinase (IKK)/KB pathway and nucleotide-binding oligomerization domain 1 and 2 (NOD1/2)/receptor-interacting serine/threonine-protein kinase 2 (RIPK2) pathways. In addition, both IRE1 $\alpha$-mediated IRE1 $\alpha$-dependent decay (RIDD)/retinoic-acid inducible gene 1 (RIG-1) pathway and IRE1 $\alpha$-induced expression of spliced $x$-box-binding protein 1 (XBP1s) are responsible for activating NF-kB. In addition to the activation of NF-KB, IRE1 $\alpha$-TRAF2 complex can also recruit apoptosis signal-regulating kinase 1 (ASK1) and subsequently activate JNK, thereby resulting in expression of pro-inflammatory genes by stimulating the bZIP transcription factor activator protein 1(AP-1). Upon ER stress, ATF6 is transported to Golgi, where it is cleaved by Site-1 protease (S1P) and Site-2 protease (S2P), releasing its active cytosolic fragment (ATF6f). ATF6f as a transcription factor, directly participate in regulating inflammatory response. Besides, ATF6f can also activate NF- $\mathrm{kB}$ by inducing the phosphorylation of the AKT.

Consistent with this observation, the inhibition of PERK by GSK2606414 dampened the receptor activator of NF- $\mathrm{KB}$ ligand (RANKL)-induced osteoclast differentiation through inhibition of MAPK and NF- $\mathrm{KB}(135)$.

\section{Endoplasmic Reticulum Stress and Microglia-Mediated Immune Response in the Central Nervous System}

Microglia, resident macrophages of the CNS, play key roles in regulating brain development, maintaining neuronal networks, clearing cellular debris, and producing neurotrophic factors (136, 137). Microglia are always activated earlier than other types of glial cells under pathological conditions, such as acute brain injury and neurodegeneration; subsequently, they induce a broad spectrum of pro-inflammatory responses and neurotoxic factors, accelerating neuronal death and brain damage (105). However, microglia can also release anti-inflammatory cytokines and neurotrophic factors, which in turn produce neuroprotective effects (138). These distinct outcomes are determined according to the polarization state of the microglia; the M1 phenotype aggravates neuronal damage, and the M2 phenotype protects neurons from insults (139). The essential involvement of ER stress in the activation and polarization of microglia in neurological diseases has been widely reported. 
In a study on the effects of mild ER stress on neuronal death, tunicamycin-induced mild ER stress was shown to significantly attenuate LPS-induced pro-inflammatory cytokine production in primary cultured microglia, which promoted the polarization of microglia from the M1 to M2 phenotype (140). In contrast, excessive ER stress triggers a series of pro-inflammatory signaling pathways in microglia, resulting in microgliamediated neuroinflammation. Cocaine, one of the most commonly abused drugs, has been shown to promote microglia-mediated inflammatory responses (141). Further investigation revealed that ER stress elicited cocaine-induced autophagy, which in turn promoted microglial activation and the release of inflammatory cytokines (142). Consistent with this observation, another study showed that exposure of microglial cells to cocaine upregulated the expression of TLR2 through the PERK/ATF4 pathway, resulting in microglial activation and proinflammatory cytokine production (143). Furthermore, a recent study demonstrated that the protein tyrosine phosphatase $1 \mathrm{~B}$ (PTP1B) inhibitor sc-222227 effectively promotes microglial M1to-M2 transformation and inhibits the release of microgliamediated inflammatory cytokines following cerebral ischemia/ reperfusion (IR) injury by modulating the ER stress-autophagy axis via PERK signaling in microglia (144). These observations collectively indicate that the ER stress-autophagy axis plays an essential role in modulating microglia-mediated neuroinflammation. Additionally, another study that explored the association between the extent of UPR signaling and type I interferons (IFN) showed that the impairment of proteasome activity in microglia induced an IFN $\beta 1$ response and concomitant IL- 6 secretion in an IRE1 $\alpha$-dependent manner. In this case, inhibition of IRE $1 \alpha$ endoribonuclease activity attenuated Tank-binding kinase 1-mediated type I IFN activation (145). Interestingly, this study further showed that both PERK/CHOP and IRE1 $\alpha / \mathrm{XBP} 1 \mathrm{~s}$ are involved in modulating IL-6 secretion in microglia (145). Furthermore, the eIF2 $\alpha /$ ATF4 signaling pathway has been reported to be involved in modulating microglial activation and M1/M2 polarization, which in turn regulates microglia-mediated generation of inflammatory cytokines (146-149). Recently, MAP kinase phosphatase 1 (MKP1), an antiapoptotic protein, has been shown to inhibit microglial activation by modulating ER stress and mitochondrial function (150). Additionally, a previous study that explored the role of ATF $6 \alpha$ in experimental autoimmune encephalomyelitis (EAE) mice found that ATF6 $\alpha$ deficiency effectively inhibited microglial activation and pro-inflammatory cytokines by activating NF- $\mathrm{BB}$ signaling, thereby ameliorating demyelination and clinical symptoms (151).

Collectively, these findings suggest that ER stress plays a pivotal role in regulating microglial functions under both physiological and pathological conditions because of the key signaling molecules in its downstream signaling pathway. Indeed, in response to insult and injury, cellular ER stress, through its downstream signaling pathways, directly participates in modulating microglia-mediated neuroinflammation. However, the mechanism by which this occurs has only been partly elucidated; further investigation needs to conduct regarding the interplay between ER stress; microglial activation; and neurological diseases such as $\mathrm{PD}, \mathrm{AD}$, and TBI.

\section{Endoplasmic Reticulum Stress and Astrocyte-Mediated Immune Response in the Central Nervous System}

Astrocytes are the most abundant glial cells; they perform essential functions in the CNS physiology, including synaptogenesis, neurotransmission, BBB formation, and metabolic regulation (152). Meanwhile, reactive astrocytes can also participate in CNS inflammatory responses and exacerbate neuroinflammation by interacting with other immune cells. Indeed, reactive astrocytes responding to various insults or injuries can directly secrete a series of pro-inflammatory cytokines, such as IL- $1 \beta$ and TNF- $\alpha$, along with increased generation of ROS, thereby playing an essential role in neurological diseases and neurological outcomes (153, 154). Astrocytes undergo molecular and morphological changes in response to various stresses, a process known as astrogliosis (155). Astrogliosis is characterized by increased levels of glial fibrillary acidic protein (GFAP), proliferation, and hypertrophy. Recently, single-cell RNA sequencing (scRNA-seq) has been used for the detection of increased UPR signaling in expanded subpopulations of astrocytes during EAE (156). Astrocytes express all three trans-ER membrane stress sensors (IRE1 $\alpha$, PERK, and ATF6) and specifically express old astrocyte specifically induced substance (OASIS). Accumulating evidence suggests that aberrant ER stress in astrocytes plays a pathological role in neuroinflammation in various neurological diseases (157).

In addition to its implication in microglial activation, the ER stress-autophagy axis has been reported to play an essential role in astrocyte activation and concomitant inflammatory responses (158, 159). Preconditioning of cells with mesencephalic astrocyte-derived neurotrophic factor (MANF) and conserved dopamine neurotrophic factor (CDNF) has been shown to effectively inhibit ER stress and alleviate cell damage and inflammatory cytokine production in rat primary astrocytes $(160,161)$. Additionally, preconditioning of astrocytes with progesterone effectively protects them from amyloid $\beta$ (A $\beta)$ induced inflammation by suppressing ER stress activation (162). Selenoprotein S, an ER-resident protein, attenuates proinflammatory responses by reducing ER stress in astrocytes (163). Accumulating evidence indicates that the PERKmediated arm of the UPR in astrocytes is linked to the induction of inflammatory responses. Moreover, recent evidence has indicated that genetic haploinsufficiency or inhibition of PERK in primary astrocytes inhibits ER stressassociated inflammation (IL-6, CCL2, and CCL20 production) at both the mRNA and protein levels (164). Additionally, the interplay between the PERK-mediated arm of the UPR and JAK/STAT-signaling-dependent inflammation has been well described in astrocytes $(112,164-166)$. The JAK1/STAT3 pathway regulates the expression of various inflammatory genes, as well as immunological functions (167). PERK signaling-induced activation of JAK1/STAT3 results in the 
generation of various cytokines, such as IL-6 and oncostatin M (OSM).

Additionally, free IL-6 can bind to its cell membrane receptor and further activate JAK1/STAT3 (168). Thus, these free IL-6 cytokines may synergize with ER stress in astrocytes, amplifying inflammation (112). Recently, a study investigating the role of IRE $1 \alpha$ in a mouse model of AD found that genetic ablation of the RNase domain of IRE1 $\alpha$ significantly reduced amyloid deposition and astrogliosis (169). Furthermore, another study aimed at identifying signaling pathways involved in pathogenic neuroinflammation in multiple sclerosis (MS), revealed that IRE1 $\alpha / \mathrm{XBP} 1$ signaling in astrocytes is a driver of genomic programs and that it modulates astrocyte pro-inflammatory activities (170).

Collectively, these in vivo and in vitro findings revealed that ER stress plays an essential role in modulating astrocyte activation and astrocyte-driven inflammatory activities in the CNS. However, studies on the implications of ATF6 and OASIS in astrocyte activation during various neurological diseases remain undefined, and further investigations are required in this regard.

\section{THE ROLE OF ENDOPLASMIC RETICULUM STRESS IN NEUROLOGICAL DISEASES}

The aberrant accumulation of misfolded/unfolded proteins inside the ER lumen activates ER stress responses, which subsequently trigger sophisticated and coordinated UPRs, thereby restoring homeostasis and normal ER function (Figure 1). Indeed, the adaptive UPR can enhance the adaptive capacity of the ER and promote cell resistance to external stimuli by altering the transcriptome and proteome (171). However, the intense and devastating ER stress that occurs in acute CNS injury and the prolonged ER stress that develops in neurodegenerative disorders, are considered to disrupt the protective mechanisms of the UPR, resulting in the activation of neuronal death and inflammatory responses in the CNS. In the following sections, we briefly generalize the roles of ER stress in multiple neurological diseases, ranging from acute CNS injuries to neurodegenerative diseases (Table 1).

\section{The Role of Endoplasmic Reticulum Stress in Intracerebral Hemorrhage}

Spontaneous $\mathrm{ICH}$ is defined as bleeding within the brain parenchyma caused by a ruptured brain aneurysm. ICH is the most lethal subtype of stroke, with high mortality, morbidity, and recurrence rates. Currently, there is no effective treatment for improving the functional outcomes in patients with ICH (242). Primary brain injury refers to the formation and expansion of hematomas within the first few hours after ICH, which results in mass effects and increased intracranial pressure that can lead to herniation and death of patients. Secondary brain injury is complex; however, it primarily results from hematoma-induced edema, inflammatory activities, oxidative stress, and toxic biochemical effects $(243,244)$. Recently, ER stress has been considered as one of the molecular mechanisms involved in ICH-induced secondary brain injury (33).

The first evidence of activated ER stress in ICH was reported in patients with $\mathrm{ICH}$ with pathogenic mutations, two of the three putative mutations being COL4A2 $2^{\mathbf{E 1 1 2 3 G}}$ and COL4A2 $2^{\mathbf{Q 1 1 5 0 K}}$ (245). In a rat model of ICH, ER stress was activated after $\mathrm{ICH}$, and inhibition of ER stress by TUDCA exerted neuroprotective effects in the brain (172). Importantly, it was indicated in a mouse model of ICH that TUDCA-induced inhibition of ER stress significantly alleviated neurological deficits by preventing neuronal pyroptosis via decreasing IL-13 expression (67). Additionally, in both in vivo and in vitro experimental models of ICH, the PERK inhibitor GSK2606414 effectively inhibited ER-stress-associated neuronal apoptosis following ICH, whereas the inhibitory effect was abolished in mice or cells receiving the eIF2 $\alpha$ dephosphorylation inhibitor salubrinal (173). A study that explored the neuroprotective effects of melatonin in ICH showed that siRNA-induced inhibition of CHOP signaling effectively attenuated the proapoptotic effects of ATF6 induced by ICH (50). Heme, which is released from hemoglobin or other heme proteins following $\mathrm{ICH}$, has been reported to increase autophagic neuron death by directly activating ER stress (101, 246). Moreover, oligodendrocyte apoptosis, which is associated with ICHinduced demyelination, has been reported to be mediated via ER stress (247).

\section{The Role of Endoplasmic Reticulum Stress in Ischemic Stroke}

Stroke is the second leading cause of death and a leading cause of disability worldwide (248). Ischemia stroke, defined as arterial occlusion, represents approximately $71 \%$ of all strokes globally (249). Currently, the main practices to recanalize blood flow in acute ischemic stroke include intravenous tissue plasminogen activator (t-PA) and endovascular thrombectomy for large-vessel occlusion. Nevertheless, cerebral-ischemia-induced hypoxia and subsequent reperfusion-induced damage impair proteostasis and subsequently induce ER stress, leading to further devastating brain injury (250).

In a 2002 study, Ito et al. first reported that the expression of the ER stress markers GRP78 and IRE1 $\alpha$ signaling molecules was increased in the ischemic rat brain (251). Importantly, in the same year, in mice, administration of the ER stress inhibitor TUDCA after transient middle cerebral artery occlusion (tMCAO) was shown to reduce the number of apoptotic cells and infarct size, as well as improve neurological outcomes (184). Additionally, in cerebral ischemic mice, PERK signaling molecules were found to be strongly increased (252). This study further indicated that tPA directly binds to cell surface GRP78, which, in turn, triggers a signal that attenuates ER stress overactivation in neurons, providing neuroprotection in ischemic mice (252). Sodium 4-phenylbutyrate (4-PBA sodium), a chemical chaperone that reverses misfolded proteins, was reported for the first time to reduce ER-stressinduced neuronal death in mice subjected to cerebral ischemic 
TABLE 1 | Functional impact of ER stress in neurological diseases.

\begin{tabular}{|c|c|c|c|c|}
\hline Disease & Model & Intervention & Effects & Refs \\
\hline \multirow[t]{4}{*}{$\mathrm{ICH}$} & \multirow{2}{*}{$\begin{array}{l}\text { Autologous blood- } \\
\text { induced } \mathrm{ICH}\end{array}$} & TUDCA (ER stress inhibitor) & Neuroprotection & $(172)$ \\
\hline & & SiRNA CHOP & $\begin{array}{l}\text { Inhibited ER stress-associated neuronal apoptosis; alleviated neurological } \\
\text { deficits }\end{array}$ & $(50)$ \\
\hline & \multirow{2}{*}{$\begin{array}{l}\text { Collagenase-induced } \\
\mathrm{ICH}\end{array}$} & TUDCA (ER stress inhibitor) & Alleviated neurological deficits & $(67)$ \\
\hline & & PERK inhibitor GSK2606414 & Inhibited ER stress-associated neuronal apoptosis & $(173)$ \\
\hline \multirow[t]{12}{*}{ IS } & \multirow[t]{5}{*}{ OGD/R } & PERK inhibitor GSK2606414 & Neuroprotection; attenuated the ER stress-associated inflammation & $(144)$ \\
\hline & & & & $(174)$ \\
\hline & & SiRNA ATF4 & Promoted primary neuronal apoptosis & $(175)$ \\
\hline & & Overexpression of IRE1 $\alpha$ & Promoted ER stress-associated primary neuronal apoptosis & $(176)$ \\
\hline & & Overexpression of XBP1 & Inhibited primary neuronal cell death & $(177)$ \\
\hline & \multirow{7}{*}{$\begin{array}{l}\text { OGD/R; tMCAO } \\
\text { tMCAO }\end{array}$} & 4-PBA (ER stress inhibitor) & Inhibited ER stress-associated neuronal apoptosis and inflammation & $(178-183)$ \\
\hline & & TUDCA (ER stress inhibitor) & $\begin{array}{l}\text { Inhibited ER stress-associated neuronal apoptosis; alleviated neurological } \\
\text { deficits }\end{array}$ & $(184)$ \\
\hline & & PERK inhibitor GSK2606414 & Inhibited ER stress-associated neuronal apoptosis & $(185)$ \\
\hline & & PERK cKO & Aggravated neurological deficits & $(186)$ \\
\hline & & Overexpression of ATF4 & Neuroprotection; alleviated neurological deficits & $(187)$ \\
\hline & & ATF6 KI & Neuroprotection; alleviated neurological deficits & $(188)$ \\
\hline & & 147 (ATF6 activator) & Neuroprotection; alleviated neurological deficits & $(189)$ \\
\hline \multirow[t]{7}{*}{$\mathrm{TBI}$} & BOE & $\begin{array}{l}\text { Salubrinal (elF2 } \alpha \text { dephosphorylation } \\
\text { inhibitor) }\end{array}$ & $\begin{array}{l}\text { Inhibited ER stress-associated neuronal apoptosis and inflammation; } \\
\text { alleviated impulsive-like behavior }\end{array}$ & $(190-192)$ \\
\hline & LFP & $\begin{array}{l}\text { salubrinal (elF2 } \alpha \text { dephosphorylation } \\
\text { inhibitor) }\end{array}$ & Neuroprotection; attenuated the ER stress-associated neuronal apoptosis & $(193)$ \\
\hline & \multirow[t]{5}{*}{$\mathrm{CCl}$} & TUDCA (ER stress inhibitor) & $\begin{array}{l}\text { Inhibited ER stress-associated neuronal apoptosis; alleviated neurological } \\
\text { deficits }\end{array}$ & $(194)$ \\
\hline & & $\begin{array}{l}\text { Salubrinal (elF2 } \alpha \text { dephosphorylation } \\
\text { inhibitor) }\end{array}$ & $\begin{array}{l}\text { Inhibited ER stress-associated neuronal apoptosis and inflammation; } \\
\text { alleviated neurological deficits }\end{array}$ & $(195,196)$ \\
\hline & & $\begin{array}{l}\text { Low dose guanabenz (an activator of } \\
\text { elF2 } \alpha \text { phosphorylation) }\end{array}$ & $\begin{array}{l}\text { Inhibited ER stress-associated neuronal cell death; alleviated neurological } \\
\text { deficits }\end{array}$ & $(197,198)$ \\
\hline & & PERK inhibitor GSK2656157 & $\begin{array}{l}\text { Inhibited ER stress-associated neuronal cell inflammation; alleviated memory } \\
\text { deficits }\end{array}$ & $(199,200)$ \\
\hline & & $\mathrm{CHOP} \mathrm{KO}$ & Reduced newborn neurons loss; improved cognitive come & $(198)$ \\
\hline \multirow[t]{10}{*}{$A D$} & \multirow[t]{5}{*}{ APP/PS1 mice } & PERK CKO & Improved synaptic plasticity and spatial memory and LTP & $(201)$ \\
\hline & & & & $(202)$ \\
\hline & & SiRNA ATF4 & Neuroprotection & (203) \\
\hline & & overexpression of XBP1 & Improved memory deficits; restored spine density and synaptic plasticity & $(204)$ \\
\hline & & Overexpression of ATF6 & Protected retention of spatial memory & $(205)$ \\
\hline & \multirow[t]{2}{*}{ 5XFAD mice } & PERK+/- & Restored memory deficits and cholinergic neurodegeneration & (206) \\
\hline & & IRE1 $\alpha \mathrm{CKO}$ & $\begin{array}{l}\text { Improved synaptic function and LTP; restored learning and memory } \\
\text { functions }\end{array}$ & (169) \\
\hline & \multirow{2}{*}{ Tau Tg mice } & PERK inhibitor GSK2606414 & Reduced brain atrophy and abrogated the appearance of clinical signs & $(207)$ \\
\hline & & $\begin{array}{l}\text { PERK inhibitors trazodone and } \\
\text { dibenzoylmethan }\end{array}$ & $\begin{array}{l}\text { Restored memory impairment, abrogated neurological signs, prevented } \\
\text { neurodegeneration, and prolonged survival }\end{array}$ & $(208)$ \\
\hline & $2 \times \operatorname{Tg}$ mice & PERK inhibitor ECH & Ameliorated memory deficit & (209) \\
\hline \multirow[t]{9}{*}{$\mathrm{PD}$} & \multirow[t]{2}{*}{$\alpha$-synuclein Tg mice } & $\begin{array}{l}\text { Salubrinal (elF2 } \alpha \text { dephosphorylation } \\
\text { inhibitor) }\end{array}$ & Attenuated the progressive motor deficits & $(210)$ \\
\hline & & PERK inhibitor GSK2606414 & Attenuated DA neuronal cell death; improved motor performance & $(211)$ \\
\hline & $\begin{array}{l}\text { Pink1/parkin mutant } \\
\text { flies }\end{array}$ & PERK inhibitor GSK2606414 & Neuroprotection & $(212)$ \\
\hline & $\begin{array}{l}\text { Neurotoxins treated } \\
\text { primary neurons }\end{array}$ & elF2 $\alpha$ inhibitor C16 & Attenuated neuronal cell death & $(213)$ \\
\hline & Neurotoxins treated rat & overexpression of XBP1 & inhibited DA neuronal degeneration & $(214)$ \\
\hline & \multirow{4}{*}{$\begin{array}{l}\text { Neurotoxins treated } \\
\text { mice }\end{array}$} & overexpression of XBP1 & Attenuated DA neuronal cell death & $(215)$ \\
\hline & & ATF6 KO & Accelerated neuronal cell death & $(216,217)$ \\
\hline & & $\mathrm{CHOP} \mathrm{KO}$ & Neuroprotection & $(47)$ \\
\hline & & overexpression of XBP1 & Attenuated DA neuronal cell death & $(218)$ \\
\hline \multirow[t]{8}{*}{ MS } & \multirow[t]{6}{*}{ EAE mice } & temporally controlled activation of PERK & Reduced oligodendrocytes loss, demyelination, and axonal degeneration & $(219)$ \\
\hline & & & Promoted cell survival and remyelination & $(220)$ \\
\hline & & & prevented neuron loss & $(221)$ \\
\hline & & ATF6 $\alpha \mathrm{KO}$ & increased oligodendrocyte death and myelin loss & $(222)$ \\
\hline & & PERK KO & Drive neuroinflammation & $(112)$ \\
\hline & & OL-PERK ko/ko & Increased oligodendrocytes loss, demyelination, and axonal degeneration & (223) \\
\hline & \multirow[t]{2}{*}{ EAE/optic neuritis mice } & $\mathrm{CHOP}$ deletion & Promote RGC soma and axon survival & $(224)$ \\
\hline & & overexpression of XBP1 & Promote RGC soma and axon survival & $(224)$ \\
\hline
\end{tabular}


TABLE 1 | Continued

\begin{tabular}{|c|c|c|c|c|}
\hline Disease & Model & Intervention & Effects & Refs \\
\hline \multirow[t]{9}{*}{ HD } & Htt 150Q cells & overexpression of GRP78 & reduced formation of $\mathrm{mH}$ tt aggregates; prevented cell death & (225) \\
\hline & $\begin{array}{l}\text { polyQ-expanded } \mathrm{Htt} \\
\text { cells }\end{array}$ & PERK inhibitor A4 & Reduced mHtt cytotoxicity & $(226)$ \\
\hline & Htt 120Q cells & $\begin{array}{l}\text { Salubrinal (elF2 } \alpha \text { dephosphorylation } \\
\text { inhibitor) }\end{array}$ & Prevented cell death & $(227)$ \\
\hline & & IRE1 $\alpha$ inhibitor Usp14 & Protect against cell degeneration and cell death & (228) \\
\hline & SH-SY5Y cells & shRNA IRE1 $\alpha$ & Reduced neuronal toxicity & (229) \\
\hline & $\begin{array}{l}\text { AAV-Htt588Q95-mRFP } \\
\text { mice }\end{array}$ & overexpression of XBP1 & reduced the accumulation of $\mathrm{mHtt}$ inclusion & (230) \\
\hline & YAC128 HD & XBP1 cKO & Decreased the levels of $\mathrm{mHtt}$ & (231) \\
\hline & Mice & shRNA IRE1 $\alpha$ & Reduced the aggregation of pathological polyQ79-EGFP peptides & (231) \\
\hline & & shRNA XBP1 & Reduced the aggregation of pathological polyQ79-EGFP peptides & (231) \\
\hline \multirow[t]{11}{*}{ ALS } & SOD1 mutant mice & $\begin{array}{l}\text { Salubrinal (elF2 } \alpha \text { dephosphorylation } \\
\text { inhibitor) }\end{array}$ & Ameliorated disease severity and delay progression & (232) \\
\hline & $\begin{array}{l}\text { SOD1 mutant neuro2a } \\
\text { cells }\end{array}$ & $\begin{array}{l}\text { Salubrinal (elF2 } \alpha \text { dephosphorylation } \\
\text { inhibitor) }\end{array}$ & Reduced cell death & $(233)$ \\
\hline & SOD1 mutant mice & PERK+/- & $\begin{array}{l}\text { Exhibited an earlier disease onset, reduced lifespans, and earlier } \\
\text { neuropathological alterations in spinal cord }\end{array}$ & (234) \\
\hline & & GADD34 dysfunction & $\begin{array}{l}\text { Exhibited a delayed disease onset, delayed early phase of disease and } \\
\text { prolonged lifespans }\end{array}$ & $(235)$ \\
\hline & & shRNA GADD34 & Ameliorated disease severity and prolonged lifespans & (236) \\
\hline & & $\begin{array}{l}\text { Guanabenz(elF2 } \alpha \text { dephosphorylation } \\
\text { inhibitor) }\end{array}$ & $\begin{array}{l}\text { Ameliorate disease severity with a delay in the onset and prolongation of the } \\
\text { early phase of disease and survival }\end{array}$ & $(237)$ \\
\hline & & & $\begin{array}{l}\text { Exhibited delayed onset of disease symptoms, prolonged lifespan and } \\
\text { improved motor performance }\end{array}$ & $(238)$ \\
\hline & & PERK inhibitor ISRIB & Reduced neuronal death & (239) \\
\hline & mutant TDP-43 mice & $\begin{array}{l}\text { Guanabenz(elF2 } \alpha \text { dephosphorylation } \\
\text { inhibitor) }\end{array}$ & Ameliorate motor deficits and axon defects & $(240)$ \\
\hline & & $\begin{array}{l}\text { Salubrinal (elF2 } \alpha \text { dephosphorylation } \\
\text { inhibitor) }\end{array}$ & Ameliorate motor deficits and axon defects & $(240)$ \\
\hline & & PERK inhibitor GSK2606414 & Inhibited ER stress-associated TDP-43 toxicity & $(241)$ \\
\hline
\end{tabular}

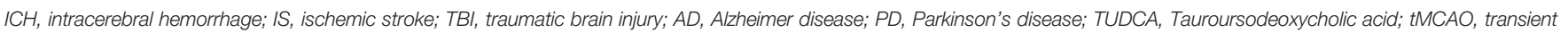

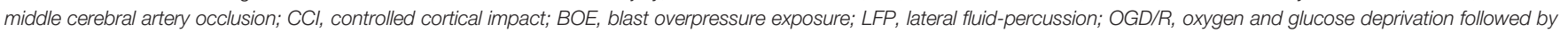

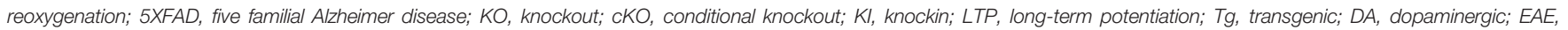
experimental autoimmune encephalomyelitis; SOD, Cu, Zn-superoxide dismutase; TDP-43, TAR DNA Binding Protein43;Htt 150Q cells, mutant huntingtin containing 150Q cells: Usp14, Ubiquitin-specific protease-14.

injury (178). Subsequently, emerging evidence has considered 4PBA as an inhibitor of ER stress, and in vitro and in vivo studies in ischemic stroke models have shown that inhibition of ER stress by 4-PBA could alleviate neuronal death, endothelial cell damage, and proinflammatory responses (179-183). Recently, it was reported that Hes1 knockdown significantly aggravated neuronal apoptosis by activating the PERK/eIF2 $\alpha /$ ATF4/ $\mathrm{CHOP}$ signaling pathway after tMCAO, whereas this effect was effectively counteracted in mice receiving the PERK inhibitor GSK2606414 (185). Consistent with this result, a previous study demonstrated that inhibition of PERK by GSK2606414 could significantly downregulate the expression of proinflammatory cytokines in primary microglia induced by oxygen and glucose deprivation followed by reoxygenation (OGD/R) (144). Another in vitro study demonstrated that preconditioning of murine cortical glial cells with GSK2606414 protected them from OGD/R-induced cell damage (174). However, a recent study demonstrated that deletion of PERK in neurons resulted in a larger infarct volume and worse neurological function scores in mice subjected to MCAO compared to that in control mice (186). A study that investigated the function of ATF4 and its underlying mechanism in cerebral ischemia/reperfusion (I/R) injury showed that overexpression of ATF4 alleviated rat cerebral
I/R injury by modulating the mitophagy-NLRP3 inflammasome axis (187), while ATF4 knockdown by siRNA induced the opposite effect. Similarly, in an in vitro stroke model of OGD, silencing of ATF4 reversed tunicamycin-and thapsigargininduced moderate ER stress and subsequent mitophagy induction, resulting in an increased apoptotic primary neuron cell ratio (175). In an in vitro model of ischemic strokes, overexpression of IRE1 $\alpha$ enhanced ER stress and concomitant primary neuron death (176). However, in an in vitro model of I/ $\mathrm{R}$, adenovirus-induced XBP1 overexpression inhibited rat primary hippocampal neuron death induced by OGD/R stress (177). In a 2017 study, Yu et al. generated a conditional and inducible short form of ATF6 knock-in (ATF6-KI) mouse, in which sATF6 was primarily expressed in the neurons of the hippocampus and cortex. Preconditioning of the ATF6-KI mice with tamoxifen after tMCAO resulted in a reduced infarct volume and better neurological outcome compared to the results in the control mice (188). Recently, the administration of compound 147, an activator of ATF6, in mice resulted in significantly decreased brain infarct sizes and alleviated neurological deficits after I/R (189).

Collectively, these findings indicate the dual roles of ER stress in ischemic stroke, in which proteostasis disturbance induces ER 
stress and overactivation of the ER stressors PERK and IRE1 $\alpha$, resulting in harmful effects in ischemic stroke. In contrast, overexpression of downstream molecules, such as ATF4 and $\mathrm{XBP} 1$, or upregulation of ATF6, provides neuroprotection in ischemic stroke.

\section{The Role of Endoplasmic Reticulum Stress in Traumatic Brain Injury}

TBI is a significant cause of mortality and long-term disability worldwide; it contributes to the economic burden on society and the low quality of life of affected individuals (253). As TBI is a highly heterogeneous injury with a complicated pathogenesis, its treatment has always been challenging. TBI is considered a "biphasic injury" characterized by an initial primary brain injury and delayed secondary brain injury. The primary brain injury causes irreversible brain damage as a consequence of mechanical injury, whereas the secondary brain injury results in further damage due to injurious biochemical cascades (254). Importantly, devastating ER stress is considered a primary contributor to the regulation of the inflammatory response and neural death in secondary brain injury.

In 1995, two studies reported significant elevation of the ERresident protein GRP78 in the rat brain following TBI $(255,256)$. GRP78 is currently considered a marker of ER stress, and alterations in GRP78 expression can modulate cell apoptotic death following brain injury (257). ER stress and concomitant UPR have been well established to be involved in brain injury (258). TUDCA, as a potent inhibitor, has been reported to effectively attenuate ER stress and subsequent neuronal apoptotic death in mice subjected to TBI, thereby improving neurological function (194). In a blast injury model of TBI, the number of apoptotic neurons and expression of apoptotic proteins were found to be significantly reduced in mice receiving the ER stress inhibitor salubrinal, also known as the eIF2 $\alpha$ dephosphorylation inhibitor (190). Consistent with this observation, multiple studies reported that salubrinal confers neuroprotection by attenuating ER-stress-associated neuronal cell death and neuroinflammation after TBI (191-193, 195, 196, 259). Concomitantly, the administration of low-dose guanabenz (an activator of eIF2 $\alpha$ phosphorylation) to mice after TBI could reduce cortical and hippocampal tissue and neuron loss, which in turn could improve motor and cognitive functions $(197,198)$. These findings suggest that prolongation of eIF $2 \alpha$ phosphorylation in acute TBI models is neuroprotective. In a mouse model of TBI, GSK2656157-treated mice exhibited increased expression of postsynaptic density 95 (PSD95), as well as better spine density and memory function compared to control mice after TBI (199). Additionally, GSK2656157 treatment of mice post injury promoted microglial phenotypic transformation from a pro-inflammatory M1-phenotype to an anti-inflammatory M2-phenotype and inhibited TBI-induced Th1 $\mathrm{T}$ cell infiltration, thereby alleviating white matter damage and symptoms of anxiety and depression (200). A recent study revealed that mice with a knockout of proapoptotic transcription factor CHOP exhibited reduced hippocampal newborn neuron loss and improved performance in context fear discrimination when compared to control mice following TBI (198). Finally, emerging evidence supports the claim that docosahexaenoic acid (DHA) is an effective inhibitor of ER stress (260). Moreover, some findings suggest that DHA administration to mice after TBI could significantly inhibit ER-stress-associated neuron damage and neuroinflammation and improve neurological function (261-263).

Collectively, these studies indicate that ER stress is implicated in secondary brain injury after TBI and that targeting ER stress responses may be a mechanism to attenuate neuronal cell death and inflammatory responses, as well as improve neurological function in TBI.

\section{The Role of Endoplasmic Reticulum Stress in Alzheimer's Disease}

$\mathrm{AD}$ is the most common cause of dementia and is characterized by progressive cognitive dysfunction and memory loss (264). AD affects more than 50 million people worldwide, and there are currently no effective drugs that can slow the progression of $\mathrm{AD}$. The pathological hallmarks of $\mathrm{AD}$ include extracellular parenchymal deposition of $A \beta$, intracellular tau-containing neurofibrillary tangles (NFTs), and subsequent neuronal death and synaptic loss $(265,266)$. During $A D$, the continuous generation of $A \beta$ and phosphorylated tau ( $p$-tau) causes a disturbance of ER calcium homeostasis and aberrant protein folding in the ER, finally eliciting intracellular induction of ER stress and concomitant UPR activation (267). Additionally, a previous study showed the co-localization of p-PERK with p-tau in the hippocampus of aged $\operatorname{TgTau}^{\mathbf{P 3 0 1 L}}$ mice and confirmed a crosstalk between ER stress and hyperphosphorylation of tau in primary cultures of cortical neurons (268). Tau proteins directly impair the ERAD pathway, resulting in the accumulation of misfolded proteins within the ER lumen (269). Additionally, A $\beta$ oligomers can directly interact with neuronal $N$-methyl-Daspartate receptors (NMDARs), provoking downstream ERstress-mediated cell death, synaptic depression, and spine elimination (270). An increasing number of studies have explored the potential therapeutic targets of TBI by unraveling the underlying mechanism of the correlation between ER stress and the pathogenesis of $\mathrm{AD}$.

Several studies have reported the involvement of ER stress in different human brain regions in patients with $\mathrm{AD}$ (271-276). PERK and eIF $2 \alpha$ are closely associated with the pathological alteration of neurons in patients with AD (277). Cognitive deficits and memory loss in patients with $\mathrm{AD}$ are reported to be associated with the expression of p-eIF $2 \alpha$ in the brain (278, 279). PERK insufficiency has been shown to effectively inhibit $\beta$ secretase enzyme BACE1 expression and concomitant $A \beta$ peptides and plaque burden, resulting in the restoration of memory deficits and cholinergic neurodegeneration in five familial AD (5XFAD) mouse models (206). Moreover, in a mouse model of $\mathrm{AD}$, inhibition of eIF $2 \alpha$ phosphorylation by conditional deletion of PERK effectively decreased amyloidogenesis and restored normal expression of plasticityrelated proteins, thereby improving synaptic plasticity and spatial memory in AD mice (201). Consistently targeting 
PERK expression in the brain in a mouse model of $\mathrm{AD}$ demonstrated that deletion of PERK improved memory impairment and long-term potentiation (LTP) (202). Furthermore, the pharmacological inhibition of PERK by GSK2606414 restored the cognitive deficits in AD mice, which was associated with improved hippocampal metabotropic glutamate receptor (mGluR)-long-term depression (LTD) impairments (202). In a mouse model of frontotemporal dementia, GSK2606414 treatment of mice effectively restored protein synthesis rates and reduced neuronal loss in the brain, further reducing brain atrophy and abrogating the appearance of clinical signs (207). Echinacoside (ECH), another inhibitor of PERK, was reported to dramatically suppress $A \beta$ generation and accumulation by inhibiting the translation of BACE1, ameliorating memory deficits in AD mice (209). A recent study demonstrated that treatment of AD mice with two PERK inhibitors, trazodone and dibenzoylmethane, effectively restored memory impairment, abrogated neurological signs, prevented neurodegeneration, and prolonged survival (208). Additionally, both eIF2 $\alpha$ kinase GCN2 (201) and double-stranded RNAdependent kinase (PKR) $(280,281)$ have also been reported to be involved in the regulation of memory impairment in in vivo models of $\mathrm{AD}$. In an in vitro $\mathrm{AD}$ model, inhibition of eIF $2 \alpha$ dephosphorylation by salubrinal effectively increased the translation of BACE1 and production of $A \beta$ in primary neurons (275). Moreover, the expression of ATF4 at the mRNA and protein levels is significantly upregulated in the brains of patients with AD. Studies in mouse models and cell culture have demonstrated that axonally synthesized ATF4 is required to transmit neurodegenerative signals through cellnonautonomous mechanisms (203). The correlation between the pathology of $\mathrm{AD}$ and the activation of IRE1 $\alpha$ was detected in the brains of patients with AD (169). Genetic ablation of the RNase domain of IRE $1 \alpha$ reduced amyloid deposition and astrocyte activation in the cortical and hippocampal areas of $\mathrm{AD}$ mice. Moreover, IRE1 $\alpha$ deletion in the brains of $\mathrm{AD}$ mice significantly improved synaptic function and LTP, thereby restoring learning and memory functions (169). Furthermore, the transcription factor XBP1 is considered an essential contributor to the progression of learning and memory deficits. In line with this, mice with XBP1 conditional knockout showed significant learning and memory deficits, whereas mice with XBP1 overexpression exhibited improved LTP and synaptic transmission, both of which are associated with better learning and memory functions (282).

This concept has been applied to a mouse model of $\mathrm{AD}$, in which virus-mediated delivery of the active spliced transcription factor XBP1s in the hippocampus improved memory deficits and restored spine density and synaptic plasticity (204). Studies in fly models have also demonstrated that XBP1 overexpression in neurons protects against neurotoxicity induced by $\mathrm{A} \beta$ and tau $(283,284)$. The role of ATF6 in AD has not been reported until recently, when Du et al. found a reduction in ATF6 expression in the brains of AD mice (205). This study demonstrated, both in vivo and in vitro, that ATF6 overexpression reduced A $\beta$ production by inhibiting amyloid precursor protein (APP) expression, downregulated the promoter activity and expression of $\mathrm{BACE} 1$, and protected the retention of spatial memory in $\mathrm{AD}$ mice.

Collectively, numerous studies have demonstrated the involvement of ER stress in the pathogenesis of $\mathrm{AD}$. Pharmacological or genetic targeting of ER stress may represent a strategy for attenuation of the continuous generation of $\mathrm{A} \beta$ - and $\mathrm{p}$-tau-associated neuronal cell death and neuroinflammation, which, in turn, may improve memory deficits and synaptic plasticity in AD. However, most studies have focused on the underlying mechanism of PERK in $A D$, and further investigation is required to clarify the additional roles of IRE1 $\alpha$ and ATF6 in AD.

\section{The Role of Endoplasmic Reticulum Stress in Parkinson's Disease}

$\mathrm{PD}$ is a chronic and progressive neurodegenerative disorder characterized by classic motor symptoms, such as tremor and bradykinesia, and non-motor manifestations, such as rapid eye movement sleep disorder, anosmia, constipation, and depression) (285). Pathologically, the symptoms of PD are accompanied by a profound loss of dopaminergic (DA) neurons in the substantia nigra pars compacta (SNpc). Dopaminergic neuron degeneration is associated with the appearance of Lewy bodies, which are predominantly composed of misfolded and/or mutated $\alpha$-synuclein proteins (286). Emerging evidence supports the concept that the aberrant accumulation of misfolded and/or mutated proteins, such as $\alpha$ synuclein, contributes to persistent ER stress and concomitant UPR activation, thereby resulting in dopaminergic neuronal death and degeneration, which is associated with PD (287).

Postmortem evidence has shown that upregulation of ER stress markers, such as in GRP78, p-PERK, and p-eIF2 $\alpha$, is detected in neuromelanin-containing DA neurons in the SNpc in the brains of humans with $\mathrm{PD}(211,267,288,289)$. Furthermore, the colocalization of p-PERK and $\alpha$-synuclein was detected in the SNpc of PD human brains (290). Similarly, $\alpha$-synuclein was found to be broadly expressed in ER/microsomes fractions in the brains of both humans and mice with PD (210). Moreover, $\alpha$-synuclein has been shown to directly bind to GRP78, and $\alpha$-synuclein overexpression increases the sensitivity of neuronal cells to ERstress-induced toxicity. These findings indicate that $\alpha$-synuclein directly regulates ER-stress-associated neuronal death (210). Several studies have consistently demonstrated that $\alpha$-synuclein proteins regulate ER stress by directly interacting with GRP78 (291, 292). Several in vivo and in vitro experimental studies have revealed that inhibition of ER stress exerts protective effects in PD physiopathology.

Salubrinal, an inhibitor of ER stress, has been reported to attenuate progressive motor deficits without protecting against neuronal death in an AAV-rat model of DA neurodegeneration (210). Subsequent studies have reported the potential pharmacological use of salubrinal in PD pathology (293-295). Recently, the targeting of PERK inhibition in a mouse model of PD indicated that the PERK inhibitor GSK2606414 protected DA neurons in the SNpc against cell death induced by the PD 
neurotoxin 6-hydroxydopamine (6-OHDA), thereby improving the motor performance of PD mice (211). Similarly, pharmacological inhibition of PERK with GSK2606414 was neuroprotective in the pink1/parkin model of PD (212).

The PD neurotoxins 1-methyl-4-phenyl-pyridinium $\left(\mathrm{MPP}^{+}\right)$ and 6-OHDA have been shown to promote DA neuronal cell death in an ATF4-dependent manner (213). The study further demonstrated that ATF4-deficient DA neurons were resistant to cell death induced by $\mathrm{PD}$ neurotoxins. Importantly, pharmacological inhibition of ATF4 with the eIF2 $\alpha$ inhibitor C16 protected against PD-neurotoxin-induced cell death. In contrast, a previous study demonstrated that ATF4 overexpression in the brain by recombinant adeno-associated virus (rAAV) aggravated DA neuron loss in the SNpc in a rat model of PD (296). Deletion of CHOP was shown to exert a neuroprotective effect in a mouse model of $\mathrm{PD}$, particularly during the acute period of PD (47).

Additionally, a previous study demonstrated that XBP1 overexpression exerted protective effects against DA neuronal death induced by PD inducers $\mathrm{MPP}^{+}$and 1-methyl-4-phenyl1,2,3,6-tetrahydropyridine (MPTP) (218). Consistently, viral transfection for XBP1 expression in the substantia nigra inhibited DA neuronal degeneration caused by PD-inducing neurotoxins (214). Furthermore, another study in a mouse model of PD demonstrated that XBP1-deficient DA neurons were resistant to $\mathrm{PD}$ neurotoxin 6-OHDA, whereas $\mathrm{XBP} 1$ overexpression in the $\mathrm{SNpc}$ of mice protected DA neurons against 6-OHDA-induced cell death (215). However, in mouse PD models, genetic ablation of ATF6 has been shown to present with accelerated DA neuronal death induced by PD neurotoxins $(216,217)$.

Collectively, these findings highlight the importance of ER stress in the physiopathology of PD and indicate that ER stress plays a vital role in inhibiting DA neuronal loss and degeneration induced by various PD neurotoxins. Pharmacological or genetic targeting of ER stress markers may represent a potential mechanism for the development of therapeutic strategies against $\mathrm{PD}$.

\section{The Role of Endoplasmic Reticulum Stress in Multiple Sclerosis}

Multiple sclerosis (MS) is a chronic autoimmune-mediated inflammatory disease of the CNS characterized by demyelination with concomitant axonal and neuronal degeneration (297). While the etiology of MS remains unknown, it is believed to be initiated by autoreactive $\mathrm{T}$ lymphocytes that have crossed the $\mathrm{BBB}$ and triggered an autoimmune response by self-CNS antigens (298). ER stress induced by the accumulation of misfolded proteins is a hallmark of MS pathology (299). Microarray analysis showed that the levels of the ER stress markers ATF4 and heat shock protein 70 in MS demyelinated lesions were highly upregulated $(300,301)$. Furthermore, the levels of the ER stress markers GRP78, ATF4, and CHOP were found to be significantly upregulated in the white matter of MS patients compared with that in non-MS individuals (302). Consistent with this observation, detailed semiquantitative immunohistochemical and molecular analyses of multiple CNS cell types in biopsy specimens and in postmortem samples revealed that GRP78, $\mathrm{XBP} 1$, and $\mathrm{CHOP}$ were significantly increased in astrocytes, microglia, and oligodendrocytes in MS lesions (303-305). Studies in an experimental autoimmune encephalomyelitis (EAE) model of MS indicated that ER stress regulates oligodendrocyte viability during EAE and subsequently influences MS progression $(219,223,306)$. A prominent MAM regulatory protein, guanosine triphosphatase (GTPase) Rab32, was reported to be correlated with ER stress proteins in the MS brain; it connects ER stress to mitochondrial dysfunction in MS (307). Alternatively, upregulation of human endogenous retrovirus (HERV) envelop proteins may aggravate MS pathology by triggering ER stress and neuroinflammation in the brain $(308,309)$.

Interferon- $\gamma($ IFN- $\gamma)$ plays a dual role in the pathology of MS (58). CNS-expression of IFN- $\gamma$ before EAE onset significantly promoted activation of the PERK/eIF $2 \alpha$ pathway in oligodendrocytes, preventing oligodendrocyte death, demyelination, and axonal degeneration in the CNS of EAE mice (306). Furthermore, CNS delivery of IFN- $\gamma$ before EAE onset does not ameliorate the severity of disease course or inhibit EAE-induced oligodendrocyte death, demyelination, and axonal degeneration in PERK-deficient mice. These results demonstrate that the beneficial role of IFN- $\gamma$ in EAE is dependent on PERK activation. However, several studies have demonstrated that CNS expression of IFN- $\boldsymbol{\gamma}$ during development promotes myelinating oligodendrocyte death, hypomyelination, and inflammation (310-312). Interestingly, CNS expression of IFN- $\gamma$ activates the PERK/eIF2 $\alpha$ pathway in myelinating oligodendrocytes, and the increased expression of IFN- $\gamma$ in PERK-deficient mice dramatically promoted CNS hypomyelination and enhanced oligodendrocyte death $(313,314)$. These results indicate that PERK plays a neuroprotective role in MS progression, regardless of whether IFN- $\gamma$ expression is beneficial or deleterious in immune-mediated demyelination. Subsequent studies further validated these results and concluded that moderate PERK activation exerts protective effects on oligodendrocytes in a model of MS. In a mouse model (PLP/Fv2E-PERK mice) that allows for temporally controlled activation of PERK signaling specifically in oligodendrocytes, moderate PERK activation in oligodendrocytes significantly attenuated the EAE disease course, which was associated with reduced oligodendrocyte loss, demyelination, and axonal degeneration (219). Similarly, in the same mouse model for MS and EAE, another study showed that enhancing PERK activation in oligodendrocytes protects the cells and myelin against the deleterious effects of IFN- $\gamma$ (220). Consistent with this result, oligodendrocyte (OL)-specific PERK-knockout (OL-PERK ${ }^{\mathrm{ko} / \mathrm{ko}}$ ) mice were reported to be susceptible to EAE (223). These mice exhibited a significantly more severe EAE disease course, which was associated with oligodendrocyte loss, demyelination, and axonal degeneration (223). A recent study confirmed that PERK activation specifically in oligodendrocytes significantly prevented neuronal loss in the CNS of EAE mice (221). Further investigation demonstrated that 
ATF4 inactivation specifically in oligodendrocytes did not alter EAE disease severity and did not significantly affect oligodendrocyte loss, demyelination, or axonal degeneration in the CNS of EAE mice. Consistent with this finding, a previous report demonstrated that $\mathrm{CHOP}$ deficiency did not influence the development of EAE (308). Although moderate PERK activation in oligodendrocytes is generally believed to protect oligodendrocytes (both mature and remyelinating oligodendrocytes) against inflammatory attacks in immunemediated demyelinating diseases, a recent study has revealed that PERK may exert deleterious effects on the development of MS. This study showed that ER stress is involved in inflammation and astrogliosis primarily via the PERK/JAK1/ STAT3 pathway in the MS mouse model of EAE (112). In addition, modulation of ER stress by inhibition of eIF2 $\alpha$ / CHOP and activation of XBP1 prevented optic neuritis in MS (224). ATF6, another branch of the UPR, has recently been implicated in the development of MS. A study revealed that ATF $6 \alpha$ deficiency increased the sensitivity of myelinating oligodendrocytes to IFN- $\boldsymbol{\gamma}$-induced ER stress and exacerbated EAE disease severity, which was associated with increased oligodendrocyte death and myelin loss (222).

Collectively, these findings highlight the importance of ER stress in the pathology of MS and indicate that ER stress may exert a neuroprotective role in EAE onset and development. Of the three key sensors of the UPR, the role of PERK signaling in oligodendrocytes has been the best described. Although the IRE1 $\alpha / \mathrm{XBP} 1$ pathway is the most conserved branch of the UPR, there is no evidence indicating that this pathway plays a vital role in oligodendrocytes or even in the pathology of MS.

\section{The Role of Endoplasmic Reticulum Stress in Huntington Disease}

Huntington disease (HD) is a rare but fatal autosomal dominant neurodegenerative disease caused by a repeat CAG expansion, encoding polyglutamine (polyQ) stretch in the huntingtin ( $\mathrm{Htt}$ ) gene, resulting in motor and cognitive deficits that are progressively disabling (315). In $\mathrm{HD}$, expansion of polyQ stretch within the first exon of $\mathrm{Htt}$ results in mutant $\mathrm{Htt}$ (mHtt) misfolding aggregation. Emerging evidence has identified that accumulation of $\mathrm{mHtt}$ in the ER and the concomitant induction of ER stress play a crucial role in the pathology of HD $(226,316-319)$. Postmortem evidence has shown that ER stress markers, such as $\mathrm{BiP}$ and $\mathrm{CHOP}$, are upregulated in HD human brains (320). Several in vivo and in vitro experimental studies have revealed that modulation of ER stress may be an attractive approach to reduce cellular toxicity and identify a potential therapeutic target for the treatment of HD.

A previous study showed that GRP78 overexpression significantly protected $\mathrm{N} 2 \mathrm{a}$ cells against $\mathrm{mHtt}$, reduced the formation of mutant huntingtin aggregates, and prevented caspase-12-mediated cell death (225). An in vitro study aimed at revealing the role of eIF $2 \alpha$ phosphorylation status in striatal cell death showed that the PERK inhibitor A4 considerably reduced, in a dose-dependent manner, the additional cytotoxicity in polyQ-expanded Htt (STHdh Q111/111) cells to the level in the full-length wild-type (WT) Htt form (STHdh ${ }^{\text {Q7/7 }}$ ) cells (226). In addition, salubrinal, an inhibitor of ER stress, has been reported to reduce the accumulation of $\mathrm{mHtt}$ by upregulation of $\mathrm{BiP}$ and p-eIF2 $\alpha$, preventing caspase-12-mediated PC6.3 cell death (227). Additionally, IRE1 $\alpha$ has been reported to play a vital role in the ER stress-mediated aggregation of mutant huntingtin. Recently, ubiquitin-specific protease-14 (Usp14), which can directly interact with IRE1 $\alpha$, was reported to reduce cellular aggregates in mHtt-expressing cells and protect against cell degeneration and caspase-3-mediated cell death primarily by inhibiting the phosphorylation of IRE1 $\alpha$ (228). IRE $1 \alpha$ knockdown by shRNA significantly reduced ER stress-induced mHtt toxicity (229). In a study that used AAV-mediated delivery of XBP1 into the stratum of mice, the accumulation of $\mathrm{mHtt}$ inclusion was dramatically reduced when XBP1 was co-expressed in the stratum (230). In addition, XBP1 deficiency in the nervous system significantly decreased the levels of $\mathrm{mHtt}$ in the striatum of HD transgenic mice (231). In this study, shRNA-mediated knockdown of both IRE1 $\alpha$ and XBP1 in two neuronal cell lines showed a significant reduction in the aggregation of pathological polyQ79-EGFP peptides. Furthermore, ATF5, as a part of the $\mathrm{UPR}$, is decreased and sequestered into polyQ inclusions in HD. Decreased ATF5 levels exacerbated polyQ toxicity in vivo. Conversely, overexpression of ATF5 inhibited polyQ-induced apoptosis in a cell model of HD (321).

Collectively, these studies indicate that ER stress plays an important role in regulating the cellular aggregation of $\mathrm{mHtt}$ and protecting cells against cellular toxicity during HD. Targeting ER stress responses may be a mechanism to ameliorate motor and cognitive deficits in HD.

\section{The Roles of Endoplasmic Reticulum Stress in Amyotrophic Lateral Sclerosis}

Amyotrophic lateral sclerosis (ALS) is a devastating adult-onset neurodegenerative disease characterized by progressive degeneration of both upper and lower motoneurons, which results in muscle weakness, paralysis, and eventual death (322). Currently, no effective drugs have been demonstrated to be effective against ALS. Emerging evidence supports the concept that the accumulation of neurotoxic misfolded proteins, inclusions, and aggregates in motoneurons is the main pathological hallmark of ALS (323). These protein aggregates are believed to disrupt cellular proteostasis and eventually lead to ER stress within the motoneuron. Postmortem evidence has shown that the expression of the UPR pathway is significantly upregulated in the spinal cords of patients with sporadic or familial ALS (324-328). In addition, structural changes associated with ER stress, such as fragmentation, were detected in the anterior horn of the spinal cord in ALS, and several ER stress markers were observed in the cerebrospinal fluid (CSF) of patients with sporadic ALS patients (328-330). Notably, mutant $\mathrm{Cu}, \mathrm{Zn}$-superoxide dismutase (mtSOD1) has been reported to directly interact with GRP78, which upregulates GRP78 expression in ALS mice before the onset of motor symptoms (331). Furthermore, a recent study indicated that ER stress is responsible for the accumulation of wild-type SOD1 aggregates in sporadic ALS (332). 
Emerging evidence has confirmed that ER stress is implicated in the onset and progression of ALS and that targeting the UPR/ integrated stress response (ISR) may serve as a strategy for ameliorating motor symptoms and extend the lifespan in ALS (333).

The ER stress inhibitor salubrinal was reported to ameliorate disease severity and delay progression in ALS (232). Furthermore, in vitro experiments demonstrated that salubrinal protected Neuro2a cells against mtSOD1-induced cell death (233). In a G85R mtSOD1 transgenic mouse model of ALS, compared to PERK ${ }^{+/+}$mice, PERK $^{+-}$mice exhibited an earlier disease onset, reduced lifespan, and earlier neuropathological alterations in the spinal cord (234). In parallel with this finding, in the same ALS model, mice with GADD34 dysfunction (GADD34 ${ }^{\Delta \mathrm{C}}$ ) exhibited delayed disease onset, delayed early phase of disease, and prolonged lifespan compared with the control littermate G85R mice (235). Consistent with this result, GADD34 knockdown, using AAVmediated delivery of GADD34 shRNA into G85R mtSOD1 mice, was found to significantly ameliorate disease severity and prolong lifespan in mice (236). Guanabenz, an inhibitor of GADD34-mediated dephosphorylation of p-eIF2 $\alpha$, has been reported to ameliorate disease severity with a delay in the onset and prolongation of the early phase of disease and survival of mtSOD1 transgenic mice (237). Further validation showed that guanabenz ameliorated disease severity by attenuating proapoptotic protein-mediated neuron loss, which was associated with delayed onset of disease symptoms, prolonged lifespan, and improved motor performance (238). TAR DNA binding protein 43 (TDP-43) links both familial and sporadic forms of ALS as mutations are the leading cause of disease, and cytoplasmic aggregates are a pathological hallmark

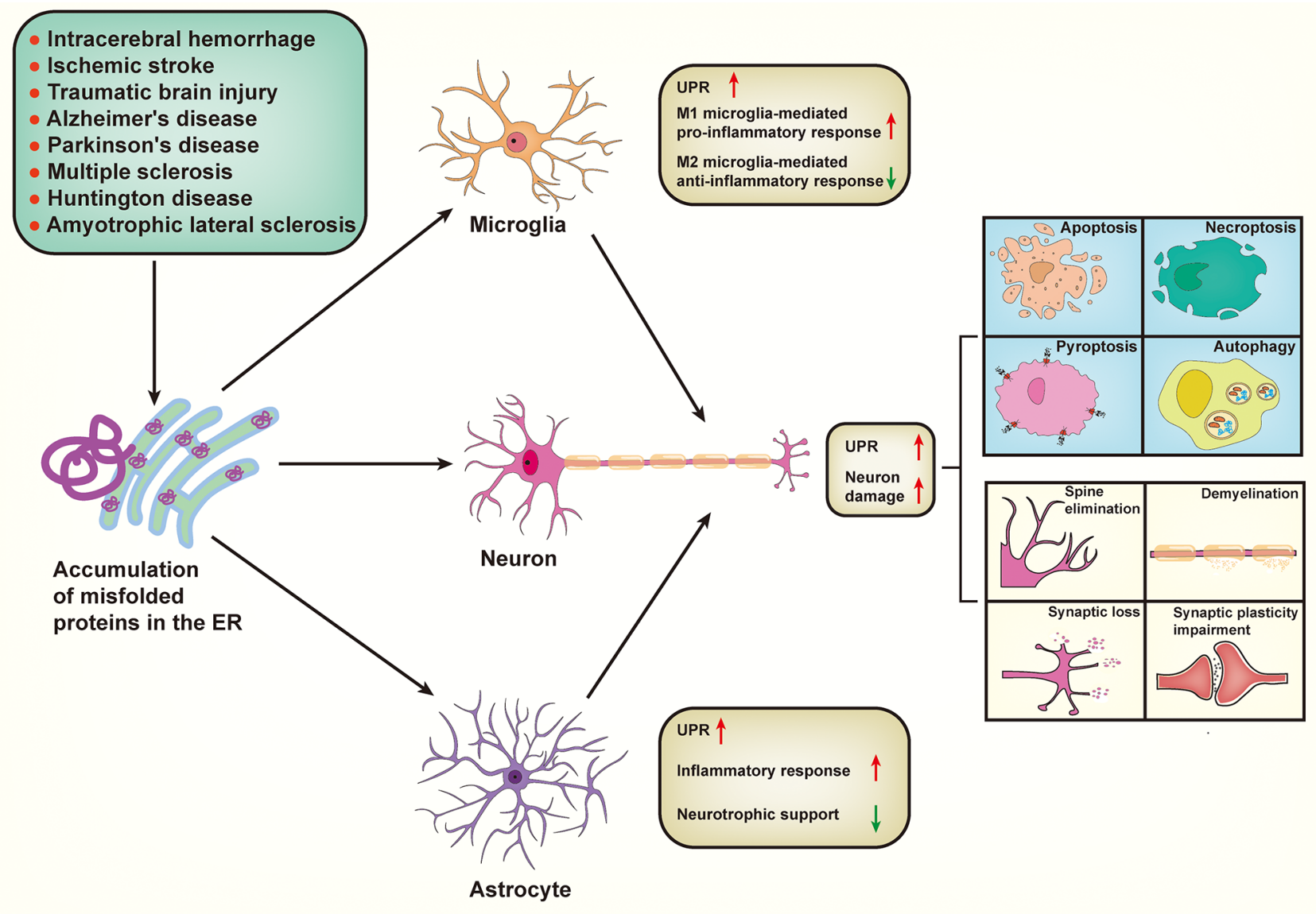

FIGURE 3 | Proposed mechanism by which endoplasmic reticulum stress signaling impacts the overall central nervous system envirment. Various neurological diseases share a common pathogenesis, that is aberrant accumulation of misfolded proteins within the endoplasmic reticulum (ER). Pathologically, accumulation of misfolded proteins in ER subsequently triggers ER stress and concomitant unfolded protein response (UPR) in microglia, astrocytes, and neurons in various neurological diseases. ER stress occurred in neurons can trigger UPR, resulting in a series of neuronal damage including cell death (apoptosis, necroptosis, pyroptosis, and autophagy), spine elimination, demyelination, synaptic loss, and synaptic plasticity impairment. In addition, UPR-activated microglia promote the polarization of microglia from pro-inflammatory M1 phenotype to anti-inflammatory M2 phenotype. Similarly, UPR-activated astrocytes exhibit an increase of inflammatory response but a decrease of neurotrophic support. Importantly, both microglia-mediated and astrocyte-mediated inflammatory responses can "transmit" ER stress to neurons, thereby aggravating neuronal damage. 
of almost all cases (334). Importantly, recent studies indicate that mutant TDP-43 may be driven by the activation of ER stress in motor neurons (335-337). Recently, both guanabenz and salubrinal have been reported to ameliorate motor deficits and axon defects, which are associated with mutant TDP-43-induced toxicity in the mutant TDP-43 model of ALS (240). However, in contrast to these observations, a later study demonstrated that guanabenz treatment could accelerate the progression of ALSlike disease in mtSOD1 transgenic mice (338). In general, these observations suggest that GADD34, a protein downstream of the PERK/eIF2 $\alpha$ pathway, plays a vital role in the onset and progression of ALS. Additionally, both in vivo and in vitro experiments demonstrated that the PERK inhibitor GSK2606414 effectively inhibited ER-stress-associated TDP-43 toxicity (241). Another PERK inhibitor, ISRIB, was reported to effectively decrease G93A SOD1-mediated neuronal death by regulating the ER stress response (239).

Collectively, these findings indicate the potential therapeutic role of ER stress in ALS. Pharmacological or genetic targeting of ER stress has been reported to ameliorate disease severity and improve ALS symptomatology in animal experiments. Nevertheless, of the three key sensors of the UPR, the role of PERK signaling in ALS has been the best described. Therefore, further investigations are needed for demonstrating the role of IRE $1 \alpha$ and ATF6 in the alteration of ALS symptomatology.

\section{CONCLUSION AND FUTURE PERSPECTIVE}

In this review, we comprehensively discuss the underlying mechanism of ER stress in neuron damage and immune responses in the CNS, emphasizing their pivotal roles in the pathogenesis of various neurological diseases and potential therapeutic strategies (Figure 3).

Currently, there is no effective therapeutic approach in clinical treatments that can improve the prognosis of most neurological diseases. Therefore, it is urgent to identify novel therapeutic targets to modulate disease-associated signaling cascades. Pathologically, neuronal cell death and the inflammatory response are the two most common hallmarks of acute CNS injury and chronic degenerative disorders. Importantly, myriad clinical trials and preclinical animal experiments have indicated that the aggregation and accumulation of proteins and the concomitant

\section{REFERENCES}

1. Phillips MJ, Voeltz GK. Structure and Function of ER Membrane Contact Sites With Other Organelles. Nat Rev Mol Cell Biol (2016) 17(2):69-82. doi: 10.1038/ nrm.2015.8

2. Rapoport TA. Protein Translocation Across the Eukaryotic Endoplasmic Reticulum and Bacterial Plasma Membranes. Nature (2007) 450(7170):6639. doi: $10.1038 /$ nature 06384

3. Kim YE, Hipp MS, Bracher A, Hayer-Hartl M, Hartl FU. Molecular Chaperone Functions in Protein Folding and Proteostasis. Annu Rev Biochem (2013) 82:323-55. doi: 10.1146/annurev-biochem-060208-092442 induction of ER stress are closely associated with neuronal death and neuroinflammation in many neurological diseases. The induction of the UPR by ER stress is a sophisticated and coordinated biochemical response that is aimed to maintain cellular proteostasis, whereas its hyperactivation is closely associated with cell death and immune response. Thus, understanding how to control the balance between the physiological UPR and the pathological UPR in many disease states, and how this delicate balance can be manipulated to restore homeostasis to enable appropriate cell death and immune responses, are essential directions for further investigation.

To date, numerous preclinical studies have demonstrated the potential therapeutic effects of the pharmacological targeting of ER stress in animal models of neurological diseases. However, the pharmacological targeting of ER stress remains challenging, as the response is broadly engaged in the physiopathology of various cell types and organs, such as the liver and heart, so the long-term administration of drugs may lead to serious adverse effects. Genetic targeting of the ER has gradually been placed as an attractive and therapeutic alternative to drugs because it can selectively target specific brain regions. Nevertheless, both the pharmacological and the genetic targeting of ER stress as therapeutic approaches for neurological disease remain limited to preclinical animal studies with no clinical evidence. Therefore, further efforts are needed to translate such work into clinical studies.

\section{AUTHOR CONTRIBUTIONS}

MS searched the bibliography and drafted the manuscript. YC prepared the figures. JZ and XC critically revised the manuscript. All authors contributed to the article and approved the submitted version.

\section{FUNDING}

This work was supported by grants from the National Natural Science Foundation of China (no. 816719029), and the Project of Tianjin Applied Basic and Cutting-edge Technological Research (17JCYBJC25200) and by the Tianjin Health Care Elite Prominent Young Doctor Development Program and the Young and Middle-aged Backbone Innovative Talent Program.

4. Hwang J, Qi L. Quality Control in the Endoplasmic Reticulum: Crosstalk Between ERAD and UPR Pathways. Trends Biochem Sci (2018) 43(8):593-605 doi: 10.1016/j.tibs.2018.06.005

5. Walter P, Ron D. The Unfolded Protein Response: From Stress Pathway to Homeostatic Regulation. Science (2011) 334(6059):1081-6. doi: 10.1126/ science. 1209038

6. Hetz C, Saxena S. ER Stress and the Unfolded Protein Response in Neurodegeneration. Nat Rev Neurol (2017) 13(8):477-91. doi: 10.1038/ nrneurol.2017.99

7. Xu C, Bailly-Maitre B, Reed JC. Endoplasmic Reticulum Stress: Cell Life and Death Decisions. J Clin Invest (2005) 115(10):2656-64. doi: 10.1172/JCI26373 
8. Tabas I, Ron D. Integrating the Mechanisms of Apoptosis Induced by Endoplasmic Reticulum Stress. Nat Cell Biol (2011) 13(3):184-90. doi: $10.1038 / \mathrm{ncb} 0311-184$

9. Grootjans J, Kaser A, Kaufman RJ, Blumberg RS. The Unfolded Protein Response in Immunity and Inflammation. Nat Rev Immunol (2016) 16 (8):469-84. doi: 10.1038/nri.2016.62

10. Oakes SA, Papa FR. The Role of Endoplasmic Reticulum Stress in Human Pathology. Annu Rev Pathol (2015) 10:173-94. doi: 10.1146/annurev-pathol012513-104649

11. Kaufman RJ. Orchestrating the Unfolded Protein Response in Health and Disease. J Clin Invest (2002) 110(10):1389-98. doi: 10.1172/JCI16886

12. Chen X, Cubillos-Ruiz JR. Endoplasmic Reticulum Stress Signals in the Tumour and Its Microenvironment. Nat Rev Cancer (2021) 21(2):71-88. doi: 10.1038/s41568-020-00312-2

13. Bertolotti A, Zhang Y, Hendershot LM, Harding HP, Ron D. Dynamic Interaction of $\mathrm{BiP}$ and ER Stress Transducers in the Unfolded-Protein Response. Nat Cell Biol (2000) 2(6):326-32. doi: 10.1038/35014014

14. Karagoz GE, Acosta-Alvear D, Nguyen HT, Lee CP, Chu F, Walter P. An Unfolded Protein-Induced Conformational Switch Activates Mammalian IRE1. Elife (2017) 6:e30700. doi: 10.7554/eLife.30700

15. Wang P, Li J, Sha B. The ER Stress Sensor PERK Luminal Domain Functions as a Molecular Chaperone to Interact With Misfolded Proteins. Acta Crystallogr D Struct Biol (2016) 72(Pt 12):1290-7. doi: 10.1107/ S2059798316018064

16. Wang P, Li J, Tao J, Sha B. The Luminal Domain of the ER Stress Sensor Protein PERK Binds Misfolded Proteins and Thereby Triggers PERK Oligomerization. J Biol Chem (2018) 293(11):4110-21. doi: 10.1074/ jbc.RA117.001294

17. Calfon M, Zeng H, Urano F, Till JH, Hubbard SR, Harding HP, et al. IRE1 Couples Endoplasmic Reticulum Load to Secretory Capacity by Processing the XBP-1 mRNA. Nature (2002) 415(6867):92-6. doi: 10.1038/415092a

18. Maurel M, Chevet E, Tavernier J, Gerlo S. Getting RIDD of RNA: IRE1 in Cell Fate Regulation. Trends Biochem Sci (2014) 39(5):245-54. doi: 10.1016/ j.tibs.2014.02.008

19. Hollien J, Weissman JS. Decay of Endoplasmic Reticulum-Localized mRNAs During the Unfolded Protein Response. Science (2006) 313(5783):104-7. doi: 10.1126/science.1129631

20. Hetz C, Axten JM, Patterson JB. Pharmacological Targeting of the Unfolded Protein Response for Disease Intervention. Nat Chem Biol (2019) 15(8):76475. doi: 10.1038/s41589-019-0326-2

21. Rozpedek-Kaminska W, Siwecka N, Wawrzynkiewicz A, Wojtczak R, Pytel D, Diehl JA, et al. The PERK-Dependent Molecular Mechanisms as a Novel Therapeutic Target for Neurodegenerative Diseases. Int J Mol Sci (2020) 21 (6):2108. doi: 10.3390/ijms21062108

22. Fu S, Yang L, Li P, Hofmann O, Dicker L, Hide W, et al. Aberrant Lipid Metabolism Disrupts Calcium Homeostasis Causing Liver Endoplasmic Reticulum Stress in Obesity. Nature (2011) 473(7348):528-31. doi: 10.1038/ nature09968

23. Volmer R, van der Ploeg K, Ron D. Membrane Lipid Saturation Activates Endoplasmic Reticulum Unfolded Protein Response Transducers Through Their Transmembrane Domains. Proc Natl Acad Sci U S A (2013) 110 (12):4628-33. doi: 10.1073/pnas.1217611110

24. Jackson RJ, Hellen CU, Pestova TV. The Mechanism of Eukaryotic Translation Initiation and Principles of Its Regulation. Nat Rev Mol Cell Biol (2010) 11(2):113-27. doi: 10.1038/nrm2838

25. Wang M, Kaufman RJ. Protein Misfolding in the Endoplasmic Reticulum as a Conduit to Human Disease. Nature (2016) 529(7586):326-35. doi: 10.1038/ nature17041

26. Connor JH, Weiser DC, Li S, Hallenbeck JM, Shenolikar S. Growth Arrest and DNA Damage-Inducible Protein GADD34 Assembles a Novel Signaling Complex Containing Protein Phosphatase 1 and Inhibitor 1. Mol Cell Biol (2001) 21(20):6841-50. doi: 10.1128/MCB.21.20.6841-6850.2001

27. Hetz C, Chevet E, Oakes SA. Proteostasis Control by the Unfolded Protein Response. Nat Cell Biol (2015) 17(7):829-38. doi: 10.1038/ncb3184

28. Adachi Y, Yamamoto K, Okada T, Yoshida H, Harada A, Mori K. ATF6 is a Transcription Factor Specializing in the Regulation of Quality Control Proteins in the Endoplasmic Reticulum. Cell Struct Funct (2008) 33(1):7589. doi: $10.1247 /$ csf.07044
29. Bommiasamy H, Back SH, Fagone P, Lee K, Meshinchi S, Vink E, et al. ATF6alpha Induces XBP1-Independent Expansion of the Endoplasmic Reticulum. J Cell Sci (2009) 122(Pt 10):1626-36. doi: 10.1242/jcs.045625

30. Asada R, Kanemoto S, Kondo S, Saito A, Imaizumi K. The Signalling From Endoplasmic Reticulum-Resident bZIP Transcription Factors Involved in Diverse Cellular Physiology. J Biochem (2011) 149(5):507-18. doi: 10.1093/ $\mathrm{jb} / \mathrm{mvr} 041$

31. Dekkers MP, Barde YA. Developmental Biology. Programmed Cell Death in Neuronal Development. Science (2013) 340(6128):39-41. doi: 10.1126/ science. 1236152

32. Fricker M, Tolkovsky AM, Borutaite V, Coleman M, Brown GC. Neuronal Cell Death. Physiol Rev (2018) 98(2):813-80. doi: 10.1152/physrev.00011.2017

33. Thangaraj A, Sil S, Tripathi A, Chivero ET, Periyasamy P, Buch S. Targeting Endoplasmic Reticulum Stress and Autophagy as Therapeutic Approaches for Neurological Diseases. Int Rev Cell Mol Biol (2020) 350:285-325. doi: 10.1016/ bs.ircmb.2019.11.001

34. Mohammed Thangameeran SI, Tsai ST, Hung HY, Hu WF, Pang CY, Chen SY, et al. A Role for Endoplasmic Reticulum Stress in Intracerebral Hemorrhage. Cells (2020) 9(3):750. doi: 10.3390/cells9030750

35. Katayama T, Imaizumi K, Manabe T, Hitomi J, Kudo T, Tohyama M. Induction of Neuronal Death by ER Stress in Alzheimer's Disease. J Chem Neuroanat (2004) 28(1-2):67-78. doi: 10.1016/j.jchemneu.2003.12.004

36. Xu B, Xu J, Cai N, Li M, Liu L, Qin Y, et al. Roflumilast Prevents Ischemic Stroke-Induced Neuronal Damage by Restricting GSK3beta-Mediated Oxidative Stress and IRE1alpha/TRAF2/JNK Pathway. Free Radic Biol Med (2021) 163:281-96. doi: 10.1016/j.freeradbiomed.2020.12.018

37. Ji M, Niu S, Guo J, Mi H, Jiang P. Silencing RNF13 Alleviates Parkinson's Disease - Like Problems in Mouse Models by Regulating the Endoplasmic Reticulum Stress-Mediated IRE1alpha-TRAF2-ASK1-JNK Pathway. J Mol Neurosci (2020) 70(12):1977-86. doi: 10.1007/s12031-020-01599-4

38. Putcha GV, Le S, Frank S, Besirli CG, Clark K, Chu B, et al. JNK-Mediated BIM Phosphorylation Potentiates BAX-Dependent Apoptosis. Neuron (2003) 38(6):899-914. doi: 10.1016/s0896-6273(03)00355-6

39. Lei K, Davis RJ. JNK Phosphorylation of Bim-Related Members of the Bcl2 Family Induces Bax-Dependent Apoptosis. Proc Natl Acad Sci U S A (2003) 100(5):2432-7. doi: 10.1073/pnas.0438011100

40. Hetz C, Bernasconi P, Fisher J, Lee AH, Bassik MC, Antonsson B, et al. Proapoptotic BAX and BAK Modulate the Unfolded Protein Response by a Direct Interaction With IRE1alpha. Science (2006) 312(5773):572-6. doi: $10.1126 /$ science. 1123480

41. Nakagawa T, Zhu H, Morishima N, Li E, Xu J, Yankner BA, et al. Caspase-12 Mediates Endoplasmic-Reticulum-Specific Apoptosis and Cytotoxicity by Amyloid-Beta. Nature (2000) 403(6765):98-103. doi: 10.1038/47513

42. Chen L, Gao X. Neuronal Apoptosis Induced by Endoplasmic Reticulum Stress. Neurochem Res (2002) 27(9):891-8. doi: 10.1023/a:1020387414086

43. Wu M, Gao R, Dang B, Chen G. The Blood Component Iron Causes Neuronal Apoptosis Following Intracerebral Hemorrhage via the PERK Pathway. Front Neurol (2020) 11:588548. doi: 10.3389/fneur.2020.588548

44. Liu X, Chen Y, Wang H, Wei Y, Yuan Y, Zhou Q, et al. Microglia-Derived ILlbeta Promoted Neuronal Apoptosis Through ER Stress-Mediated Signaling Pathway PERK/eIF2alpha/ATF4/CHOP Upon Arsenic Exposure. J Hazard Mater (2021) 417:125997. doi: 10.1016/j.jhazmat.2021.125997

45. Wu MY, Gao F, Tang JF, Shen JC, Gao R, Dang BQ, et al. Possible Mechanisms of the PERK Pathway on Neuronal Apoptosis in a Rat Model of Surgical Brain Injury. Am J Transl Res (2021) 13(2):732-42.

46. Oyadomari S, Koizumi A, Takeda K, Gotoh T, Akira S, Araki E, et al. Targeted Disruption of the Chop Gene Delays Endoplasmic Reticulum Stress-Mediated Diabetes. J Clin Invest (2002) 109(4):525-32. doi: 10.1172/JCI14550

47. Silva RM, Ries V, Oo TF, Yarygina O, Jackson-Lewis V, Ryu EJ, et al. CHOP/ GADD153 is a Mediator of Apoptotic Death in Substantia Nigra Dopamine Neurons in an In Vivo Neurotoxin Model of Parkinsonism. J Neurochem (2005) 95(4):974-86. doi: 10.1111/j.1471-4159.2005.03428.x

48. Zinszner H, Kuroda M, Wang X, Batchvarova N, Lightfoot RT, Remotti H, et al. CHOP is Implicated in Programmed Cell Death in Response to Impaired Function of the Endoplasmic Reticulum. Genes Dev (1998) 12(7):982-95. doi: 10.1101/gad.12.7.982

49. Xu L, Bi Y, Xu Y, Wu Y, Du X, Mou Y, et al. Suppression of CHOP Reduces Neuronal Apoptosis and Rescues Cognitive Impairment Induced by 
Intermittent Hypoxia by Inhibiting Bax and Bak Activation. Neural Plast (2021) 2021:4090441. doi: 10.1155/2021/4090441

50. Xu W, Lu X, Zheng J, Li T, Gao L, Lenahan C, et al. Melatonin Protects Against Neuronal Apoptosis via Suppression of the ATF6/CHOP Pathway in a Rat Model of Intracerebral Hemorrhage. Front Neurosci (2018) 12:638. doi: $10.3389 /$ fnins.2018.00638

51. Ma Y, Brewer JW, Diehl JA, Hendershot LM. Two Distinct Stress Signaling Pathways Converge Upon the CHOP Promoter During the Mammalian Unfolded Protein Response. J Mol Biol (2002) 318(5):1351-65. doi: 10.1016/ s0022-2836(02)00234-6

52. Cybulsky AV. Endoplasmic Reticulum Stress, the Unfolded Protein Response and Autophagy in Kidney Diseases. Nat Rev Nephrol (2017) 13(11):681-96. doi: 10.1038/nrneph.2017.129

53. Xu W, Gao L, Li T, Zheng J, Shao A, Zhang J. Apelin-13 Alleviates Early Brain Injury After Subarachnoid Hemorrhage via Suppression of Endoplasmic Reticulum Stress-Mediated Apoptosis and Blood-Brain Barrier Disruption: Possible Involvement of ATF6/CHOP Pathway. Neuroscience (2018) 388:28496. doi: 10.1016/j.neuroscience.2018.07.023

54. Yu B, Wen L, Xiao B, Han F, Shi Y. Single Prolonged Stress Induces ATF6 Alpha-Dependent Endoplasmic Reticulum Stress and the Apoptotic Process in Medial Frontal Cortex Neurons. BMC Neurosci (2014) 15:115. doi: 10.1186/ s12868-014-0115-5

55. Yuan J, Amin P, Ofengeim D. Necroptosis and RIPK1-Mediated Neuroinflammation in CNS Diseases. Nat Rev Neurosci (2019) 20(1):19-33. doi: 10.1038/s41583-018-0093-1

56. Zhu P, Hu S, Jin Q, Li D, Tian F, Toan S, et al. Ripk3 Promotes ER StressInduced Necroptosis in Cardiac IR Injury: A Mechanism Involving Calcium Overload/XO/ROS/mPTP Pathway. Redox Biol (2018) 16:157-68. doi: 10.1016/j.redox.2018.02.019

57. Lv Y, Shao G, Zhang Q, Wang X, Meng Y, Wang L, et al. The Antimicrobial Peptide PFR Induces Necroptosis Mediated by ER Stress and Elevated Cytoplasmic Calcium and Mitochondrial ROS Levels: Cooperation With Ara-C to Act Against Acute Myeloid Leukemia. Signal Transduct Target Ther (2019) 4:38. doi: 10.1038/s41392-019-0073-6

58. Saveljeva S, Mc Laughlin SL, Vandenabeele P, Samali A, Bertrand MJ. Endoplasmic Reticulum Stress Induces Ligand-Independent TNFR1Mediated Necroptosis in L929 Cells. Cell Death Dis (2015) 6:e1587. doi: $10.1038 /$ cddis. 2014.548

59. Rojas-Rivera D, Delvaeye T, Roelandt R, Nerinckx W, Augustyns K, Vandenabeele P, et al. When PERK Inhibitors Turn Out to be New Potent RIPK1 Inhibitors: Critical Issues on the Specificity and Use of GSK2606414 and GSK2656157. Cell Death Differ (2017) 24(6):1100-10. doi: 10.1038/ cdd.2017.58

60. Wang W, Qing X, Wang B, Ma K, Wei Y, Shao Z. Tauroursodeoxycholic Acid Protects Nucleus Pulposus Cells From Compression-Induced Apoptosis and Necroptosis via Inhibiting Endoplasmic Reticulum Stress. Evid Based Complement Alternat Med (2018) 2018:6719460. doi: 10.1155/2018/6719460

61. Fan H, Tang HB, Kang J, Shan L, Song H, Zhu K, et al. Involvement of Endoplasmic Reticulum Stress in the Necroptosis of Microglia/Macrophages After Spinal Cord Injury. Neuroscience (2015) 311:362-73. doi: 10.1016/ j.neuroscience.2015.10.049

62. Oshima R, Hasegawa T, Tamai K, Sugeno N, Yoshida S, Kobayashi J, et al. ESCRT-0 Dysfunction Compromises Autophagic Degradation of Protein Aggregates and Facilitates ER Stress-Mediated Neurodegeneration via Apoptotic and Necroptotic Pathways. Sci Rep (2016) 6:24997. doi: 10.1038/ srep 24997

63. Font-Belmonte E, Ugidos IF, Santos-Galdiano M, Gonzalez-Rodriguez P, Anuncibay-Soto B, Perez-Rodriguez D, et al. Post-Ischemic Salubrinal Administration Reduces Necroptosis in a Rat Model of Global Cerebral Ischemia. J Neurochem (2019) 151(6):777-94. doi: 10.1111/jnc.14789

64. Vande Walle L, Lamkanfi M. Pyroptosis. Curr Biol (2016) 26(13):R568-R72. doi: 10.1016/j.cub.2016.02.019

65. McKenzie BA, Dixit VM, Power C. Fiery Cell Death: Pyroptosis in the Central Nervous System. Trends Neurosci (2020) 43(1):55-73. doi: 10.1016/ j.tins.2019.11.005

66. Zhou Y, Tong Z, Jiang S, Zheng W, Zhao J, Zhou X. The Roles of Endoplasmic Reticulum in NLRP3 Inflammasome Activation. Cells (2020) 9(5):1219. doi: $10.3390 /$ cells 9051219
67. Chen G, Gao C, Yan Y, Wang T, Luo C, Zhang M, et al. Inhibiting ER Stress Weakens Neuronal Pyroptosis in a Mouse Acute Hemorrhagic Stroke Model. Mol Neurobiol (2020) 57(12):5324-35. doi: 10.1007/s12035-020-02097-9

68. Talty A, Deegan S, Ljujic M, Mnich K, Naicker SD, Quandt D, et al. Inhibition of IRE1alpha RNase Activity Reduces NLRP3 Inflammasome Assembly and Processing of Pro-ILlbeta. Cell Death Dis (2019) 10(9):622. doi: 10.1038/ s41419-019-1847-z

69. Lerner AG, Upton JP, Praveen PV, Ghosh R, Nakagawa Y, Igbaria A, et al. IRE1alpha Induces Thioredoxin-Interacting Protein to Activate the NLRP3 Inflammasome and Promote Programmed Cell Death Under Irremediable ER Stress. Cell Metab (2012) 16(2):250-64. doi: 10.1016/j.cmet.2012.07.007

70. Oslowski CM, Hara T, O'Sullivan-Murphy B, Kanekura K, Lu S, Hara M, et al. Thioredoxin-Interacting Protein Mediates ER Stress-Induced Beta Cell Death Through Initiation of the Inflammasome. Cell Metab (2012) 16(2):265-73. doi: 10.1016/j.cmet.2012.07.005

71. Schroder K, Zhou R, Tschopp J. The NLRP3 Inflammasome: A Sensor for Metabolic Danger? Science (2010) 327(5963):296-300. doi: 10.1126/ science. 1184003

72. Ding R, Ou W, Chen C, Liu Y, Li H, Zhang X, et al. Endoplasmic Reticulum Stress and Oxidative Stress Contribute to Neuronal Pyroptosis Caused by Cerebral Venous Sinus Thrombosis in Rats: Involvement of TXNIP/ peroxynitrite-NLRP3 Inflammasome Activation. Neurochem Int (2020) 141:104856. doi: 10.1016/j.neuint.2020.104856

73. Huang J, Lu W, Doycheva DM, Gamdzyk M, Hu X, Liu R, et al. IRE1alpha Inhibition Attenuates Neuronal Pyroptosis via miR-125/NLRP1 Pathway in a Neonatal Hypoxic-Ischemic Encephalopathy Rat Model. J Neuroinflamm (2020) 17(1):152. doi: 10.1186/s12974-020-01796-3

74. Huang G, Yao J, Zeng W, Mizuno Y, Kamm KE, Stull JT, et al. ER Stress Disrupts Ca2+-Signaling Complexes and Ca2+ Regulation in Secretory and Muscle Cells From PERK-Knockout Mice. J Cell Sci (2006) 119(Pt 1):153-61. doi: $10.1242 /$ jcs. 02731

75. Han CY, Rho HS, Kim A, Kim TH, Jang K, Jun DW, et al. FXR Inhibits Endoplasmic Reticulum Stress-Induced NLRP3 Inflammasome in Hepatocytes and Ameliorates Liver Injury. Cell Rep (2018) 24(11):2985-99. doi: 10.1016/j.celrep.2018.07.068

76. Liu Y, Wen D, Gao J, Xie B, Yu H, Shen Q, et al. Methamphetamine Induces GSDME-Dependent Cell Death in Hippocampal Neuronal Cells Through the Endoplasmic Reticulum Stress Pathway. Brain Res Bull (2020) 162:73-83. doi: 10.1016/j.brainresbull.2020.06.005

77. Simard JC, Vallieres F, de Liz R, Lavastre V, Girard D. Silver Nanoparticles Induce Degradation of the Endoplasmic Reticulum Stress Sensor Activating Transcription Factor-6 Leading to Activation of the NLRP-3 Inflammasome. J Biol Chem (2015) 290(9):5926-39. doi: 10.1074/jbc.M114.610899

78. Stockwell BR, Jiang X, Gu W. Emerging Mechanisms and Disease Relevance of Ferroptosis. Trends Cell Biol (2020) 30(6):478-90. doi: 10.1016/ j.tcb.2020.02.009

79. Weiland A, Wang Y, Wu W, Lan X, Han X, Li Q, et al. Ferroptosis and Its Role in Diverse Brain Diseases. Mol Neurobiol (2019) 56(7):4880-93. doi: 10.1007/ s12035-018-1403-3

80. Dixon SJ, Patel DN, Welsch M, Skouta R, Lee ED, Hayano M, et al. Pharmacological Inhibition of Cystine-Glutamate Exchange Induces Endoplasmic Reticulum Stress and Ferroptosis. Elife (2014) 3:e02523. doi: $10.7554 /$ eLife. 02523

81. Rahmani M, Davis EM, Crabtree TR, Habibi JR, Nguyen TK, Dent P, et al. The Kinase Inhibitor Sorafenib Induces Cell Death Through a Process Involving Induction of Endoplasmic Reticulum Stress. Mol Cell Biol (2007) 27(15):5499-513. doi: 10.1128/MCB.01080-06

82. Lee YS, Lee DH, Choudry HA, Bartlett DL, Lee YJ. Ferroptosis-Induced Endoplasmic Reticulum Stress: Cross-Talk Between Ferroptosis and Apoptosis. Mol Cancer Res (2018) 16(7):1073-6. doi: 10.1158/1541-7786.MCR-18-0055

83. Chen D, Fan Z, Rauh M, Buchfelder M, Eyupoglu IY, Savaskan N. ATF4 Promotes Angiogenesis and Neuronal Cell Death and Confers Ferroptosis in a xCT-Dependent Manner. Oncogene (2017) 36(40):5593-608. doi: 10.1038/ onc. 2017.146

84. Chen Y, Mi Y, Zhang X, Ma Q, Song Y, Zhang L, et al. DihydroartemisininInduced Unfolded Protein Response Feedback Attenuates Ferroptosis via PERK/ATF4/HSPA5 Pathway in Glioma Cells. J Exp Clin Cancer Res (2019) 38(1):402. doi: 10.1186/s13046-019-1413-7 
85. Cullinan SB, Diehl JA. PERK-Dependent Activation of Nrf2 Contributes to Redox Homeostasis and Cell Survival Following Endoplasmic Reticulum Stress. J Biol Chem (2004) 279(19):20108-17. doi: 10.1074/jbc.M314219200

86. Cullinan SB, Zhang D, Hannink M, Arvisais E, Kaufman RJ, Diehl JA. Nrf2 is a Direct PERK Substrate and Effector of PERK-Dependent Cell Survival. Mol Cell Biol (2003) 23(20):7198-209. doi: 10.1128/MCB.23.20.7198-7209.2003

87. Dodson M, Castro-Portuguez R, Zhang DD. NRF2 Plays a Critical Role in Mitigating Lipid Peroxidation and Ferroptosis. Redox Biol (2019) 23:101107. doi: 10.1016/j.redox.2019.101107

88. Song X, Long D. Nrf2 and Ferroptosis: A New Research Direction for Neurodegenerative Diseases. Front Neurosci (2020) 14:267. doi: 10.3389/ fnins.2020.00267

89. Zeeshan HM, Lee GH, Kim HR, Chae HJ. Endoplasmic Reticulum Stress and Associated ROS. Int J Mol Sci (2016) 17(3):327. doi: 10.3390/ijms17030327

90. Zhang Z, Zhang L, Zhou L, Lei Y, Zhang Y, Huang C. Redox Signaling and Unfolded Protein Response Coordinate Cell Fate Decisions Under ER Stress. Redox Biol (2019) 25:101047. doi: 10.1016/j.redox.2018.11.005

91. Jung S, Jeong H, Yu SW. Autophagy as a Decisive Process for Cell Death. Exp Mol Med (2020) 52(6):921-30. doi: 10.1038/s12276-020-0455-4

92. Denton D, Kumar S. Autophagy-Dependent Cell Death. Cell Death Differ (2019) 26(4):605-16. doi: 10.1038/s41418-018-0252-y

93. Fouillet A, Levet C, Virgone A, Robin M, Dourlen P, Rieusset J, et al. ER Stress Inhibits Neuronal Death by Promoting Autophagy. Autophagy (2012) 8 (6):915-26. doi: 10.4161/auto.19716

94. Kong FJ, Ma LL, Guo JJ, Xu LH, Li Y, Qu S. Endoplasmic Reticulum Stress/ Autophagy Pathway is Involved in Diabetes-Induced Neuronal Apoptosis and Cognitive Decline in Mice. Clin Sci (Lond) (2018) 132(1):111-25. doi: 10.1042/ CS20171432

95. Sharma M, Bhattacharyya S, Sharma KB, Chauhan S, Asthana S, Abdin MZ, et al. Japanese Encephalitis Virus Activates Autophagy Through XBP1 and ATF6 ER Stress Sensors in Neuronal Cells. J Gen Virol (2017) 98(5):1027-39. doi: 10.1099 /jgv.0.000792

96. Alirezaei M, Kiosses WB, Flynn CT, Brady NR, Fox HS. Disruption of Neuronal Autophagy by Infected Microglia Results in Neurodegeneration. PLoS One (2008) 3(8):e2906. doi: 10.1371/journal.pone.0002906

97. Feng D, Wang B, Wang L, Abraham N, Tao K, Huang L, et al. Pre-Ischemia Melatonin Treatment Alleviated Acute Neuronal Injury After Ischemic Stroke by Inhibiting Endoplasmic Reticulum Stress-Dependent Autophagy via PERK and IRE1 Signalings. J Pineal Res (2017) 62(3). doi: 10.1111/jpi.12395

98. Niu Q, Chen J, Xia T, Li P, Zhou G, Xu C, et al. Excessive ER Stress and the Resulting Autophagic Flux Dysfunction Contribute to Fluoride-Induced Neurotoxicity. Environ Pollut (2018) 233:889-99. doi: 10.1016/ j.envpol.2017.09.015

99. Yan C, Liu J, Gao J, Sun Y, Zhang L, Song H, et al. IRE1 Promotes Neurodegeneration Through Autophagy-Dependent Neuron Death in the Drosophila Model of Parkinson's Disease. Cell Death Dis (2019) 10(11):800. doi: 10.1038/s41419-019-2039-6

100. Sozen E, Yazgan B, Tok OE, Demirel T, Ercan F, Proto JD, et al. Cholesterol Induced Autophagy via IRE1/JNK Pathway Promotes Autophagic Cell Death in Heart Tissue. Metabolism (2020) 106:154205. doi: 10.1016/ j.metabol.2020.154205

101. Yang Z, Zhou C, Shi H, Zhang N, Tang B, Ji N. Heme Induces BECN1/ ATG5-Mediated Autophagic Cell Death via ER Stress in Neurons. Neurotox Res (2020) 38(4):1037-48. doi: 10.1007/s12640-020-00275-0

102. Lee IN, Yang JT, Hsieh MJ, Huang C, Huang HC, Ku YJ, et al. Knockdown of Amphiregulin Triggers Doxorubicin-Induced Autophagic and Apoptotic Death by Regulating Endoplasmic Reticulum Stress in Glioblastoma Cells. J Mol Neurosci (2020) 70(10):1461-70. doi: 10.1007/s12031-020-01598-5

103. Zielke S, Kardo S, Zein L, Mari M, Covarrubias-Pinto A, Kinzler MN, et al. ATF4 Links ER Stress With Reticulophagy in Glioblastoma Cells. Autophagy (2020) 17(9):2432-48.17. doi: 10.1080/15548627.2020.1827780

104. Liao Y, Duan B, Zhang Y, Zhang X, Xia B. Excessive ER-Phagy Mediated by the Autophagy Receptor FAM134B Results in ER Stress, the Unfolded Protein Response, and Cell Death in HeLa Cells. J Biol Chem (2019) 294 (52):20009-23. doi: 10.1074/jbc.RA119.008709

105. Yang QQ, Zhou JW. Neuroinflammation in the Central Nervous System: Symphony of Glial Cells. Glia (2019) 67(6):1017-35. doi: 10.1002/glia.23571
106. DiSabato DJ, Quan N, Godbout JP. Neuroinflammation: The Devil is in the Details. J Neurochem (2016) 139 Suppl 2:136-53. doi: 10.1111/jnc.13607

107. Xanthos DN, Sandkuhler J. Neurogenic Neuroinflammation: Inflammatory CNS Reactions in Response to Neuronal Activity. Nat Rev Neurosci (2014) 15 (1):43-53. doi: 10.1038/nrn3617

108. Garcia-Gonzalez P, Cabral-Miranda F, Hetz C, Osorio F. Interplay Between the Unfolded Protein Response and Immune Function in the Development of Neurodegenerative Diseases. Front Immunol (2018) 9:2541. doi: 10.3389/ fimmu.2018.02541

109. Martino ME, Olsen JC, Fulcher NB, Wolfgang MC, O'Neal WK, Ribeiro CM. Airway Epithelial Inflammation-Induced Endoplasmic Reticulum Ca2+ Store Expansion is Mediated by X-Box Binding Protein-1. J Biol Chem (2009) 284(22):14904-13. doi: 10.1074/jbc.M809180200

110. Lubamba BA, Jones LC, O'Neal WK, Boucher RC, Ribeiro CM. X-BoxBinding Protein 1 and Innate Immune Responses of Human Cystic Fibrosis Alveolar Macrophages. Am J Respir Crit Care Med (2015) 192(12):1449-61. doi: 10.1164/rccm.201504-0657OC

111. Iwasaki Y, Suganami T, Hachiya R, Shirakawa I, Kim-Saijo M, Tanaka M, et al. Activating Transcription Factor 4 Links Metabolic Stress to Interleukin6 Expression in Macrophages. Diabetes (2014) 63(1):152-61. doi: 10.2337/ db13-0757

112. Meares GP, Liu Y, Rajbhandari R, Qin H, Nozell SE, Mobley JA, et al. PERKDependent Activation of JAK1 and STAT3 Contributes to Endoplasmic Reticulum Stress-Induced Inflammation. Mol Cell Biol (2014) 34(20):391125. doi: 10.1128/MCB.00980-14

113. Stengel ST, Fazio A, Lipinski S, Jahn MT, Aden K, Ito G, et al. Activating Transcription Factor 6 Mediates Inflammatory Signals in Intestinal Epithelial Cells Upon Endoplasmic Reticulum Stress. Gastroenterology (2020) 159(4):1357-74 e10. doi: 10.1053/j.gastro.2020.06.088

114. Bettigole SE, Glimcher LH. Endoplasmic Reticulum Stress in Immunity. Annu Rev Immunol (2015) 33:107-38. doi: 10.1146/annurev-immunol032414-112116

115. Zhang K, Shen X, Wu J, Sakaki K, Saunders T, Rutkowski DT, et al. Endoplasmic Reticulum Stress Activates Cleavage of CREBH to Induce a Systemic Inflammatory Response. Cell (2006) 124(3):587-99. doi: 10.1016/ j.cell.2005.11.040

116. Hoesel B, Schmid JA. The Complexity of NF-kappaB Signaling in Inflammation and Cancer. Mol Cancer (2013) 12:86. doi: 10.1186/14764598-12-86

117. Hu P, Han Z, Couvillon AD, Kaufman RJ, Exton JH. Autocrine Tumor Necrosis Factor Alpha Links Endoplasmic Reticulum Stress to the Membrane Death Receptor Pathway Through IRE1alpha-Mediated NFkappaB Activation and Down-Regulation of TRAF2 Expression. Mol Cell Biol (2006) 26(8):3071-84. doi: 10.1128/MCB.26.8.3071-3084.2006

118. Byndloss MX, Keestra-Gounder AM, Baumler AJ, Tsolis RM. NOD1 and NOD2: New Functions Linking Endoplasmic Reticulum Stress and Inflammation. DNA Cell Biol (2016) 35(7):311-3. doi: 10.1089/ dna.2016.3396

119. Keestra-Gounder AM, Byndloss MX, Seyffert N, Young BM, Chavez-Arroyo A, Tsai AY, et al. NOD1 and NOD2 Signalling Links ER Stress With Inflammation. Nature (2016) 532(7599):394-7. doi: 10.1038/nature17631

120. Zhou CM, Luo LM, Lin P, Pu Q, Wang B, Qin S, et al. Annexin A2 Regulates Unfolded Protein Response via IRE1-XBP1 Axis in Macrophages During P. Aeruginosa Infection. J Leukoc Biol (2021) 110(2):375-84. doi: 10.1002/ JLB.3A1219-686RR

121. Zhang C, Chen X, Wang C, Ran Y, Sheng K. Inhibition of XBP1 Alleviates LPS-Induced Cardiomyocytes Injury by Upregulating XIAP Through Suppressing the NF-kappaB Signaling Pathway. Inflammation (2021) 44 (3):974-84. doi: 10.1007/s10753-020-01392-w

122. Chen L, Xie ZY, Liu L, Zhu L, Wang F, Fan P, et al. Nuclear Factor-Kappa BDependent X-Box Binding Protein 1 Signalling Promotes the Proliferation of Nucleus Pulposus Cells Under Tumour Necrosis Factor Alpha Stimulation. Cell Prolif (2019) 52(2):e12542. doi: 10.1111/cpr.12542

123. Zhang H, Song G, Zhang Z, Song H, Tang X, Deng A, et al. Colitis Is Effectively Ameliorated by (+/-)-8-Acetonyl-Dihydrocoptisine via the XBP1NF-kappaB Pathway. Front Pharmacol (2017) 8:619. doi: 10.3389/ fphar.2017.00619 
124. Cho JA, Lee AH, Platzer B, Cross BCS, Gardner BM, De Luca H, et al. The Unfolded Protein Response Element IRE1alpha Senses Bacterial Proteins Invading the ER to Activate RIG-I and Innate Immune Signaling. Cell Host Microbe (2013) 13(5):558-69. doi: 10.1016/j.chom. 2013.03.011

125. Deng J, Lu PD, Zhang Y, Scheuner D, Kaufman RJ, Sonenberg N, et al. Translational Repression Mediates Activation of Nuclear Factor Kappa B by Phosphorylated Translation Initiation Factor 2. Mol Cell Biol (2004) 24 (23):10161-8. doi: 10.1128/MCB.24.23.10161-10168.2004

126. Tam AB, Mercado EL, Hoffmann A, Niwa M. ER Stress Activates NFkappaB by Integrating Functions of Basal IKK Activity, IRE1 and PERK. PLoS One (2012) 7(10):e45078. doi: 10.1371/journal.pone.0045078

127. Nakajima S, Hiramatsu N, Hayakawa K, Saito Y, Kato H, Huang T, et al. Selective Abrogation of BiP/GRP78 Blunts Activation of NF-kappaB Through the ATF6 Branch of the UPR: Involvement of C/EBPbeta and mTOR-Dependent Dephosphorylation of Akt. Mol Cell Biol (2011) 31 (8):1710-8. doi: 10.1128/MCB.00939-10

128. Yamazaki H, Hiramatsu N, Hayakawa K, Tagawa Y, Okamura M, Ogata R, et al. Activation of the Akt-NF-kappaB Pathway by Subtilase Cytotoxin Through the ATF6 Branch of the Unfolded Protein Response. J Immunol (2009) 183(2):1480-7. doi: 10.4049/jimmunol.0900017

129. Arthur JS, Ley SC. Mitogen-Activated Protein Kinases in Innate Immunity. Nat Rev Immunol (2013) 13(9):679-92. doi: 10.1038/nri3495

130. Urano F, Wang X, Bertolotti A, Zhang Y, Chung P, Harding HP, et al. Coupling of Stress in the ER to Activation of JNK Protein Kinases by Transmembrane Protein Kinase IRE1. Science (2000) 287(5453):664-6. doi: $10.1126 /$ science.287.5453.664

131. Shaulian E, Karin M. AP-1 as a Regulator of Cell Life and Death. Nat Cell Biol (2002) 4(5):E131-6. doi: 10.1038/ncb0502-e131

132. Kaser A, Lee AH, Franke A, Glickman JN, Zeissig S, Tilg H, et al. XBP1 Links ER Stress to Intestinal Inflammation and Confers Genetic Risk for Human Inflammatory Bowel Disease. Cell (2008) 134(5):743-56. doi: 10.1016/ j.cell.2008.07.021

133. Zhong Y, Li J, Chen Y, Wang JJ, Ratan R, Zhang SX. Activation of Endoplasmic Reticulum Stress by Hyperglycemia is Essential for Muller Cell-Derived Inflammatory Cytokine Production in Diabetes. Diabetes (2012) 61(2):492-504. doi: 10.2337/db11-0315

134. Ge X, Sun J, Fei A, Gao C, Pan S, Wu Z. Hydrogen Sulfide Treatment Alleviated Ventilator-Induced Lung Injury Through Regulation of Autophagy and Endoplasmic Reticulum Stress. Int J Biol Sci (2019) 15 (13):2872-84. doi: 10.7150/ijbs.38315

135. Guo J, Ren R, Sun K, Yao X, Lin J, Wang G, et al. PERK Controls Bone Homeostasis Through the Regulation of Osteoclast Differentiation and Function. Cell Death Dis (2020) 11(10):847. doi: 10.1038/s41419-02003046-z

136. Colonna M, Butovsky O. Microglia Function in the Central Nervous System During Health and Neurodegeneration. Annu Rev Immunol (2017) 35:44168. doi: 10.1146/annurev-immunol-051116-052358

137. Prinz M, Jung S, Priller J. Microglia Biology: One Century of Evolving Concepts. Cell (2019) 179(2):292-311. doi: 10.1016/j.cell.2019.08.053

138. Jassam YN, Izzy S, Whalen M, McGavern DB, El Khoury J. Neuroimmunology of Traumatic Brain Injury: Time for a Paradigm Shift. Neuron (2017) 95(6):1246-65. doi: 10.1016/j.neuron.2017.07.010

139. Lan X, Han X, Li Q, Yang QW, Wang J. Modulators of Microglial Activation and Polarization After Intracerebral Haemorrhage. Nat Rev Neurol (2017) 13 (7):420-33. doi: 10.1038/nrneurol.2017.69

140. Wang YW, Zhou Q, Zhang X, Qian QQ, Xu JW, Ni PF, et al. Mild Endoplasmic Reticulum Stress Ameliorates Lipopolysaccharide-Induced Neuroinflammation and Cognitive Impairment via Regulation of Microglial Polarization. J Neuroinflamm (2017) 14(1):233. doi: 10.1186/ s12974-017-1002-7

141. Thangaraj A, Periyasamy P, Guo ML, Chivero ET, Callen S, Buch S. Mitigation of Cocaine-Mediated Mitochondrial Damage, Defective Mitophagy and Microglial Activation by Superoxide Dismutase Mimetics. Autophagy (2020) 16(2):289-312. doi: 10.1080/15548627.2019.1607686

142. Guo ML, Liao K, Periyasamy P, Yang L, Cai Y, Callen SE, et al. CocaineMediated Microglial Activation Involves the ER Stress-Autophagy Axis. Autophagy (2015) 11(7):995-1009. doi: 10.1080/15548627.2015.1052205
143. Liao K, Guo M, Niu F, Yang L, Callen SE, Buch S. Cocaine-Mediated Induction of Microglial Activation Involves the ER Stress-TLR2 Axis. J Neuroinflamm (2016) 13:33. doi: 10.1186/s12974-016-0501-2

144. Zhu Y, Yu J, Gong J, Shen J, Ye D, Cheng D, et al. PTP1B Inhibitor Alleviates Deleterious Microglial Activation and Neuronal Injury After Ischemic Stroke by Modulating the ER Stress-Autophagy Axis via PERK Signaling in Microglia. Aging (Albany NY) (2021) 13(3):3405-27. doi: 10.18632/ aging. 202272

145. Studencka-Turski M, Cetin G, Junker H, Ebstein F, Kruger E. Molecular Insight Into the IRE1alpha-Mediated Type I Interferon Response Induced by Proteasome Impairment in Myeloid Cells of the Brain. Front Immunol (2019) 10:2900. doi: 10.3389/fimmu.2019.02900

146. Huang TC, Luo L, Jiang SH, Chen C, He HY, Liang CF, et al. Targeting Integrated Stress Response Regulates Microglial M1/M2 Polarization and Attenuates Neuroinflammation Following Surgical Brain Injury in Rat. Cell Signal (2021) 85:110048. doi: 10.1016/j.cellsig.2021.110048

147. Hara H, Kimoto D, Kajita M, Takada C, Kamiya T, Adachi T. Apomorphine Prevents LPS-Induced IL-23 P19 mRNA Expression via Inhibition of JNK and ATF4 in HAPI Cells. Eur J Pharmacol (2017) 795:108-14. doi: 10.1016/ j.ejphar.2016.12.014

148. Inoue T, Yamakage H, Tanaka M, Kusakabe T, Shimatsu A, Satoh-Asahara N. Oxytocin Suppresses Inflammatory Responses Induced by Lipopolysaccharide Through Inhibition of the eIF-2-ATF4 Pathway in Mouse Microglia. Cells (2019) 8(6):527. doi: 10.3390/cells8060527

149. Jin Y, Yao G, Wang Y, Teng L, Wang Y, Chen H, et al. MiR-30c-5p Mediates Inflammatory Responses and Promotes Microglia Survival by Targeting eIF2alpha During Cryptococcus Neoformans Infection. Microb Pathog (2020) 141:103959. doi: 10.1016/j.micpath.2019.103959

150. Huang D, Jiang Y. MKP1 Reduces Neuroinflammation via Inhibiting Endoplasmic Reticulum Stress and Mitochondrial Dysfunction. J Cell Physiol (2020) 235(5):4316-25. doi: 10.1002/jcp.29308

151. Ta HM, Le TM, Ishii H, Takarada-Iemata M, Hattori T, Hashida K, et al. Atf6alpha Deficiency Suppresses Microglial Activation and Ameliorates Pathology of Experimental Autoimmune Encephalomyelitis. J Neurochem (2016) 139(6):1124-37. doi: 10.1111/jnc.13714

152. Molofsky AV, Deneen B. Astrocyte Development: A Guide for the Perplexed. Glia (2015) 63(8):1320-9. doi: 10.1002/glia.22836

153. Han RT, Kim RD, Molofsky AV, Liddelow SA. Astrocyte-Immune Cell Interactions in Physiology and Pathology. Immunity (2021) 54(2):211-24. doi: 10.1016/j.immuni.2021.01.013

154. Neal M, Richardson JR. Epigenetic Regulation of Astrocyte Function in Neuroinflammation and Neurodegeneration. Biochim Biophys Acta Mol Basis Dis (2018) 1864(2):432-43. doi: 10.1016/j.bbadis.2017.11.004

155. Sofroniew MV. Molecular Dissection of Reactive Astrogliosis and Glial Scar Formation. Trends Neurosci (2009) 32(12):638-47. doi: 10.1016/ j.tins.2009.08.002

156. Wheeler MA, Clark IC, Tjon EC, Li Z, Zandee SEJ, Couturier CP, et al. MAFG-Driven Astrocytes Promote CNS Inflammation. Nature (2020) 578 (7796):593-9. doi: 10.1038/s41586-020-1999-0

157. Sims SG, Cisney RN, Lipscomb MM, Meares GP. The Role of Endoplasmic Reticulum Stress in Astrocytes. Glia (2021) 70(1):5-19.18. doi: 10.1002/ glia. 24082

158. Sil S, Periyasamy P, Guo ML, Callen S, Buch S. Morphine-Mediated Brain Region-Specific Astrocytosis Involves the ER Stress-Autophagy Axis. Mol Neurobiol (2018) 55(8):6713-33. doi: 10.1007/s12035-018-0878-2

159. Periyasamy P, Guo ML, Buch S. Cocaine Induces Astrocytosis Through ER Stress-Mediated Activation of Autophagy. Autophagy (2016) 12(8):1310-29. doi: 10.1080/15548627.2016.1183844

160. Zhao H, Liu Y, Cheng L, Liu B, Zhang W, Guo YJ, et al. Mesencephalic Astrocyte-Derived Neurotrophic Factor Inhibits Oxygen-Glucose Deprivation-Induced Cell Damage and Inflammation by Suppressing Endoplasmic Reticulum Stress in Rat Primary Astrocytes. J Mol Neurosci (2013) 51(3):671-8. doi: 10.1007/s12031-013-0042-4

161. Cheng L, Zhao H, Zhang W, Liu B, Liu Y, Guo Y, et al. Overexpression of Conserved Dopamine Neurotrophic Factor (CDNF) in Astrocytes Alleviates Endoplasmic Reticulum Stress-Induced Cell Damage and Inflammatory Cytokine Secretion. Biochem Biophys Res Commun (2013) 435(1):34-9. doi: 10.1016/j.bbrc.2013.04.029 
162. Hong Y, Wang X, Sun S, Xue G, Li J, Hou Y. Progesterone Exerts Neuroprotective Effects Against Abeta-Induced Neuroinflammation by Attenuating ER Stress in Astrocytes. Int Immunopharmacol (2016) 33:839. doi: 10.1016/j.intimp.2016.02.002

163. Fradejas N, Serrano-Perez Mdel C, Tranque P, Calvo S. Selenoprotein S Expression in Reactive Astrocytes Following Brain Injury. Glia (2011) 59 (6):959-72. doi: 10.1002/glia.21168

164. Guthrie LN, Abiraman K, Plyler ES, Sprenkle NT, Gibson SA, McFarland BC, et al. Attenuation of PKR-Like ER Kinase (PERK) Signaling Selectively Controls Endoplasmic Reticulum Stress-Induced Inflammation Without Compromising Immunological Responses. J Biol Chem (2016) 291 (30):15830-40. doi: 10.1074/jbc.M116.738021

165. Sims SG, Meares GP. Janus Kinase 1 Is Required for Transcriptional Reprograming of Murine Astrocytes in Response to Endoplasmic Reticulum Stress. Front Cell Neurosci (2019) 13:446. doi: 10.3389/ fncel.2019.00446

166. Nowery JD, Cisney RN, Feldmann JW, Meares GP. Nitric Oxide Induces a Janus Kinase-1-Dependent Inflammatory Response in Primary Murine Astrocytes. ASN Neuro (2021) 13:17590914211033650. doi: 10.1177/ 17590914211033650

167. Villarino AV, Kanno Y, O'Shea JJ. Mechanisms and Consequences of JakSTAT Signaling in the Immune System. Nat Immunol (2017) 18(4):374-84. doi: $10.1038 /$ ni.3691

168. O'Shea JJ, Plenge R. JAK and STAT Signaling Molecules in Immunoregulation and Immune-Mediated Disease. Immunity (2012) 36 (4):542-50. doi: 10.1016/j.immuni.2012.03.014

169. Duran-Aniotz C, Cornejo VH, Espinoza S, Ardiles AO, Medinas DB, Salazar C, et al. IRE1 Signaling Exacerbates Alzheimer's Disease Pathogenesis. Acta Neuropathol (2017) 134(3):489-506. doi: 10.1007/s00401-017-1694-x

170. Wheeler MA, Jaronen M, Covacu R, Zandee SEJ, Scalisi G, Rothhammer V, et al. Environmental Control of Astrocyte Pathogenic Activities in CNS Inflammation. Cell (2019) 176(3):581-96 e18. doi: 10.1016/j.cell.2018.12.012

171. Di Conza G, Ho PC. ER Stress Responses: An Emerging Modulator for Innate Immunity. Cells (2020) 9(3):695. doi: 10.3390/cells9030695

172. Duan XC, Wang W, Feng DX, Yin J, Zuo G, Chen DD, et al. Roles of Autophagy and Endoplasmic Reticulum Stress in Intracerebral HemorrhageInduced Secondary Brain Injury in Rats. CNS Neurosci Ther (2017) 23 (7):554-66. doi: 10.1111/cns.12703

173. Meng C, Zhang J, Dang B, Li H, Shen H, Li X, et al. PERK Pathway Activation Promotes Intracerebral Hemorrhage Induced Secondary Brain Injury by Inducing Neuronal Apoptosis Both In Vivo and In Vitro. Front Neurosci (2018) 12:111. doi: 10.3389/fnins.2018.00111

174. Habib P, Stamm AS, Schulz JB, Reich A, Slowik A, Capellmann S, et al. EPO and TMBIM3/GRINA Promote the Activation of the Adaptive Arm and Counteract the Terminal Arm of the Unfolded Protein Response After Murine Transient Cerebral Ischemia. Int J Mol Sci (2019) 20(21):5421. doi: 10.3390/ijms20215421

175. Zhang X, Yuan Y, Jiang L, Zhang J, Gao J, Shen Z, et al. Endoplasmic Reticulum Stress Induced by Tunicamycin and Thapsigargin Protects Against Transient Ischemic Brain Injury: Involvement of PARK2Dependent Mitophagy. Autophagy (2014) 10(10):1801-13. doi: 10.4161/ auto. 32136

176. Mo ZT, Liao YL, Zheng J, Li WN. Icariin Protects Neurons From Endoplasmic Reticulum Stress-Induced Apoptosis After OGD/R Injury via Suppressing IRE1alpha-XBP1 Signaling Pathway. Life Sci (2020) 255:117847. doi: 10.1016/j.lfs.2020.117847

177. Ibuki T, Yamasaki Y, Mizuguchi H, Sokabe M. Protective Effects of XBP1 Against Oxygen and Glucose Deprivation/Reoxygenation Injury in Rat Primary Hippocampal Neurons. Neurosci Lett (2012) 518(1):45-8. doi: 10.1016/j.neulet.2012.04.053

178. Qi X, Hosoi T, Okuma Y, Kaneko M, Nomura Y. Sodium 4-Phenylbutyrate Protects Against Cerebral Ischemic Injury. Mol Pharmacol (2004) 66(4):899908. doi: 10.1124/mol.104.001339

179. Xiaohong W, Jun Z, Hongmei G, Fan Q. CFLAR is a Critical Regulator of Cerebral Ischaemia-Reperfusion Injury Through Regulating Inflammation and Endoplasmic Reticulum (ER) Stress. BioMed Pharmacother (2019) 117:109155. doi: 10.1016/j.biopha.2019.109155
180. Lin M, Ling J, Geng X, Zhang J, Du J, Chen L. RTN1-C is Involved in High Glucose-Aggravated Neuronal Cell Subjected to Oxygen-Glucose Deprivation and Reoxygenation Injury via Endoplasmic Reticulum Stress. Brain Res Bull (2019) 149:129-36. doi: 10.1016/j.brainresbull.2019.04.010

181. Tung WF, Chen WJ, Hung HC, Liu GY, Tung JN, Huang CC, et al. 4Phenylbutyric Acid (4-PBA) and Lithium Cooperatively Attenuate Cell Death During Oxygen-Glucose Deprivation (OGD) and Reoxygenation. Cell Mol Neurobiol (2015) 35(6):849-59. doi: 10.1007/s10571-015-0179-5

182. Xin J, Ma X, Chen W, Zhou W, Dong H, Wang Z, et al. Regulation of BloodBrain Barrier Permeability by Salvinorin A via Alleviating Endoplasmic Reticulum Stress in Brain Endothelial Cell After Ischemia Stroke. Neurochem Int (2021) 149:105093. doi: 10.1016/j.neuint.2021.105093

183. Nan D, Jin H, Deng J, Yu W, Liu R, Sun W, et al. Cilostazol Ameliorates Ischemia/Reperfusion-Induced Tight Junction Disruption in Brain Endothelial Cells by Inhibiting Endoplasmic Reticulum Stress. FASEB J (2019) 33(9):10152-64. doi: 10.1096/fj.201900326R

184. Rodrigues CM, Spellman SR, Sola S, Grande AW, Linehan-Stieers C, Low WC, et al. Neuroprotection by a Bile Acid in an Acute Stroke Model in the Rat. J Cereb Blood Flow Metab (2002) 22(4):463-71. doi: 10.1097/00004647200204000-00010

185. Li Y, Zhang Y, Fu H, Huang H, Lu Q, Qin H, et al. Hes1 Knockdown Exacerbates Ischemic Stroke Following tMCAO by Increasing ER StressDependent Apoptosis via the PERK/eIF2alpha/ATF4/CHOP Signaling Pathway. Neurosci Bull (2020) 36(2):134-42. doi: 10.1007/s12264-01900411-7

186. Wang YC, Li X, Shen Y, Lyu J, Sheng H, Paschen W, et al. PERK (Protein Kinase RNA-Like ER Kinase) Branch of the Unfolded Protein Response Confers Neuroprotection in Ischemic Stroke by Suppressing Protein Synthesis. Stroke (2020) 51(5):1570-7. doi: 10.1161/STROKEAHA.120.029071

187. He Q, Li Z, Meng C, Wu J, Zhao Y, Zhao J. Parkin-Dependent Mitophagy is Required for the Inhibition of ATF4 on NLRP3 Inflammasome Activation in Cerebral Ischemia-Reperfusion Injury in Rats. Cells (2019) 8(8):897. doi: 10.3390/cells 8080897

188. Yu Z, Sheng H, Liu S, Zhao S, Glembotski CC, Warner DS, et al. Activation of the ATF6 Branch of the Unfolded Protein Response in Neurons Improves Stroke Outcome. J Cereb Blood Flow Metab (2017) 37(3):1069-79. doi: 10.1177/0271678X16650218

189. Blackwood EA, Azizi K, Thuerauf DJ, Paxman RJ, Plate L, Kelly JW, et al. Pharmacologic ATF6 Activation Confers Global Protection in Widespread Disease Models by Reprograming Cellular Proteostasis. Nat Commun (2019) 10(1):187. doi: 10.1038/s41467-018-08129-2

190. Logsdon AF, Turner RC, Lucke-Wold BP, Robson MJ, Naser ZJ, Smith KE, et al. Altering Endoplasmic Reticulum Stress in a Model of Blast-Induced Traumatic Brain Injury Controls Cellular Fate and Ameliorates Neuropsychiatric Symptoms. Front Cell Neurosci (2014) 8:421. doi: 10.3389/fncel.2014.00421

191. Lucke-Wold BP, Logsdon AF, Turner RC, Huber JD, Rosen CL. Endoplasmic Reticulum Stress Modulation as a Target for Ameliorating Effects of Blast Induced Traumatic Brain Injury. J Neurotrauma (2017) 34 (S1):S62-70. doi: 10.1089/neu.2016.4680

192. Logsdon AF, Lucke-Wold BP, Nguyen L, Matsumoto RR, Turner RC, Rosen CL, et al. Salubrinal Reduces Oxidative Stress, Neuroinflammation and Impulsive-Like Behavior in a Rodent Model of Traumatic Brain Injury. Brain Res (2016) 1643:140-51. doi: 10.1016/j.brainres.2016.04.063

193. Tan HP, Guo Q, Hua G, Chen JX, Liang JC. Inhibition of Endoplasmic Reticulum Stress Alleviates Secondary Injury After Traumatic Brain Injury. Neural Regener Res (2018) 13(5):827-36. doi: 10.4103/1673-5374.232477

194. Sun D, Gu G, Wang J, Chai Y, Fan Y, Yang M, et al. Administration of Tauroursodeoxycholic Acid Attenuates Early Brain Injury via Akt Pathway Activation. Front Cell Neurosci (2017) 11:193. doi: 10.3389/fncel.2017.00193

195. Gao Y, Zhang MY, Wang T, Fan YY, Yu LS, Ye GH, et al. IL-33/ST2L Signaling Provides Neuroprotection Through Inhibiting Autophagy, Endoplasmic Reticulum Stress, and Apoptosis in a Mouse Model of Traumatic Brain Injury. Front Cell Neurosci (2018) 12:95. doi: 10.3389/ fncel.2018.00095

196. Wang ZF, Gao C, Chen W, Gao Y, Wang HC, Meng Y, et al. Salubrinal Offers Neuroprotection Through Suppressing Endoplasmic Reticulum Stress, 
Autophagy and Apoptosis in a Mouse Traumatic Brain Injury Model. Neurobiol Learn Mem (2019) 161:12-25. doi: 10.1016/j.nlm.2019.03.002

197. Dash PK, Hylin MJ, Hood KN, Orsi SA, Zhao J, Redell JB, et al. Inhibition of Eukaryotic Initiation Factor 2 Alpha Phosphatase Reduces Tissue Damage and Improves Learning and Memory After Experimental Traumatic Brain Injury. J Neurotrauma (2015) 32(20):1608-20. doi: 10.1089/neu.2014.3772

198. Hood KN, Zhao J, Redell JB, Hylin MJ, Harris B, Perez A, et al. Endoplasmic Reticulum Stress Contributes to the Loss of Newborn Hippocampal Neurons After Traumatic Brain Injury. J Neurosci (2018) 38(9):2372-84. doi: 10.1523/ JNEUROSCI.1756-17.2018

199. Sen T, Gupta R, Kaiser H, Sen N. Activation of PERK Elicits Memory Impairment Through Inactivation of CREB and Downregulation of PSD95 After Traumatic Brain Injury. J Neurosci (2017) 37(24):5900-11. doi: 10.1523/JNEUROSCI.2343-16.2017

200. Sen T, Saha P, Gupta R, Foley LM, Jiang T, Abakumova OS, et al. Aberrant ER Stress Induced Neuronal-IFNbeta Elicits White Matter Injury Due to Microglial Activation and T-Cell Infiltration After TBI. J Neurosci (2020) 40 (2):424-46. doi: 10.1523/JNEUROSCI.0718-19.2019

201. Ma T, Trinh MA, Wexler AJ, Bourbon C, Gatti E, Pierre P, et al. Suppression of eIF2alpha Kinases Alleviates Alzheimer's Disease-Related Plasticity and Memory Deficits. Nat Neurosci (2013) 16(9):1299-305. doi: 10.1038/nn.3486

202. Yang W, Zhou X, Zimmermann HR, Cavener DR, Klann E, Ma T. Repression of the eIF2alpha Kinase PERK Alleviates Mglur-LTD Impairments in a Mouse Model of Alzheimer's Disease. Neurobiol Aging (2016) 41:19-24. doi: 10.1016/j.neurobiolaging.2016.02.005

203. Baleriola J, Walker CA, Jean YY, Crary JF, Troy CM, Nagy PL, et al. Axonally Synthesized ATF4 Transmits a Neurodegenerative Signal Across Brain Regions. Cell (2014) 158(5):1159-72. doi: 10.1016/j.cell.2014.07.001

204. Cisse M, Duplan E, Lorivel T, Dunys J, Bauer C, Meckler X, et al. The Transcription Factor XBP1s Restores Hippocampal Synaptic Plasticity and Memory by Control of the Kalirin-7 Pathway in Alzheimer Model. Mol Psychiatry (2017) 22(11):1562-75. doi: 10.1038/mp.2016.152

205. Du Y, Liu X, Zhu X, Liu Y, Wang X, Wu X. Activating Transcription Factor 6 Reduces Abeta1-42 and Restores Memory in Alzheimer's Disease Model Mice. Int J Neurosci (2020) 130(10):1015-23. doi: 10.1080/ 00207454.2020 .1715977

206. Devi L, Ohno M. PERK Mediates eIF2alpha Phosphorylation Responsible for BACE1 Elevation, CREB Dysfunction and Neurodegeneration in a Mouse Model of Alzheimer's Disease. Neurobiol Aging (2014) 35(10):2272-81. doi: 10.1016/j.neurobiolaging.2014.04.031

207. Radford H, Moreno JA, Verity N, Halliday M, Mallucci GR. PERK Inhibition Prevents Tau-Mediated Neurodegeneration in a Mouse Model of Frontotemporal Dementia. Acta Neuropathol (2015) 130(5):633-42. doi: $10.1007 / \mathrm{s} 00401-015-1487-\mathrm{z}$

208. Halliday M, Radford H, Zents KAM, Molloy C, Moreno JA, Verity NC, et al. Repurposed Drugs Targeting eIF2\&alpha;-P-Mediated Translational Repression Prevent Neurodegeneration in Mice. Brain (2017) 140(6):176883. doi: $10.1093 / \mathrm{brain} / \mathrm{awx} 074$

209. Dai Y, Han G, Xu S, Yuan Y, Zhao C, Ma T. Echinacoside Suppresses Amyloidogenesis and Modulates F-Actin Remodeling by Targeting the ER Stress Sensor PERK in a Mouse Model of Alzheimer's Disease. Front Cell Dev Biol (2020) 8:593659. doi: 10.3389/fcell.2020.593659

210. Colla E, Coune P, Liu Y, Pletnikova O, Troncoso JC, Iwatsubo T, et al. Endoplasmic Reticulum Stress is Important for the Manifestations of AlphaSynucleinopathy In Vivo. J Neurosci (2012) 32(10):3306-20. doi: 10.1523/ JNEUROSCI.5367-11.2012

211. Mercado G, Castillo V, Soto P, Lopez N, Axten JM, Sardi SP, et al. Targeting PERK Signaling With the Small Molecule GSK2606414 Prevents Neurodegeneration in a Model of Parkinson's Disease. Neurobiol Dis (2018) 112:136-48. doi: 10.1016/j.nbd.2018.01.004

212. Celardo I, Costa AC, Lehmann S, Jones C, Wood N, Mencacci NE, et al. Mitofusin-Mediated ER Stress Triggers Neurodegeneration in Pink1/Parkin Models of Parkinson's Disease. Cell Death Dis (2016) 7(6):e2271. doi: $10.1038 /$ cddis. 2016.173

213. Demmings MD, Tennyson EC, Petroff GN, Tarnowski-Garner HE, Cregan SP. Activating Transcription Factor-4 Promotes Neuronal Death Induced by Parkinson's Disease Neurotoxins and Alpha-Synuclein Aggregates. Cell Death Differ (2021) 28(5):1627-43. doi: 10.1038/s41418-020-00688-6
214. Si L, Xu T, Wang F, Liu Q, Cui M. X-Box-Binding Protein 1-Modified Neural Stem Cells for Treatment of Parkinson's Disease. Neural Regener Res (2012) 7 (10):736-40. doi: 10.3969/j.issn.1673-5374.2012.10.003

215. Valdes P, Mercado G, Vidal RL, Molina C, Parsons G, Court FA, et al. Control of Dopaminergic Neuron Survival by the Unfolded Protein Response Transcription Factor XBP1. Proc Natl Acad Sci U S A (2014) 111 (18):6804-9. doi: 10.1073/pnas.1321845111

216. Egawa N, Yamamoto K, Inoue H, Hikawa R, Nishi K, Mori K, et al. The Endoplasmic Reticulum Stress Sensor, ATF6alpha, Protects Against Neurotoxin-Induced Dopaminergic Neuronal Death. J Biol Chem (2011) 286(10):7947-57. doi: 10.1074/jbc.M110.156430

217. Hashida K, Kitao Y, Sudo H, Awa Y, Maeda S, Mori K, et al. ATF6alpha Promotes Astroglial Activation and Neuronal Survival in a Chronic Mouse Model of Parkinson's Disease. PLoS One (2012) 7(10):e47950. doi: 10.1371/ journal.pone.0047950

218. Sado M, Yamasaki Y, Iwanaga T, Onaka Y, Ibuki T, Nishihara S, et al. Protective Effect Against Parkinson's Disease-Related Insults Through the Activation of XBP1. Brain Res (2009) 1257:16-24. doi: 10.1016/ j.brainres.2008.11.104

219. Lin W, Lin Y, Li J, Fenstermaker AG, Way SW, Clayton B, et al. Oligodendrocyte-Specific Activation of PERK Signaling Protects Mice Against Experimental Autoimmune Encephalomyelitis. J Neurosci (2013) 33(14):5980-91. doi: 10.1523/JNEUROSCI.1636-12.2013

220. Lin Y, Huang G, Jamison S, Li J, Harding HP, Ron D, et al. PERK Activation Preserves the Viability and Function of Remyelinating Oligodendrocytes in Immune-Mediated Demyelinating Diseases. Am J Pathol (2014) 184(2):50719. doi: 10.1016/j.ajpath.2013.10.009

221. Yue Y, Stanojlovic M, Lin Y, Karsenty G, Lin W. Oligodendrocyte-Specific ATF4 Inactivation Does Not Influence the Development of EAE. J Neuroinflamm (2019) 16(1):23. doi: 10.1186/s12974-019-1415-6

222. Stone S, Wu S, Jamison S, Durose W, Pallais JP, Lin W. Activating Transcription Factor 6alpha Deficiency Exacerbates Oligodendrocyte Death and Myelin Damage in Immune-Mediated Demyelinating Diseases. Glia (2018) 66(7):1331-45. doi: 10.1002/glia.23307

223. Hussien Y, Cavener DR, Popko B. Genetic Inactivation of PERK Signaling in Mouse Oligodendrocytes: Normal Developmental Myelination With Increased Susceptibility to Inflammatory Demyelination. Glia (2014) 62 (5):680-91. doi: 10.1002/glia.22634

224. Huang H, Miao L, Liang F, Liu X, Xu L, Teng X, et al. Neuroprotection by eIF2alpha-CHOP Inhibition and XBP-1 Activation in EAE/optic Neuritiss. Cell Death Dis (2017) 8(7):e2936. doi: 10.1038/cddis.2017.329

225. Jiang Y, Lv H, Liao M, Xu X, Huang S, Tan H, et al. GRP78 Counteracts Cell Death and Protein Aggregation Caused by Mutant Huntingtin Proteins. Neurosci Lett (2012) 516(2):182-7. doi: 10.1016/j.neulet.2012.03.074

226. Leitman J, Barak B, Benyair R, Shenkman M, Ashery U, Hartl FU, et al. ER Stress-Induced eIF2-Alpha Phosphorylation Underlies Sensitivity of Striatal Neurons to Pathogenic Huntingtin. PLoS One (2014) 9(3):e90803. doi: 10.1371/journal.pone.0090803

227. Reijonen S, Putkonen N, Norremolle A, Lindholm D, Korhonen L. Inhibition of Endoplasmic Reticulum Stress Counteracts Neuronal Cell Death and Protein Aggregation Caused by N-Terminal Mutant Huntingtin Proteins. Exp Cell Res (2008) 314(5):950-60. doi: 10.1016/j.yexcr.2007.12.025

228. Hyrskyluoto A, Bruelle C, Lundh SH, Do HT, Kivinen J, Rappou E, et al. Ubiquitin-Specific Protease-14 Reduces Cellular Aggregates and Protects Against Mutant Huntingtin-Induced Cell Degeneration: Involvement of the Proteasome and ER Stress-Activated Kinase IRElalpha. Hum Mol Genet (2014) 23(22):5928-39. doi: 10.1093/hmg/ddu317

229. Lee H, Noh JY, Oh Y, Kim Y, Chang JW, Chung CW, et al. IRE1 Plays an Essential Role in ER Stress-Mediated Aggregation of Mutant Huntingtin via the Inhibition of Autophagy Flux. Hum Mol Genet (2012) 21(1):101-14. doi: $10.1093 / \mathrm{hmg} / \mathrm{ddr} 445$

230. Zuleta A, Vidal RL, Armentano D, Parsons G, Hetz C. AAV-Mediated Delivery of the Transcription Factor XBP1s Into the Striatum Reduces Mutant Huntingtin Aggregation in a Mouse Model of Huntington's Disease. Biochem Biophys Res Commun (2012) 420(3):558-63. doi: 10.1016/j.bbrc.2012.03.033

231. Vidal RL, Figueroa A, Court FA, Thielen P, Molina C, Wirth C, et al. Targeting the UPR Transcription Factor XBP1 Protects Against 
Huntington's Disease Through the Regulation of FoxO1 and Autophagy. Hum Mol Genet (2012) 21(10):2245-62. doi: 10.1093/hmg/dds040

232. Saxena S, Cabuy E, Caroni P. A Role for Motoneuron Subtype-Selective ER Stress in Disease Manifestations of FALS Mice. Nat Neurosci (2009) 12 (5):627-36. doi: 10.1038/nn.2297

233. Oh YK, Shin KS, Yuan J, Kang SJ. Superoxide Dismutase 1 Mutants Related to Amyotrophic Lateral Sclerosis Induce Endoplasmic Stress in Neuro2a Cells. J Neurochem (2008) 104(4):993-1005. doi: 10.1111/j.1471-4159.2007.05053.x

234. Wang L, Popko B, Roos RP. The Unfolded Protein Response in Familial Amyotrophic Lateral Sclerosis. Hum Mol Genet (2011) 20(5):1008-15. doi: $10.1093 / \mathrm{hmg} / \mathrm{ddq} 546$

235. Wang L, Popko B, Roos RP. An Enhanced Integrated Stress Response Ameliorates Mutant SOD1-Induced ALS. Hum Mol Genet (2014) 23 (10):2629-38. doi: 10.1093/hmg/ddt658

236. Ghadge GD, Sonobe Y, Camarena A, Drigotas C, Rigo F, Ling KK, et al. Knockdown of GADD34 in Neonatal Mutant SOD1 Mice Ameliorates ALS. Neurobiol Dis (2020) 136:104702. doi: 10.1016/j.nbd.2019.104702

237. Wang L, Popko B, Tixier E, Roos RP. Guanabenz, Which Enhances the Unfolded Protein Response, Ameliorates Mutant SOD1-Induced Amyotrophic Lateral Sclerosis. Neurobiol Dis (2014) 71:317-24. doi: 10.1016/j.nbd.2014.08.010

238. Jiang HQ, Ren M, Jiang HZ, Wang J, Zhang J, Yin X, et al. Guanabenz Delays the Onset of Disease Symptoms, Extends Lifespan, Improves Motor Performance and Attenuates Motor Neuron Loss in the SOD1 G93A Mouse Model of Amyotrophic Lateral Sclerosis. Neuroscience (2014) 277:132-8. doi: 10.1016/j.neuroscience.2014.03.047

239. Bugallo R, Marlin E, Baltanas A, Toledo E, Ferrero R, Vinueza-Gavilanes R, et al. Fine Tuning of the Unfolded Protein Response by ISRIB Improves Neuronal Survival in a Model of Amyotrophic Lateral Sclerosis. Cell Death Dis (2020) 11(5):397. doi: 10.1038/s41419-020-2601-2

240. Vaccaro A, Patten SA, Aggad D, Julien C, Maios C, Kabashi E, et al. Pharmacological Reduction of ER Stress Protects Against TDP-43 Neuronal Toxicity In Vivo. Neurobiol Dis (2013) 55:64-75. doi: 10.1016/ j.nbd.2013.03.015

241. Kim HJ, Raphael AR, LaDow ES, McGurk L, Weber RA, Trojanowski JQ, et al. Therapeutic Modulation of eIF2alpha Phosphorylation Rescues TDP43 Toxicity in Amyotrophic Lateral Sclerosis Disease Models. Nat Genet (2014) 46(2):152-60. doi: 10.1038/ng.2853

242. Cordonnier C, Demchuk A, Ziai W, Anderson CS. Intracerebral Haemorrhage: Current Approaches to Acute Management. Lancet (2018) 392(10154):1257-68. doi: 10.1016/S0140-6736(18)31878-6

243. Wang J. Preclinical and Clinical Research on Inflammation After Intracerebral Hemorrhage. Prog Neurobiol (2010) 92(4):463-77. doi: 10.1016/j.pneurobio.2010.08.001

244. Zhu H, Wang Z, Yu J, Yang X, He F, Liu Z, et al. Role and Mechanisms of Cytokines in the Secondary Brain Injury After Intracerebral Hemorrhage. Prog Neurobiol (2019) 178:101610. doi: 10.1016/j.pneurobio.2019.03.003

245. Jeanne M, Labelle-Dumais C, Jorgensen J, Kauffman WB, Mancini GM, Favor J, et al. COL4A2 Mutations Impair COL4A1 and COL4A2 Secretion and Cause Hemorrhagic Stroke. Am J Hum Genet (2012) 90(1):91-101. doi: 10.1016/j.ajhg.2011.11.022

246. Gall T, Balla G, Balla J. Heme, Heme Oxygenase, and Endoplasmic Reticulum Stress-A New Insight Into the Pathophysiology of Vascular Diseases. Int J Mol Sci (2019) 20(15):3675. doi: 10.3390/ijms20153675

247. Zhuo F, Qiu G, Xu J, Yang M, Wang K, Liu H, et al. Both Endoplasmic Reticulum and Mitochondrial Pathways Are Involved in Oligodendrocyte Apoptosis Induced by Capsular Hemorrhage. Mol Cell Neurosci (2016) 72:64-71. doi: 10.1016/j.mcn.2016.01.009

248. Campbell BCV, De Silva DA, Macleod MR, Coutts SB, Schwamm LH, Davis SM, et al. Ischaemic Stroke. Nat Rev Dis Primers (2019) 5(1):70. doi: 10.1038/ s41572-019-0118-8

249. Collaborators GBDLRoSFeigin VL, Nguyen G, Cercy K, Johnson CO, Alam T, et al. Global, Regional, and Country-Specific Lifetime Risks of Stroke, 1990 and 2016. N Engl J Med (2018) 379(25):2429-37. doi: 10.1056/ NEJMoa1 804492

250. Han Y, Yuan M, Guo YS, Shen XY, Gao ZK, Bi X. Mechanism of Endoplasmic Reticulum Stress in Cerebral Ischemia. Front Cell Neurosci (2021) 15:704334. doi: 10.3389/fncel.2021.704334
251. Ito D, Tanaka K, Suzuki S, Dembo T, Kosakai A, Fukuuchi Y. Up-Regulation of the Ire1-Mediated Signaling Molecule, Bip, in Ischemic Rat Brain. Neuroreport (2001) 12(18):4023-8. doi: 10.1097/00001756-20011221000034

252. Louessard M, Bardou I, Lemarchand E, Thiebaut AM, Parcq J, Leprince J, et al. Activation of Cell Surface GRP78 Decreases Endoplasmic Reticulum Stress and Neuronal Death. Cell Death Differ (2017) 24(9):1518-29. doi: 10.1038/cdd.2017.35

253. Quaglio G, Gallucci M, Brand H, Dawood A, Cobello F. Traumatic Brain Injury: A Priority for Public Health Policy. Lancet Neurol (2017) 16(12):9512. doi: 10.1016/S1474-4422(17)30370-8

254. Lingsma HF, Roozenbeek B, Steyerberg EW, Murray GD, Maas AI. Early Prognosis in Traumatic Brain Injury: From Prophecies to Predictions. Lancet Neurol (2010) 9(5):543-54. doi: 10.1016/S1474-4422(10)70065-X

255. Hayes RL, Yang K, Raghupathi R, McIntosh TK. Changes in Gene Expression Following Traumatic Brain Injury in the Rat. J Neurotrauma (1995) 12(5):779-90. doi: 10.1089/neu.1995.12.779

256. Raghupathi R, McIntosh TK, Smith DH. Cellular Responses to Experimental Brain Injury. Brain Pathol (1995) 5(4):437-42. doi: 10.1111/j.17503639.1995.tb00622.x

257. Keane RW, Kraydieh S, Lotocki G, Alonso OF, Aldana P, Dietrich WD. Apoptotic and Antiapoptotic Mechanisms After Traumatic Brain Injury. J Cereb Blood Flow Metab (2001) 21(10):1189-98. doi: 10.1097/00004647200110000-00007

258. Larner SF, Hayes RL, Wang KK. Unfolded Protein Response After Neurotrauma. J Neurotrauma (2006) 23(6):807-29. doi: 10.1089/ neu.2006.23.807

259. Rubovitch V, Barak S, Rachmany L, Goldstein RB, Zilberstein Y, Pick CG. The Neuroprotective Effect of Salubrinal in a Mouse Model of Traumatic Brain Injury. Neuromolecular Med (2015) 17(1):58-70. doi: 10.1007/s12017015-8340-3

260. Begum G, Harvey L, Dixon CE, Sun D. ER Stress and Effects of DHA as an ER Stress Inhibitor. Transl Stroke Res (2013) 4(6):635-42. doi: 10.1007/ s12975-013-0282-1

261. Begum G, Yan HQ, Li L, Singh A, Dixon CE, Sun D. Docosahexaenoic Acid Reduces ER Stress and Abnormal Protein Accumulation and Improves Neuronal Function Following Traumatic Brain Injury. J Neurosci (2014) 34(10):3743-55. doi: 10.1523/JNEUROSCI.2872-13.2014

262. Harvey LD, Yin Y, Attarwala IY, Begum G, Deng J, Yan HQ, et al. Administration of DHA Reduces Endoplasmic Reticulum StressAssociated Inflammation and Alters Microglial or Macrophage Activation in Traumatic Brain Injury. ASN Neuro (2015) 7(6). doi: 10.1177/ 1759091415618969

263. Yin Y, Li E, Sun G, Yan HQ, Foley LM, Andrzejczuk LA, et al. Effects of DHA on Hippocampal Autophagy and Lysosome Function After Traumatic Brain Injury. Mol Neurobiol (2018) 55(3):2454-70. doi: 10.1007/s12035-017-0504-8

264. Hodson R. Alzheimer's Disease. Nature (2018) 559(7715):S1. doi: 10.1038/ d41586-018-05717-6

265. Busche MA, Hyman BT. Synergy Between Amyloid-Beta and Tau in Alzheimer's Disease. Nat Neurosci (2020) 23(10):1183-93. doi: 10.1038/ s41593-020-0687-6

266. Mattsson N, Zetterberg H, Janelidze S, Insel PS, Andreasson U, Stomrud E, et al. Plasma Tau in Alzheimer Disease. Neurology (2016) 87(17):1827-35. doi: 10.1212/WNL.0000000000003246

267. Ghemrawi R, Khair M. Endoplasmic Reticulum Stress and Unfolded Protein Response in Neurodegenerative Diseases. Int J Mol Sci (2020) 21(17):6127. doi: 10.3390/ijms21176127

268. Ho YS, Yang X, Lau JC, Hung CH, Wuwongse S, Zhang Q, et al. Endoplasmic Reticulum Stress Induces Tau Pathology and Forms a Vicious Cycle: Implication in Alzheimer's Disease Pathogenesis. J Alzheimers Dis (2012) 28(4):839-54. doi: 10.3233/JAD-2011-111037

269. Abisambra JF, Jinwal UK, Blair LJ, O'Leary JC3rd, Li Q, Brady S, et al. Tau Accumulation Activates the Unfolded Protein Response by Impairing Endoplasmic Reticulum-Associated Degradation. J Neurosci (2013) 33 (22):9498-507. doi: 10.1523/JNEUROSCI.5397-12.2013

270. Liu J, Chang L, Song Y, Li H, Wu Y. The Role of NMDA Receptors in Alzheimer's Disease. Front Neurosci (2019) 13:43. doi: 10.3389/ fnins.2019.00043 
271. Hoozemans JJ, van Haastert ES, Nijholt DA, Rozemuller AJ, Eikelenboom P, Scheper W. The Unfolded Protein Response is Activated in Pretangle Neurons in Alzheimer's Disease Hippocampus. Am J Pathol (2009) 174 (4):1241-51. doi: 10.2353/ajpath.2009.080814

272. Lee JH, Won SM, Suh J, Son SJ, Moon GJ, Park UJ, et al. Induction of the Unfolded Protein Response and Cell Death Pathway in Alzheimer's Disease, But Not in Aged Tg2576 Mice. Exp Mol Med (2010) 42(5):386-94. doi: $10.3858 / \mathrm{emm} .2010 .42 .5 .040$

273. Stutzbach LD, Xie SX, Naj AC, Albin R, Gilman SPSP Genetics Study Group, et al. The Unfolded Protein Response is Activated in Disease-Affected Brain Regions in Progressive Supranuclear Palsy and Alzheimer's Disease. Acta Neuropathol Commun (2013) 1:31. doi: 10.1186/2051-5960-1-31

274. Hoozemans JJ, Stieler J, van Haastert ES, Veerhuis R, Rozemuller AJ, Baas F, et al. The Unfolded Protein Response Affects Neuronal Cell Cycle Protein Expression: Implications for Alzheimer's Disease Pathogenesis. Exp Gerontol (2006) 41(4):380-6. doi: 10.1016/j.exger.2006.01.013

275. O'Connor T, Sadleir KR, Maus E, Velliquette RA, Zhao J, Cole SL, et al. Phosphorylation of the Translation Initiation Factor eIF2alpha Increases BACE1 Levels and Promotes Amyloidogenesis. Neuron (2008) 60(6):9881009. doi: 10.1016/j.neuron.2008.10.047

276. Sharma V, Ounallah-Saad H, Chakraborty D, Hleihil M, Sood R, Barrera I, et al. Local Inhibition of PERK Enhances Memory and Reverses Age-Related Deterioration of Cognitive and Neuronal Properties. J Neurosci (2018) 38 (3):648-58. doi: 10.1523/JNEUROSCI.0628-17.2017

277. Ohno M. Roles of eIF2alpha Kinases in the Pathogenesis of Alzheimer's Disease. Front Mol Neurosci (2014) 7:22. doi: 10.3389/fnmol.2014.00022

278. Costa-Mattioli M, Gobert D, Harding H, Herdy B, Azzi M, Bruno M, et al. Translational Control of Hippocampal Synaptic Plasticity and Memory by the eIF2alpha Kinase GCN2. Nature (2005) 436(7054):1166-73. doi: 10.1038 /nature03897

279. Jiang X, Litkowski PE, Taylor AA, Lin Y, Snider BJ, Moulder KL. A Role for the Ubiquitin-Proteasome System in Activity-Dependent Presynaptic Silencing. J Neurosci (2010) 30(5):1798-809. doi: 10.1523/ JNEUROSCI.4965-09.2010

280. Lourenco MV, Clarke JR, Frozza RL, Bomfim TR, Forny-Germano L, Batista AF, et al. TNF-Alpha Mediates PKR-Dependent Memory Impairment and Brain IRS-1 Inhibition Induced by Alzheimer's Beta-Amyloid Oligomers in Mice and Monkeys. Cell Metab (2013) 18(6):831-43. doi: 10.1016/ j.cmet.2013.11.002

281. Segev Y, Barrera I, Ounallah-Saad H, Wibrand K, Sporild I, Livne A, et al. PKR Inhibition Rescues Memory Deficit and ATF4 Overexpression in ApoE Epsilon4 Human Replacement Mice. J Neurosci (2015) 35(38):12986-93. doi: 10.1523/JNEUROSCI.5241-14.2015

282. Martinez G, Vidal RL, Mardones P, Serrano FG, Ardiles AO, Wirth C, et al. Regulation of Memory Formation by the Transcription Factor Xbp1. Cell Rep (2016) 14(6):1382-94. doi: 10.1016/j.celrep.2016.01.028

283. Loewen CA, Feany MB. The Unfolded Protein Response Protects From Tau Neurotoxicity In Vivo. PLoS One (2010) 5(9):e13084. doi: 10.1371/ journal.pone.0013084

284. Casas-Tinto S, Zhang Y, Sanchez-Garcia J, Gomez-Velazquez M, RinconLimas DE, Fernandez-Funez P. The ER Stress Factor XBP1s Prevents Amyloid-Beta Neurotoxicity. Hum Mol Genet (2011) 20(11):2144-60. doi: $10.1093 / \mathrm{hmg} / \mathrm{ddr} 100$

285. Hirsch EC, Standaert DG. Ten Unsolved Questions About Neuroinflammation in Parkinson's Disease. Mov Disord (2021) 36(1):1624. doi: $10.1002 / \mathrm{mds} .28075$

286. Castonguay AM, Gravel C, Levesque M. Treating Parkinson's Disease With Antibodies: Previous Studies and Future Directions. J Parkinsons Dis (2021) 11(1):71-92. doi: 10.3233/JPD-202221

287. Mou Z, Yuan YH, Zhang Z, Song LK, Chen NH. Endoplasmic Reticulum Stress, an Important Factor in the Development of Parkinson's Disease. Toxicol Lett (2020) 324:20-9. doi: 10.1016/j.toxlet.2020.01.019

288. Esteves AR, Cardoso SM. Differential Protein Expression in Diverse Brain Areas of Parkinson's and Alzheimer's Disease Patients. Sci Rep (2020) 10 (1):13149. doi: 10.1038/s41598-020-70174-z

289. Selvaraj S, Sun Y, Watt JA, Wang S, Lei S, Birnbaumer L, et al. NeurotoxinInduced ER Stress in Mouse Dopaminergic Neurons Involves
Downregulation of TRPC1 and Inhibition of AKT/mTOR Signaling. J Clin Invest (2012) 122(4):1354-67. doi: 10.1172/JCI61332

290. Hoozemans JJ, van Haastert ES, Eikelenboom P, de Vos RA, Rozemuller JM, Scheper W. Activation of the Unfolded Protein Response in Parkinson's Disease. Biochem Biophys Res Commun (2007) 354(3):707-11. doi: 10.1016/ j.bbrc.2007.01.043

291. Bellucci A, Navarria L, Zaltieri M, Falarti E, Bodei S, Sigala S, et al. Induction of the Unfolded Protein Response by Alpha-Synuclein in Experimental Models of Parkinson's Disease. J Neurochem (2011) 116(4):588-605. doi: $10.1111 / j .1471-4159.2010 .07143 . x$

292. Bellani S, Mescola A, Ronzitti G, Tsushima H, Tilve S, Canale C, et al. GRP78 Clustering at the Cell Surface of Neurons Transduces the Action of Exogenous Alpha-Synuclein. Cell Death Differ (2014) 21(12):1971-83. doi: $10.1038 /$ cdd.2014.111

293. Gupta S, Mishra A, Singh S. Cardinal Role of Eukaryotic Initiation Factor 2 (eIF2alpha) in Progressive Dopaminergic Neuronal Death \& DNA Fragmentation: Implication of PERK:IRE1alpha:ATF6 Axis in Parkinson's Pathology. Cell Signal (2021) 81:109922. doi: 10.1016/ j.cellsig.2021.109922

294. Wu L, Luo N, Zhao HR, Gao Q, Lu J, Pan Y, et al. Salubrinal Protects Against Rotenone-Induced SH-SY5Y Cell Death via ATF4-Parkin Pathway. Brain Res (2014) 1549:52-62. doi: 10.1016/j.brainres.2014.01.003

295. Inoue $\mathrm{Y}, \mathrm{Hara} \mathrm{H}$, Mitsugi $\mathrm{Y}$, Yamaguchi E, Kamiya T, Itoh A, et al. 4Hydroperoxy-2-Decenoic Acid Ethyl Ester Protects Against 6Hydroxydopamine-Induced Cell Death via Activation of Nrf2-ARE and eIF2alpha-ATF4 Pathways. Neurochem Int (2018) 112:288-96. doi: 10.1016/ j.neuint.2017.08.011

296. Gully JC, Sergeyev VG, Bhootada Y, Mendez-Gomez H, Meyers CA, Zolotukhin S, et al. Up-Regulation of Activating Transcription Factor 4 Induces Severe Loss of Dopamine Nigral Neurons in a Rat Model of Parkinson's Disease. Neurosci Lett (2016) 627:36-41. doi: 10.1016/ j.neulet.2016.05.039

297. Faissner S, Plemel JR, Gold R, Yong VW. Progressive Multiple Sclerosis: From Pathophysiology to Therapeutic Strategies. Nat Rev Drug Discov (2019) 18(12):905-22. doi: 10.1038/s41573-019-0035-2

298. Ransohoff RM, Kivisakk P, Kidd G. Three or More Routes for Leukocyte Migration Into the Central Nervous System. Nat Rev Immunol (2003) 3 (7):569-81. doi: 10.1038/nri1130

299. Stone S, Lin W. The Unfolded Protein Response in Multiple Sclerosis. Front Neurosci (2015) 9:264. doi: 10.3389/fnins.2015.00264

300. Cwiklinska H, Mycko MP, Luvsannorov O, Walkowiak B, Brosnan CF, Raine CS, et al. Heat Shock Protein 70 Associations With Myelin Basic Protein and Proteolipid Protein in Multiple Sclerosis Brains. Int Immunol (2003) 15 (2):241-9. doi: 10.1093/intimm/dxg022

301. Mycko MP, Papoian R, Boschert U, Raine CS, Selmaj KW. Microarray Gene Expression Profiling of Chronic Active and Inactive Lesions in Multiple Sclerosis. Clin Neurol Neurosurg (2004) 106(3):223-9. doi: 10.1016/ j.clineuro.2004.02.019

302. Cunnea P, Mhaille AN, McQuaid S, Farrell M, McMahon J, FitzGerald U. Expression Profiles of Endoplasmic Reticulum Stress-Related Molecules in Demyelinating Lesions and Multiple Sclerosis. Mult Scler (2011) 17(7):80818. doi: $10.1177 / 1352458511399114$

303. Mhaille AN, McQuaid S, Windebank A, Cunnea P, McMahon J, Samali A, et al. Increased Expression of Endoplasmic Reticulum Stress-Related Signaling Pathway Molecules in Multiple Sclerosis Lesions. J Neuropathol Exp Neurol (2008) 67(3):200-11. doi: 10.1097/NEN.0b013e318165b239

304. McMahon JM, McQuaid S, Reynolds R, FitzGerald UF. Increased Expression of ER Stress- and Hypoxia-Associated Molecules in Grey Matter Lesions in Multiple Sclerosis. Mult Scler (2012) 18(10):1437-47. doi: 10.1177/ 1352458512438455

305. Ni Fhlathartaigh M, McMahon J, Reynolds R, Connolly D, Higgins E, Counihan T, et al. Calreticulin and Other Components of Endoplasmic Reticulum Stress in Rat and Human Inflammatory Demyelination. Acta Neuropathol Commun (2013) 1:37. doi: 10.1186/2051-5960-1-37

306. Lin W, Bailey SL, Ho H, Harding HP, Ron D, Miller SD, et al. The Integrated Stress Response Prevents Demyelination by Protecting Oligodendrocytes Against Immune-Mediated Damage. J Clin Invest (2007) 117(2):448-56. doi: 10.1172/JCI29571 
307. Haile Y, Deng X, Ortiz-Sandoval C, Tahbaz N, Janowicz A, Lu JQ, et al. Rab32 Connects ER Stress to Mitochondrial Defects in Multiple Sclerosis. J Neuroinflamm (2017) 14(1):19. doi: 10.1186/s12974-016-0788-z

308. Deslauriers AM, Afkhami-Goli A, Paul AM, Bhat RK, Acharjee S, Ellestad KK, et al. Neuroinflammation and Endoplasmic Reticulum Stress Are Coregulated by Crocin to Prevent Demyelination and Neurodegeneration. J Immunol (2011) 187(9):4788-99. doi: 10.4049/jimmunol.1004111

309. Dimcheff DE, Faasse MA, McAtee FJ, Portis JL. Endoplasmic Reticulum (ER) Stress Induced by a Neurovirulent Mouse Retrovirus is Associated With Prolonged BiP Binding and Retention of a Viral Protein in the ER. J Biol Chem (2004) 279(32):33782-90. doi: 10.1074/jbc.M403304200

310. Lin W, Lin Y. Interferon-Gamma Inhibits Central Nervous System Myelination Through Both STAT1-Dependent and STAT1-Independent Pathways. J Neurosci Res (2010) 88(12):2569-77. doi: 10.1002/jnr.22425

311. LaFerla FM, Sugarman MC, Lane TE, Leissring MA. Regional Hypomyelination and Dysplasia in Transgenic Mice With AstrocyteDirected Expression of Interferon-Gamma. J Mol Neurosci (2000) 15 (1):45-59. doi: 10.1385/JMN:15:1:45

312. Lin W, Kunkler PE, Harding HP, Ron D, Kraig RP, Popko B. Enhanced Integrated Stress Response Promotes Myelinating Oligodendrocyte Survival in Response to Interferon-Gamma. Am J Pathol (2008) 173(5):1508-17. doi: 10.2353/ajpath.2008.080449

313. Lin W, Harding HP, Ron D, Popko B. Endoplasmic Reticulum Stress Modulates the Response of Myelinating Oligodendrocytes to the Immune Cytokine Interferon-Gamma. J Cell Biol (2005) 169(4):603-12. doi: 10.1083/ jcb. 200502086

314. Lin W, Kemper A, Dupree JL, Harding HP, Ron D, Popko B. InterferonGamma Inhibits Central Nervous System Remyelination Through a Process Modulated by Endoplasmic Reticulum Stress. Brain (2006) 129(Pt 5):130618. doi: 10.1093/brain/awl044

315. Wright GEB, Black HF, Collins JA, Gall-Duncan T, Caron NS, Pearson CE, et al. Interrupting Sequence Variants and Age of Onset in Huntington's Disease: Clinical Implications and Emerging Therapies. Lancet Neurol (2020) 19(11):930-9. doi: 10.1016/S1474-4422(20)30343-4

316. Duennwald ML, Lindquist S. Impaired ERAD and ER Stress Are Early and Specific Events in Polyglutamine Toxicity. Genes Dev (2008) 22(23):3308-19. doi: $10.1101 / \mathrm{gad} .1673408$

317. Leitman J, Ulrich Hartl F, Lederkremer GZ. Soluble Forms of polyQExpanded Huntingtin Rather Than Large Aggregates Cause Endoplasmic Reticulum Stress. Nat Commun (2013) 4:2753. doi: 10.1038/ncomms3753

318. Jiang Y, Chadwick SR, Lajoie P. Endoplasmic Reticulum Stress: The Cause and Solution to Huntington's Disease? Brain Res (2016) 1648(Pt B):650-7. doi: 10.1016/j.brainres.2016.03.034

319. Noh JY, Lee H, Song S, Kim NS, Im W, Kim M, et al. SCAMP5 Links Endoplasmic Reticulum Stress to the Accumulation of Expanded Polyglutamine Protein Aggregates via Endocytosis Inhibition. J Biol Chem (2009) 284(17):11318-25. doi: 10.1074/jbc.M807620200

320. Carnemolla A, Fossale E, Agostoni E, Michelazzi S, Calligaris R, De Maso L, et al. Rrs1 is Involved in Endoplasmic Reticulum Stress Response in Huntington Disease. J Biol Chem (2009) 284(27):18167-73. doi: 10.1074/ jbc.M109.018325

321. Hernandez IH, Torres-Peraza J, Santos-Galindo M, Ramos-Moron E, Fernandez-Fernandez MR, Perez-Alvarez MJ, et al. The Neuroprotective Transcription Factor ATF5 is Decreased and Sequestered Into Polyglutamine Inclusions in Huntington's Disease. Acta Neuropathol (2017) 134(6):839-50. doi: 10.1007/s00401-017-1770-2

322. Brown RH, Al-Chalabi A. Amyotrophic Lateral Sclerosis. $N$ Engl J Med (2017) 377(2):162-72. doi: 10.1056/NEJMra1603471

323. Amin A, Perera ND, Beart PM, Turner BJ, Shabanpoor F. Amyotrophic Lateral Sclerosis and Autophagy: Dysfunction and Therapeutic Targeting. Cells (2020) 9(11):2413. doi: 10.3390/cells9112413

324. Ilieva EV, Ayala V, Jove M, Dalfo E, Cacabelos D, Povedano M, et al. Oxidative and Endoplasmic Reticulum Stress Interplay in Sporadic Amyotrophic Lateral Sclerosis. Brain (2007) 130(Pt 12):3111-23. doi: 10.1093/brain/awm190

325. Atkin JD, Farg MA, Walker AK, McLean C, Tomas D, Horne MK. Endoplasmic Reticulum Stress and Induction of the Unfolded Protein Response in Human Sporadic Amyotrophic Lateral Sclerosis. Neurobiol Dis (2008) 30(3):400-7. doi: 10.1016/j.nbd.2008.02.009
326. Hetz C, Thielen P, Matus S, Nassif M, Court F, Kiffin R, et al. XBP-1 Deficiency in the Nervous System Protects Against Amyotrophic Lateral Sclerosis by Increasing Autophagy. Genes Dev (2009) 23(19):2294-306. doi: $10.1101 /$ gad.1830709

327. Ito Y, Yamada M, Tanaka H, Aida K, Tsuruma K, Shimazawa M, et al. Involvement of CHOP, an ER-Stress Apoptotic Mediator, in Both Human Sporadic ALS and ALS Model Mice. Neurobiol Dis (2009) 36(3):470-6. doi: 10.1016/j.nbd.2009.08.013

328. Sasaki S. Endoplasmic Reticulum Stress in Motor Neurons of the Spinal Cord in Sporadic Amyotrophic Lateral Sclerosis. J Neuropathol Exp Neurol (2010) 69(4):346-55. doi: 10.1097/NEN.0b013e3181d44992

329. Oyanagi K, Yamazaki M, Takahashi H, Watabe K, Wada M, Komori T, et al. Spinal Anterior Horn Cells in Sporadic Amyotrophic Lateral Sclerosis Show Ribosomal Detachment From, and Cisternal Distention of the Rough Endoplasmic Reticulum. Neuropathol Appl Neurobiol (2008) 34(6):650-8. doi: 10.1111/j.1365-2990.2008.00941.x

330. Vijayalakshmi K, Alladi PA, Ghosh S, Prasanna VK, Sagar BC, Nalini A, et al. Evidence of Endoplasmic Reticular Stress in the Spinal Motor Neurons Exposed to CSF From Sporadic Amyotrophic Lateral Sclerosis Patients. Neurobiol Dis (2011) 41(3):695-705. doi: 10.1016/ j.nbd.2010.12.005

331. Tobisawa S, Hozumi Y, Arawaka S, Koyama S, Wada M, Nagai M, et al. Mutant SOD1 Linked to Familial Amyotrophic Lateral Sclerosis, But Not Wild-Type SOD1, Induces ER Stress in COS7 Cells and Transgenic Mice. Biochem Biophys Res Commun (2003) 303(2):496-503. doi: 10.1016/s0006291x(03)00353-x

332. Medinas DB, Rozas P, Martinez Traub F, Woehlbier U, Brown RH, Bosco DA, et al. Endoplasmic Reticulum Stress Leads to Accumulation of WildType SOD1 Aggregates Associated With Sporadic Amyotrophic Lateral Sclerosis. Proc Natl Acad Sci U S A (2018) 115(32):8209-14. doi: 10.1073/ pnas. 1801109115

333. Walker AK, Atkin JD. Stress Signaling From the Endoplasmic Reticulum: A Central Player in the Pathogenesis of Amyotrophic Lateral Sclerosis. IUBMB Life (2011) 63(9):754-63. doi: 10.1002/iub.520

334. Suk TR, Rousseaux MWC. The Role of TDP- 43 Mislocalization in Amyotrophic Lateral Sclerosis. Mol Neurodegener (2020) 15(1):45. doi: 10.1186/s13024-020-00397-1

335. Ayala V, Granado-Serrano AB, Cacabelos D, Naudi A, Ilieva EV, Boada J, et al. Cell Stress Induces TDP-43 Pathological Changes Associated With ERK1/2 Dysfunction: Implications in ALS. Acta Neuropathol (2011) 122 (3):259-70. doi: 10.1007/s00401-011-0850-y

336. Suzuki H, Matsuoka M. TDP-43 Toxicity is Mediated by the Unfolded Protein Response-Unrelated Induction of C/EBP Homologous Protein Expression. J Neurosci Res (2012) 90(3):641-7. doi: 10.1002/jnr.22777

337. Hicks DA, Cross LL, Williamson R, Rattray M. Endoplasmic Reticulum Stress Signalling Induces Casein Kinase 1-Dependent Formation of Cytosolic TDP-43 Inclusions in Motor Neuron-Like Cells. Neurochem Res (2020) 45 (6):1354-64. doi: 10.1007/s11064-019-02832-2

338. Vieira FG, Ping Q, Moreno AJ, Kidd JD, Thompson K, Jiang B, et al. Guanabenz Treatment Accelerates Disease in a Mutant SOD1 Mouse Model of ALS. PLoS One (2015) 10(8):e0135570. doi: 10.1371/journal.pone.0135570

Conflict of Interest: The authors declare that the research was conducted in the absence of any commercial or financial relationships that could be construed as a potential conflict of interest.

Publisher's Note: All claims expressed in this article are solely those of the authors and do not necessarily represent those of their affiliated organizations, or those of the publisher, the editors and the reviewers. Any product that may be evaluated in this article, or claim that may be made by its manufacturer, is not guaranteed or endorsed by the publisher.

Copyright (c) 2022 Shi, Chai, Zhang and Chen. This is an open-access article distributed under the terms of the Creative Commons Attribution License (CC BY). The use, distribution or reproduction in other forums is permitted, provided the original author(s) and the copyright owner(s) are credited and that the original publication in this journal is cited, in accordance with accepted academic practice. No use, distribution or reproduction is permitted which does not comply with these terms. 